\title{
ESTIMATION OF WINDS OVER THE GREAT LAKES
}

\author{
by \\ Donald T. Resio, Charles L. Vincent \\ Hydraulics Laboratory \\ U. S. Army Engineer Waterways Experiment Station \\ P. O. Box 631, Vicksburg, Miss. 39180
}

June 1976

Final Report

Approved For Public Release; Distribution Unlimited

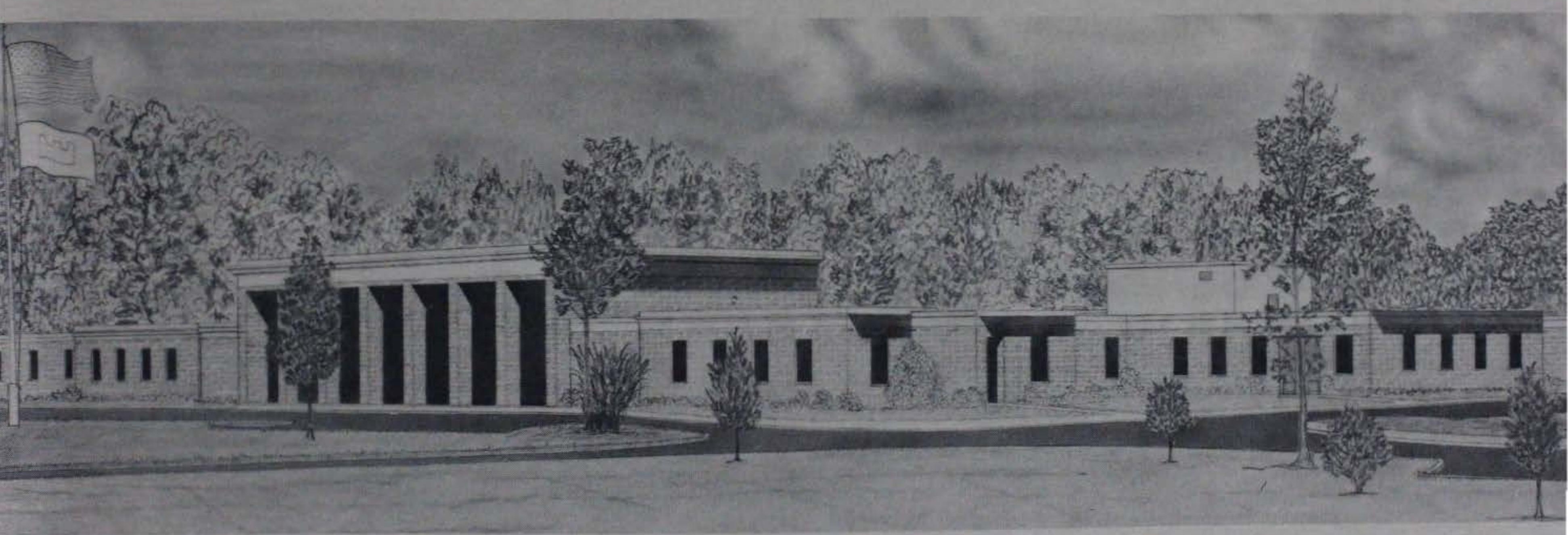

Prepared for U. S. Army Engineer Division, North Central Chicago, Illinois 60605

LIBRARY BRANCH

TECHNICAL INFORMATION CENTII

US ARMY ENGINEER WATERWAYS

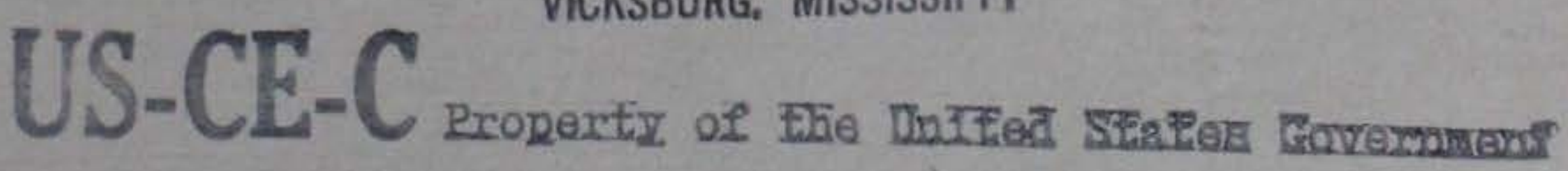

VICKSBURG, MISSISSIPPI 
Unclassified

SECURITY CLASSIFICATION OF THIS PAGE (When Data Entered)

\begin{tabular}{|c|c|}
\hline REPORT DOCUMENTATION PAGE & $\begin{array}{c}\text { READ INSTRUCTIONS } \\
\text { BEFORE COMPLETING FORM }\end{array}$ \\
\hline $\begin{array}{l}\text { 1. REPORT NUMBER } \\
\qquad \text { Miscellaneous Paper H-76-12 }\end{array}$ & 3. RECIPIENT'S CATALOG NUMBER \\
\hline \multirow[t]{2}{*}{$\begin{array}{l}\text { 4. TITLE (and Subttie) } \\
\text { ESTIMATION OF WINDS OVER THE GREAT LAKES }\end{array}$} & $\begin{array}{l}\text { 5. TYPE OF REPORT \& PERIOD COVERED } \\
\text { Final report }\end{array}$ \\
\hline & 6. PERFORMING ORG. REPORT NUMBER \\
\hline $\begin{array}{l}\text { 7. AUTHOR(s) } \\
\text { Donald T. Resio } \\
\text { Charles L. Vincent }\end{array}$ & 8. CONTRACT OR GRANT NUMBER(B) \\
\hline $\begin{array}{l}\text { 9. PERFORMING ORGANIZATION NAME AND ADDRESS } \\
\text { U. S. Army Engineer Waterways Experiment Station } \\
\text { Hydraulics Laboratory } \\
\text { P. O. Box } 631 \text {, Vicksburg, Miss. } 39180\end{array}$ & $\begin{array}{l}\text { 10. PROGRAM ELEMENT, PROJECT, TASK } \\
\text { AREA \& WORK UNIT NUMBERS }\end{array}$ \\
\hline $\begin{array}{l}\text { 11. CONTROLLING OFFICE NAME AND ADDRESS } \\
\text { U. S. Army Engineer Division, North Central }\end{array}$ & $\begin{array}{l}\text { 12. REPORT DATE } \\
\text { June } 1976 \\
\end{array}$ \\
\hline $\begin{array}{l}536 \text { South Clark Street } \\
\text { Chicago, I11. } 60605\end{array}$ & $\begin{array}{l}\text { 13. NUMBER OF PAGES } \\
71\end{array}$ \\
\hline 14. MONITORING AGENCY NAME \& ADDRESS(If different from Controlling Office) & $\begin{array}{l}\text { 15. SECURITY CLASS. (of this roport) } \\
\text { Unclassified }\end{array}$ \\
\hline & $\begin{array}{l}\text { 15a. DECLASSIFICATION/DOWNGRADING } \\
\text { SCHEDULE }\end{array}$ \\
\hline
\end{tabular}

Approved for public release; distribution unlimited.

17. DISTRIBUTION STATEMENT (of the abstract ontered in Block 20, if different from Report)

18. SUPPLEMENTARY NOTES

19. KEY WORDS (Continue on reverse side if necessary and identify by block number)

Great Lakes

Wind Velocity

20. ABSTAACT (Continue an reverses stive if necoseary and tdentily by block number)

Past efforts to estimate wind speeds over a large lake have met with very limited success. The purpose of this study is to demonstrate that, with a combined theoretical-empirical approach, winds over a lake can be obtained from transformed wind speeds at nearby 1 and stations. The theoretical results provide a basis for comparison of many empirical data sets and establish a rational means of analyzing the expected differences between winds over 1 and and those over a marine surface. This in turn affords a means of

(Continued) 


\section{ABSTRACT (Continued).}

examining systematic variations in the ratio of wind speeds over a lake to wind speeds over 1 and. The good agreement between theory and observation indicates that wind estimates over the lake can be made for a wide range of synoptic conditions with an rms error of under 5 knots. The theoretical curve for the 1 ake wind/1and wind ratio provides a stable estimate of lake winds well beyond wind speeds for which there is good empirical data. Consequently, the technique presented here offers relatively good accuracy even in extreme wind conditions where there are little or no direct measurements of winds over the 1 ake. 


\section{PREFACE}

A request for the U. S. Army Engineer Waterways Experiment Station (WES) to conduct an investigation of wave heights on the Great Lakes was made by the U. S. Army Engineer Division, North Central (NCD), in a conference held in Chicago, Illinois, on 22 July 1974. Funds were authorized by NCD on 30 August 1974. The study was conducted during the period from September 1974 to June 1975 in the Coastal Branch, Wave Dynamics Division, Hydraulics Laboratory, WES, under the direction of Mr. H. B. Simmons, Chief of the Hydraulics Laboratory, and Dr. R. W. Whalin, Chief of the Wave Dynamics Division.

Drs. D. T. Resio and C. L. Vincent conducted the study and also prepared the report. Mrs. Rebecca Brooks and Miss Pearl Smith were especially helpful in performing analytical and programming tasks.

Director of WES during the conduct of the study and the preparation of this report was COL G. H. Hilt, CE. Technical Director was Mr. F. R. Brown. 


\section{CONTENTS}

$\underline{\text { Page }}$

PREFACE . . . . . . . . . . . . . . . . . . . . 1

CONVERSION FACTORS, METRIC (SI) TO U. S. CUSTOMARY AND U. S.

CUSTOMARY TO METRIC (SI) UNITS OF MEASUREMENT . . . . . . . . . 3

PART I: INTRODUCTION . . . . . . . . . . . . . . . . . . . . . . 4

PART II: THEORETICAL TREATMENT OF WINDS OVER WATER AND

WIND OVER LAND . . . . . . . . . . . . . . . . . . 4

Winds Over Water . . . . . . . . . . . . . . . . . 6

Winds in the Constant Stress Layer . . . . . . . . . . . . . 7

Winds in the Ekman Layer . . . . . . . . . . . . . . . . . . 12

Wind Over Land . . . . . . . . . . . . . . . . . 16

PART III: COMPARISON OF LAND WINDS AND LAKE WINDS . . . . . . . 19

PART IV: ANALYSIS OF ERROR IN WIND ESTIMATES . . . . . . . . . . 32

PART V: COMPARISONS OF RESULTS TO OTHER STUDIES $\quad$. . . . . . . . 37

DISCUSSION . . . . . . . . . . . . . . . . . . . . . 46

SUMMARY . . . . . . . . . . . . . . . . . . . . . 48

REFERENCES . . . . . . . . . . . . . . . . . . . . . . 50

TABLES $1-3$. . . . . . . . . . . . . . . . . . . . . 53

NOTATION . . . . . . . . . . . . . . . . . . . . 59

APPENDIX A: COMPARISONS OF OBSERVED AND ESTIMATED WINDS . . . . A1

High Wind Comparisons . . . . . . . . . . . . . . . . . . . Al

Additional Comparisons at the Muskegon Tower . . . . . . . . A1

Comparisons of Estimated Friction Velocities ( $U_{*}$ ) with

Friction Velocities Observed at the Muskegon Tower . . . . A2

Comparisons of Data from PDCS Station to Wind Estimates

Based on Rochester Airport Data . . . . . . . . . . . A2

FIGURES Al-A8 
CONVERSION FACTORS, METRIC (SI) TO U. S. CUSTOMARY AND

U. S. CUSTOMARY TO METRIC (SI) UNITS OF MEASUREMENT

Units of measurement used in this report can be converted as follows:

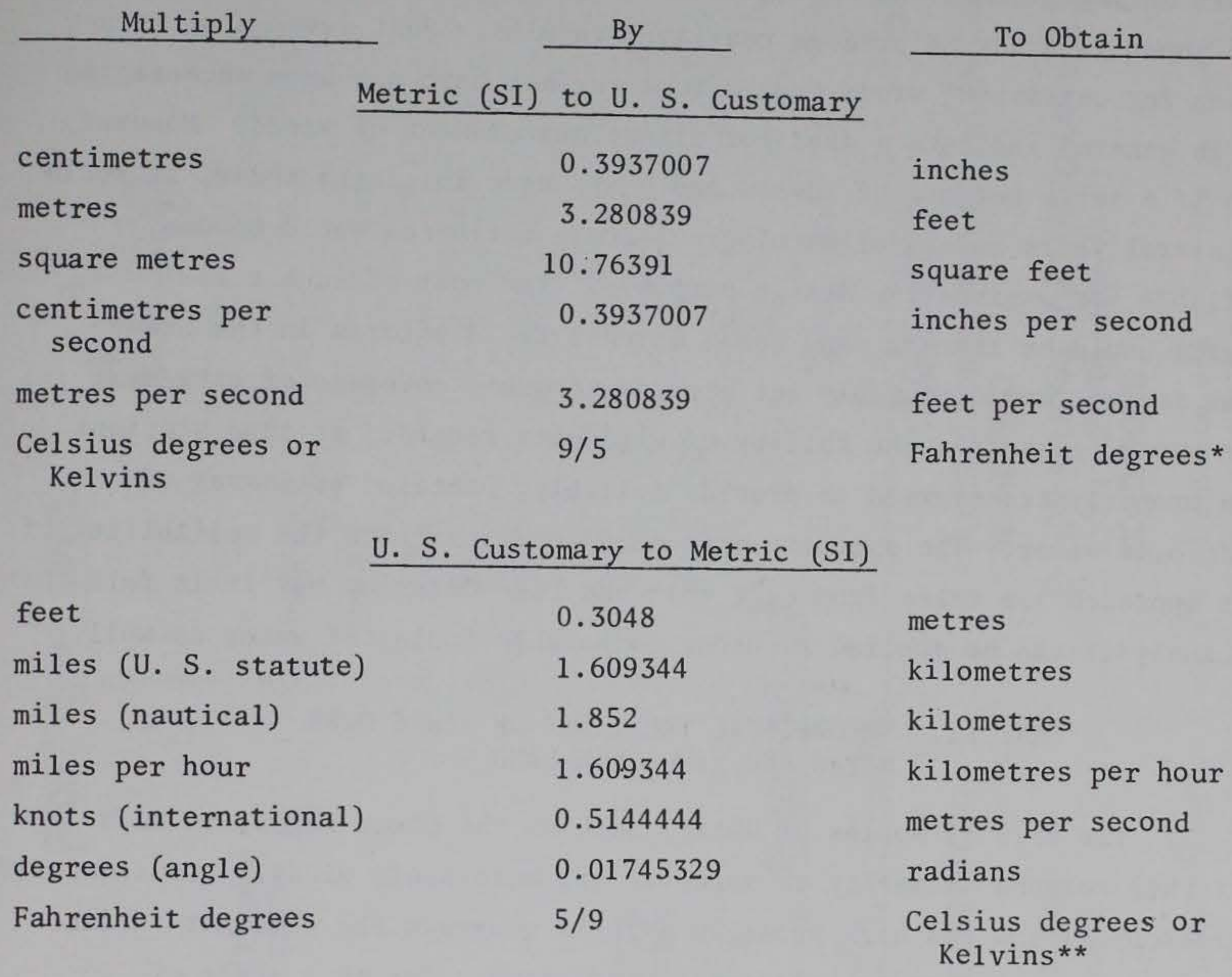

* To obtain Fahrenheit (F) temperature readings from Celsius (C) readings, use the following formula: $F=9 / 5(C)+32$. To obtain Fahrenheit readings from Kelvins $(K)$, use: $F=9 / 5(K-273.15)+32$.

** To obtain Celsius (C) temperature readings from Fahrenheit (F) readings, use the following formula: $C=5 / 9(F-32)$. To obtain Kelvin (K) readings, use: $K=5 / 9(F-32)+273.15$. 


\section{PART I. INTRODUCTION}

1. Models for estimating wind-driven circulation of lakes, surge levels during storms, and wind-generated surface waves all need reliable wind input in order to produce realistic results. Past reviews of techniques for estimating winds over a lake surface have not been encouraging and in general indicate a need for direct measurement of winds. However, even if a large network of towers and buoys were initiated today, it would be several years before climatological-scale estimates would become available for engineering design purposes. The cost of such a field program would be immense, and based on past field efforts in the Great Lakes region, would probably not provide adequate coverage of extremes. This paper reassesses the ability of wind data recorded at land stations when properly transformed to provide reliable, unbiased estimates of winds over water. The specific data used to demonstrate the reliability of this approach are taken from Lake Erie and Lake Ontario, but it is felt that the analysis can be applied to other comparable bodies of water as well.

\section{PART II. THEORETICAL TREATMENT OF WINDS OVER} WATER AND WIND OVER LAND

2. The size of bodies of water, such as the Great Lakes, is such that they respond primarily to synoptic and meso-scale winds.* Consequently, extratropical low and high pressure systems generate the dominant surface waves and current systems under most conditions. For this scale of motion, the wind near the earth's surface can be idealized as being driven by a homogeneous wind-field at some level above the surface. Figure 1 shows a schematic diagram of such a wind above a land surface and lake surface. Density stratified flow over either surface can be treated in the context of the Monin-Obukov similarity theory, in which three length scales are important: $L$, the stability length, $\delta$, the thiekness of the viscous sublayer, and $h_{S}$, the characteristic height of the surface protuberances. For a fully-roughened surface, at a height $\mathbf{z}$ above the surface where $h_{s}, \delta \ll z \ll L$, we obtain the familiar quadratic friction law

* The response time of Lake Erie and Lake Ontario is about 3-6 hrs for the full development of currents and waves. 


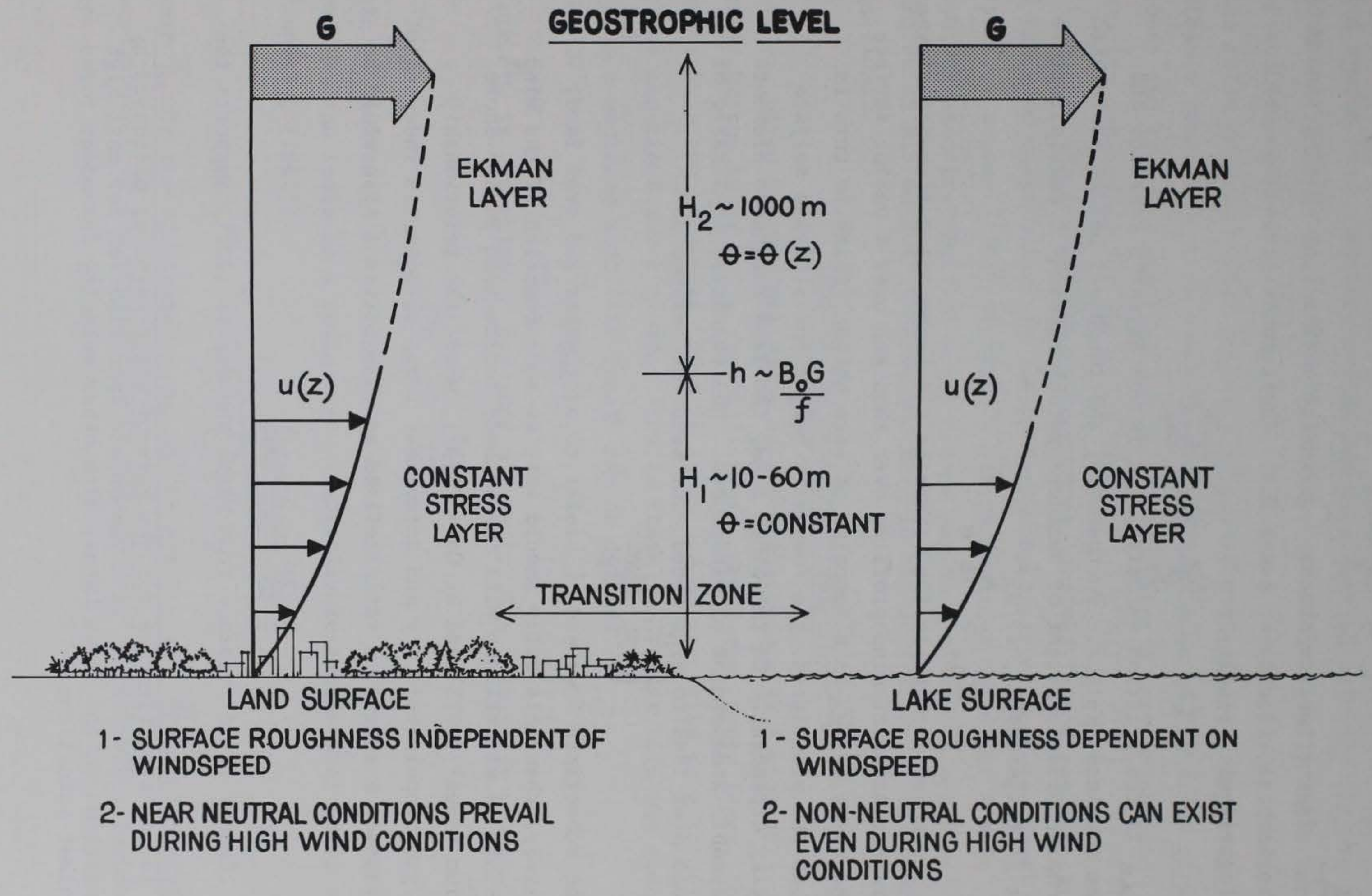

Figure 1. Idealized diagram of atmospheric flow over a land surface and a marine surface. The major differences are seen to be related to roughness length and stability 


$$
\tau=C_{D} u^{2}
$$

where $\tau$ is the surface stress, $C_{D}$ is the coefficient of drag, and $u$ is the horizontal velocity at level $\boldsymbol{Z}$. These constraints also lead to the logarithmic velocity profile

$$
u(z)=\frac{u_{*}}{K} \ln \left(\frac{z}{z_{0}}\right),
$$

where $U_{*}$ is the friction velocity, $K$ is Von Karman's constant and $Z_{0}$ is the roughness height. Furthermore, the roughness height is related to the characteristic height of surface protuberances by a multiplicative constant (Kitaigorodskii, 1970)**

$$
z_{0}=A_{s} h_{s}
$$

3. Equation 3 suggests that there is a fundamental difference between the characteristics of wind profiles over land and over a marine surface. Since the value of $Z_{0}$ is a function of wave height, which in turn is related to the wind speed, the roughness height for a marine surface is velocity dependent. On the other hand, the land roughness elements are reasonably independent of wind speed. Consequently, if a ratio of wind speed over land to wind speed over water is defined as

$$
R=\frac{U_{w}}{u_{L}} \text {, }
$$

where the subscripts $W$ and $L$ refer to over water and over 1and, respectively, then this ratio should vary as some function of the wind speed. This is at variance with the methods recommended in the Shore Protection Manual (1973) and by Cole (1967), where the relationship between geostrophic velocity and anemometer level velocity is independent of wind speed; and hence a ratio defined as in Equation 4 also would be expected to be independent of velocity.

\section{Winds Over Water}

4. Recent field evidence from Hasse and Wagner (1971) supports the

** This is not strictly true for the case of water waves as discussed by Kitaigorodskii; however, it is a reasonable approximation for most high wave conditions on the Great Lakes, with other velocity dependent forms for $Z_{0}$ in other situations. 
proposition that the relationship between geostrophic and anemometer level wind speeds over a marine surface are dependent on velocity (Figure 2). Additionally, the empirical relationships of Jacobs (1967), which were derived from data on Lake Michigan, indicate a pronounced dependence of this ratio on geostrophic velocity (Figure 2). Similarly, empirical evidence from studies on winds over the Great Lakes by Richards et al., (1966) and Richards and Phillips (1970) indicates a very pronounced velocity dependence for the value of $R$.

5. In the development of techniques involved in the specification of the wind distribution in the marine boundary layer for wave forecasting, Cardone (1969) presents a strong physical basis for a more sophisticated treatment of winds over a marine surface. A modified version of his method is presented here in the derivation of the profile equations.

\section{Winds in the Constant Stress Layer}

6. Given a two-layer model of the atmosphere with a constantstress bottom layer and a variable-stress, Ekman-type upper layer, the velocity in the planetary boundary layer can be specified as a solution to the equations for a coupled flow in these two layers. In the lower layer, a modified stability length can be defined as

$$
L^{\prime}=A_{h} L \text {, }
$$

where $A_{h}$ is the ratio of the eddy viscosity, $K_{m}$, and eddy conductivity, $k_{h}$,

$$
A_{h}=\frac{K_{h}}{K_{m}} \text {. }
$$

This is equivalent to an assumption of similarity of wind and temperature profiles and leads to a definition of a gradient length, $L^{\prime}$, as (Panofsky, (1963))

$$
L^{\prime}=\frac{u_{*}(\partial u / \partial z) T_{a}}{K g(\partial \theta / \partial z)},
$$

where $T_{a}$ is the air temperature; $g$ is gravity and $\theta$ is potential temperature. If the nondimensional wind shear is defined as 


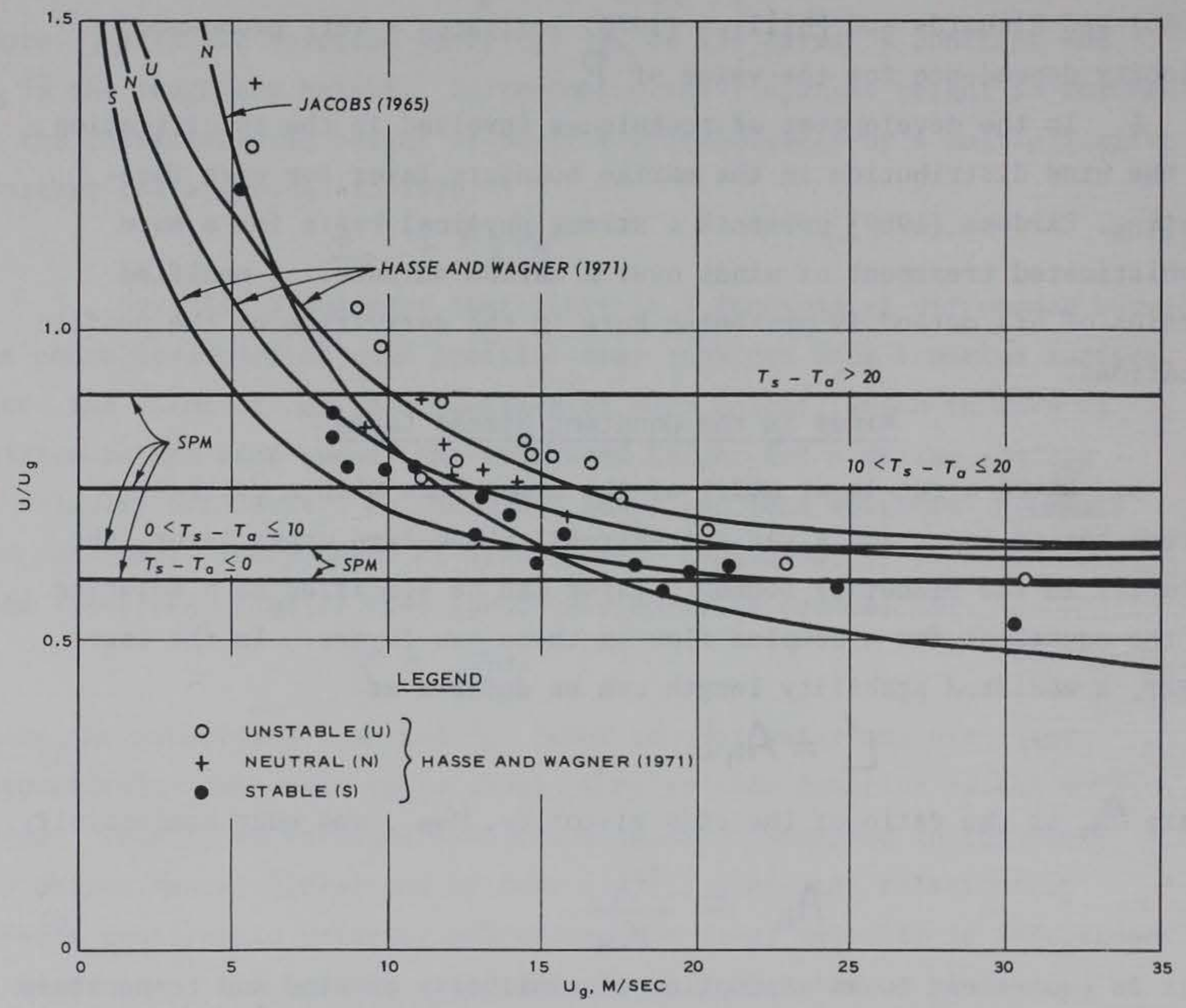

Figure 2. Relationships between surface-level wind speed (U) and geostrophic wind speed $\left(U_{g}\right)$ as determined by Hasse and Wagner (1971) and Jacobs (1965). Solid lines represent smoothed relationships as estimated by these investigators. Symbols represent data from Hasse and Wagner (1971), each based on 10 observations of surface wind and geostrophic wind 


$$
\phi_{u}\left(\frac{z}{t}\right)=\frac{k z}{u_{*}} \frac{\partial u}{\partial z} ;
$$

and, if the gradient length is constant with height, integrating Eqnation 8 up to the level $Z=L^{\prime}$ gives

$$
u(z)=\frac{U_{k}}{K}\left[\ln \left(\frac{z}{z_{0}}\right)-\Psi_{a}\left(\frac{z}{L^{\prime}}\right)\right],
$$

with

$$
\psi_{a}\left(\frac{z}{L}\right)=\int_{z_{0}}^{L^{\prime}} \frac{1-\phi\left(\frac{z}{L^{\prime}}\right)}{z} d z
$$

For a stable density stratification $(\partial \theta / \partial Z<0)$ and $Z / L^{\prime} \ll 1$ a Taylor series expansion can be used to obtain

$$
\phi\left(\frac{z}{L}\right) \approx 1+\frac{B z}{L^{\prime}},
$$

where $B$ is a constant which has been evaluated for wind profiles over land (McVehil, 1964) and over sea (Paulson, 1967) with $B=7$ providing the best fit to the data. For unstable conditions, studies by Kazanski and Morin (1956), Ellison (1957), Panofsky (1961), and Sellers (1962) have shown that the nondimensional shear is approximated by the so-called "KEYPS" profile

$$
\phi_{u}^{4}-s \phi_{u}^{3} \frac{z}{L^{\prime}}-1=0
$$

where $S$ is a constant taken to be equal to 18. Equations 11 and 12 can both be integrated directly to give analytical expressions for $\Psi_{a}$.

7. Again applying the Monin-Obukov similarity theory, the nondimensional temperature gradient is given as a universal function of

$$
\phi_{T}=\frac{z}{T_{*}} \frac{\partial \theta}{\partial z},
$$

where $T_{*}$ is a scaling temperature defined by.

$$
T_{*}=-\frac{1}{k u_{*}} \frac{H}{C_{p} p_{u}} \text {, }
$$

where $H$ is the heat flux, $C_{p}$ is the specific heat of air at constant

9 
pressure and $\rho_{a}$ is the density of air. From Equation 5 it follows that

$$
\frac{\phi_{u}\left(\frac{z}{L}\right)}{A_{h}}=\frac{z}{T_{*}} \frac{\partial \theta}{\partial z}
$$

Integrating Equation 15 and eliminating $T_{k} / A_{h}$ yield

$$
\frac{\partial \theta}{\partial z}=\frac{\left[\phi_{u}\left(z_{a} / z_{0}\right)-\psi\left(z_{a} / i\right)\right]}{\mathrm{Kg}\left(\theta_{a}-\theta_{s}\right)} \text {, }
$$

where the subscripts $\boldsymbol{a}$ and $\boldsymbol{S}$ refer to condition at the anemometer level and sea surface, respectively.

8. Substituting Equation 16 into 7 gives

$$
L^{\prime}=\frac{u_{a}^{2} \bar{\theta}\left[\ln \left(z_{a} / z_{0}\right)-\psi\left(z_{a} / L^{\prime}\right)\right]}{K_{g}\left(\theta_{a}-\theta_{s}\right)},
$$

where $\bar{\theta}$ is the average potential temperature in the layer between $Z_{a}$ and $\mathbf{Z}_{0}$.

9. Equations 9 and 17 contain three variables $U_{*}, Z_{0}$, and $L^{\prime}$ which cannot be obtained directly from a specification of wind speed, anemometer level, air-sea temperature difference, and the level of the air temperature measurement. In order to solve for these a third equation is needed. Since considerable theoretical and empirical studies have investigated the relationship between the roughness height of waves and friction velocity, this relationship was chosen to complete the system of equations.

10. Kitaigorodskii (1970) shows that any attempt to determine the relationship between the roughness length of waves and friction velocity must consider both wave mobility and the transition from an aerodynamically smooth to an aerodynamically rough surface. To account for the motion of waves relative to the wind, Kitaigorodskii (1970) introduces the wave phase velocity, $\mathbf{C}$, into Equation 7 (neglecting density stratification effects)

$$
u(z)-c=\frac{u_{*}}{k} \ln \left(\frac{z}{z_{0}}\right)
$$

which can be rearranged to give

$$
u(z)=\frac{u_{*}}{k} \ln \left[z / z_{0} \exp \left(-k c / u_{*}\right)\right]
$$


11. Equation 19 indicates that slow wave forms (shorter wave lengths) influence the velocity profile more than fast moving wave forms (1onger wave lengths). This suggests that the characteristic height of the sea be taken as.

$$
h_{s}=\sigma_{n} \exp \left(-K c_{0} / u_{*}\right),
$$

where $C_{0}$ is a parameter related to wave development and $\sigma_{n}$ is the root mean square surface displacement of the waves around sea level

$$
\sigma_{n}=\left[n(x, t)^{2}\right]^{1 / 2}
$$

The parameter $C_{0}$ is essentially the phase velocity of the wave components located at the spectral peak. Thus, the ratio Co/uk characterizes the degree of wave development or "wave age." For low values of $C_{0} / u_{\text {m }}$ (early stages of wave generation), the waves behave as an aerodynamically smooth surface; for intermediate values of $C_{0} / u_{*}$, the waves behave as an aerodynamically transitional surface; and for large values of $C_{0} / U_{*}$, the waves behave as an aerodynamically rough surface. In the limiting case for the basic stages of wave generation, the characteristic height of the wave surface can be expressed as

$$
h_{s}=\frac{u_{*}^{2}}{g} \Phi\left(\tilde{\sigma}_{n}\right),
$$

where $\tilde{\sigma}_{n}$ is a nondimensional wave height expressed as

$$
\tilde{\sigma}_{n}=\frac{g \sigma_{n}}{u_{*}^{2}},
$$

and where, according to Kitaigorodskii (1970), $\Phi\left(\tilde{\sigma}_{n}\right)$ must satisfy the conditions

$$
\begin{aligned}
& \Phi\left(\tilde{\sigma}_{n}\right)=\tilde{\sigma}_{n} \quad \text { for } \tilde{\sigma}_{n} \leq 10^{-1} \\
& \Phi\left(\tilde{\sigma}_{n}\right)=\text { constant for } \tilde{\sigma}_{n}>10^{2} .
\end{aligned}
$$

12. From Equation 22 and the assumption that $h_{s} \gg \delta$, the relationship between roughness height and friction velocity can be expressed in a general form as

$$
z_{0}=\frac{m_{0}\left(\tilde{\sigma}_{n}\right) u_{k}^{2}}{g},
$$


where $m_{0}$ is a function characterizing the wave surface. Cardone (1969) uses a series expansion in terms of $U_{\text {as }}$ asoposed by Kitaigorodskii and Volkov (1965) to cover a broad range of wind speeds in Equation 25 giving

$$
z_{0}=c_{1} / u_{*}+c_{2} u_{*}^{2}+c_{3},
$$

where $C_{1}, C_{2}$ and $C_{3}$ are dimensional constants. With $C_{1}=0.684, C_{2}=4.28$ and $C_{3}=-4.43$, Equation 26 leads to drag coefficients consistent with the analyses of Wu (1969) and Wilson (1960), and above a $6-\mathrm{m} / \mathrm{sec}+$ wind (at $10 \mathrm{~m}$ ) $Z_{0}$ tends to the Charnock-E1lison formula (Figure 3 ).

$$
z_{0} \approx 0.035 \frac{u_{*}^{2}}{g}
$$

13. The value of $Z_{0}$ given in Equations 26 and 27 for high winds has received recent support in a study of exchange processes in mature hurricanes by Moss and Rosenthal (1975). In this study, the Deardorff (1972) model of the planetary boundary layer of a hurricane was shown to yield drag coefficients which agreed remarkably well with those calculated from the angular momentum budget of Hurricane Inez, provided the value of $Z_{0}$ is given by Equation 26 or Equation 27.

14. Equations 9, 17, and 26, thus represent a system of three equations with three unknowns. Cardone (1969) developed an iterative computer routine for the solution of these equations. This routine converges rapidly and gives accurate estimates of $U_{k}, Z_{0}$, and $L^{\prime}$ from input values for air-sea temperature difference, air temperature measurement level, wind velocity, and anemometer level.

\section{Winds in the Ekman Layer}

15. In the upper layer, given a steady-state flow with density independent at height, the equations governing atmospheric motion are

$$
\begin{aligned}
-\rho_{a} f \bar{v} & =-\frac{\partial p}{\partial x}+\frac{\partial}{\partial z} \tau_{x z}, \\
-\rho_{a} f \bar{u} & =-\frac{\partial p}{\partial y}+\frac{\partial}{\partial z} \tau_{y z},
\end{aligned}
$$

where $f$ is the Coriolis parameter, $P$ is atmospheric pressure, $X$ and

t A table of factors for converting metric (SI) units of measurement to U. S. customary units and U. S. customary units to metric (SI) units is given on page 3 . 


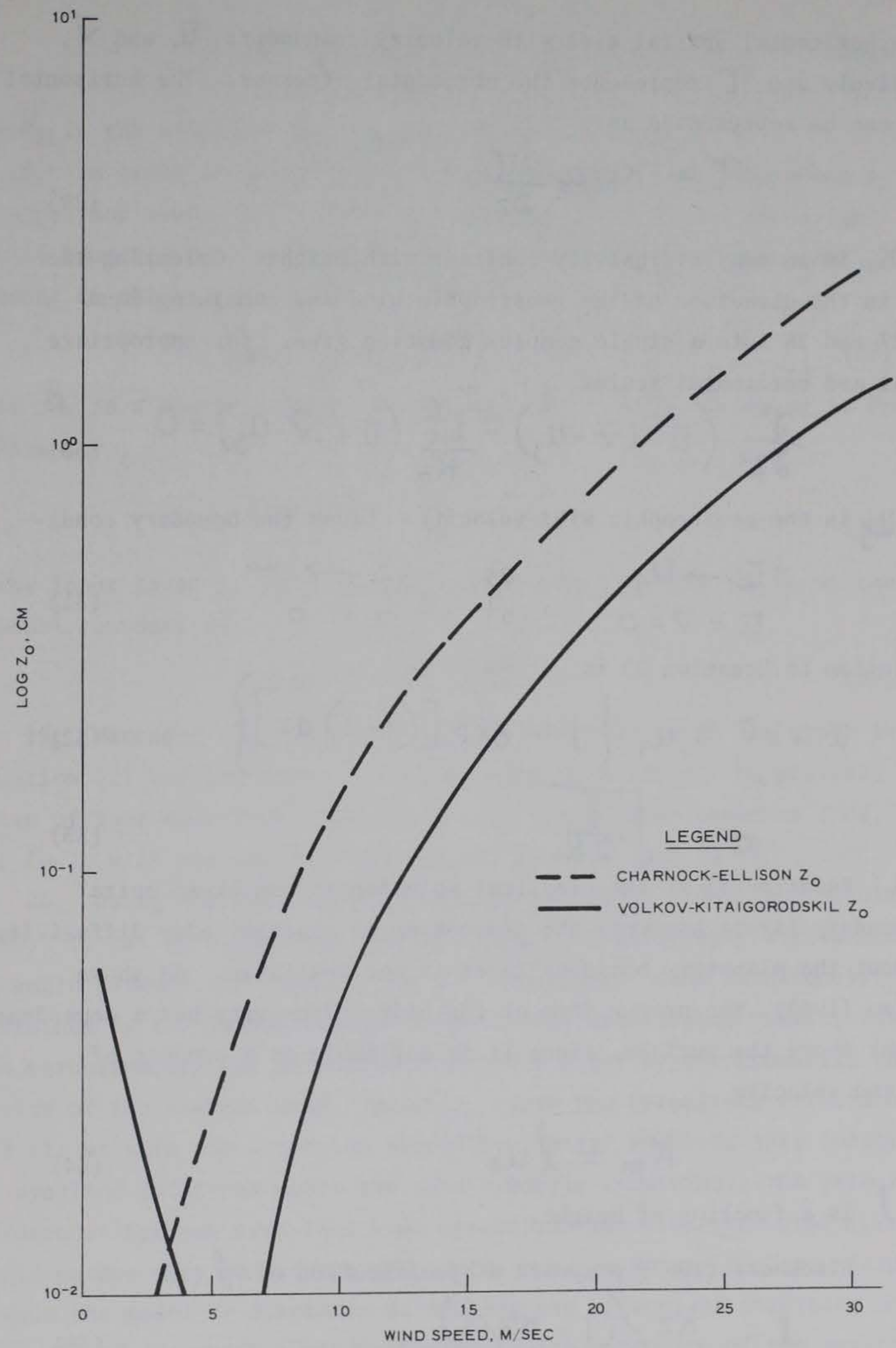

Figure 3. Comparison of roughness length formulations by Volkov and Kitaigorodskii (1965) and Charnock-Ellison, Equations 26 and 27, respectively 
$y$ are horizontal spatial axes with velocity components $\bar{u}$ and $\bar{v}$, respectively and $\tau$ represents the horizontal stresses. The horizontal stress can be represented as

$$
\tau=k_{m} \rho_{a} \frac{\partial \bar{u}}{\partial z},
$$

where $K_{m}$ is an eddy diffusivity constant with height. Orienting the $x$-axis in the direction of the geostrophic wind and combining Equaltrons 27 and 28 into a single complex equation give, for appropriate vertical and horizontal scales,

$$
\frac{\partial^{2}}{\partial z^{2}}\left(\bar{u}-i \bar{v}-u_{g}\right)-\frac{i f}{k_{m}}\left(\bar{u}+i \bar{v}-u_{g}\right)=0 \text {, }
$$

where $\mathrm{Ug}_{\mathrm{g}}$ is the geostrophic wind velocity. Given the boundary conditrons

$$
\begin{array}{lll}
\bar{u} \rightarrow u_{g} & \text { as } & z \rightarrow \infty \\
\bar{u}=\bar{v}=0 & \text { at } & z=0
\end{array}
$$

the solution to Equation 30 is

where

$$
\begin{aligned}
\bar{u}+i \bar{v} & =u_{g}\{1-\exp [(1+i) a z]\}, \\
a & =\sqrt{\frac{f}{2 K_{m}}}
\end{aligned}
$$

16. Equation 32 is the classical solution for an Ekman spiral in a boundary layer; however, the assumption of constant eddy diffusivity throughout the planetary boundary layer is not realistic. As shown by Lettau (1962), the proper form of the eddy diffusivity has a dependence on height above the surface, since it is definable as a product of length and velocity

$$
K_{m}=l u_{*},
$$

where $l$ is a function of height.

17. Blackadar (1962) proposed a specification of $l$ as

$$
l=k z /(1+k z / \lambda) \text {, }
$$

where $\lambda$ is a function of the geostrophic wind speed and the coriolis parameter and is defined as

14 


$$
\lambda=u_{*} H_{B L} / u_{g},
$$

where $H_{M L}$ is the height of the planetary boundary layer. *

18. In order to specify the internal boundary condition between the upper and lower layers and calculate the value of $\lambda$, the height of this boundary must be determined. Blackadar uses a dimensional argument to obtain

$$
H_{B L}=B_{0} u_{g} / f \text {, }
$$

where $B_{0}$ is a constant taken to be $3.0 \times 10^{-4}$. Since according to Prandt 1 we haye

$$
k_{m}=k u_{*} z
$$

in the lower layer of the atmosphere, the specification of $k_{m}$ at the interna1 boundary is

$$
K_{m}=K u_{*} \frac{B_{0} u_{9}}{f}
$$

19. Matching the velocities of the wind vectors in the upper level (Equation 32) and the lower level (Equation 9) at level $H_{B L}$ provides a system of four equations (Eqs. 9, 17, 26, 32) in four unknowns $\left(u_{*}, z_{0}\right.$, $L^{\prime}, K_{m}$ ), with the external parameters $u_{g}, f$, and $\theta_{a}-\theta_{s}$.

20. Using the similarity treatments of Lettau (1961) and Blackadar (1965), it can be shown that, for the case of a barotropic atmosphere, the angle between the surface wind and geostrophic wind is uniquely determined by the Surface Rossby Number. The geostrophic veering associated with baroclinicity can be included into the model by incorporating the effects of the thermal wind. However, since the baroclinic effects of cold air or warm air advection should be similar for over-lake locations and overland locations under the same synoptic conditions, the primary differences between over-land wind directions and over-lake wind directions should be due only to differences in the Surface Rossby Number. Cardone extends the model by Blackadar to include the effects of stability on the angle of the surface wind relative to the direction of the geostrophic

* Blackadar's original form for $\lambda$ was given by $\lambda=0.00027 \mathrm{ug} / f$. This form is equivalent to Equation 36 if $H_{B L}$ is given by $H_{B L}=0.0063 u_{g} / f$ (Blackadar, 1965). 
wind. His theoretical results agree substantially with results of a study made by Mendenhall (1967) based on observations at a weather ship in the Atlantic Ocean. Combining the results of these studies, the deviation between over-1and wind directions and over-1ake wind directions can be determined uniquely from a specification of air-sea temperature difference and wind velocity (Figure 4). Unfortunately, the wind data used in this study are not sufficiently accurate to afford a suitable test for the curves shown in Figure 4 . Consequently, these small modifications to over-1and wind angles for estimating over-lake wind angles should be regarded as a reasonable first approximation until additional information becomes available.

\section{Wind Over Land}

21. As previously indicated, the surface roughness of land is considered relatively independent of wind speed. Whereas this might not hold for a small vegetated region in which the vegetation height and shape is altered by the wind, over a large region it is a reasonable assumption. Cardone (1969) reviews the field evidence of Lettau (1966), Blackadar (1965 b) and Appleby and Ohmstede (1966) (Figure 5). These all appear to support the original hypothesis of Lettau (1959), that surface winds over land under neutral density stratification are a function only of the geostrophic wind speed and the surface Rossby number defined as

$$
R_{0}=u_{g} / f_{z}
$$

22. Under conditions with even moderate winds, as would be the case in situations important to the generation of waves and currents on a large body of water, the heat loss at the ground surface is such that it rapidly tends toward thermal equilibrium with the overlying air. Since the land does not have the heat capacity of water, nor the mixing mechanisms present in a lake, winds over a land surface can be considered to be almost always in a neutral stratification relative to winds over a lake. Consequently, the relationship shown in Figure 5 represents a good representation of the behavior of surface winds over land during these conditions. The velocity at any level, $\boldsymbol{Z}$, is then given by 


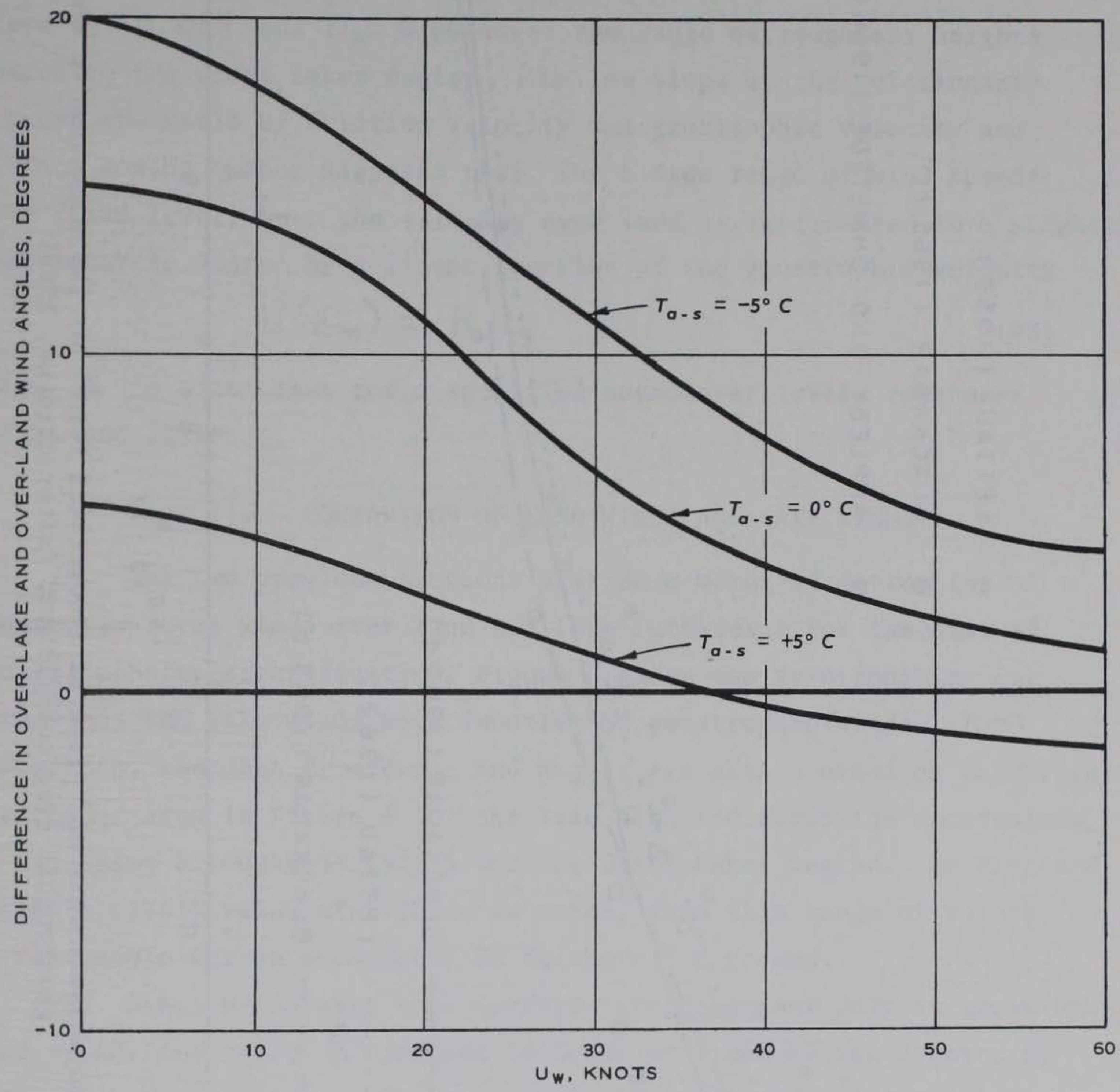

Figure 4. Difference between wind angle over land and over a large lake (away from the effects of 1 and). Positive angles represent conditions with the marine wind vector deviating to the right of the land wind vector 


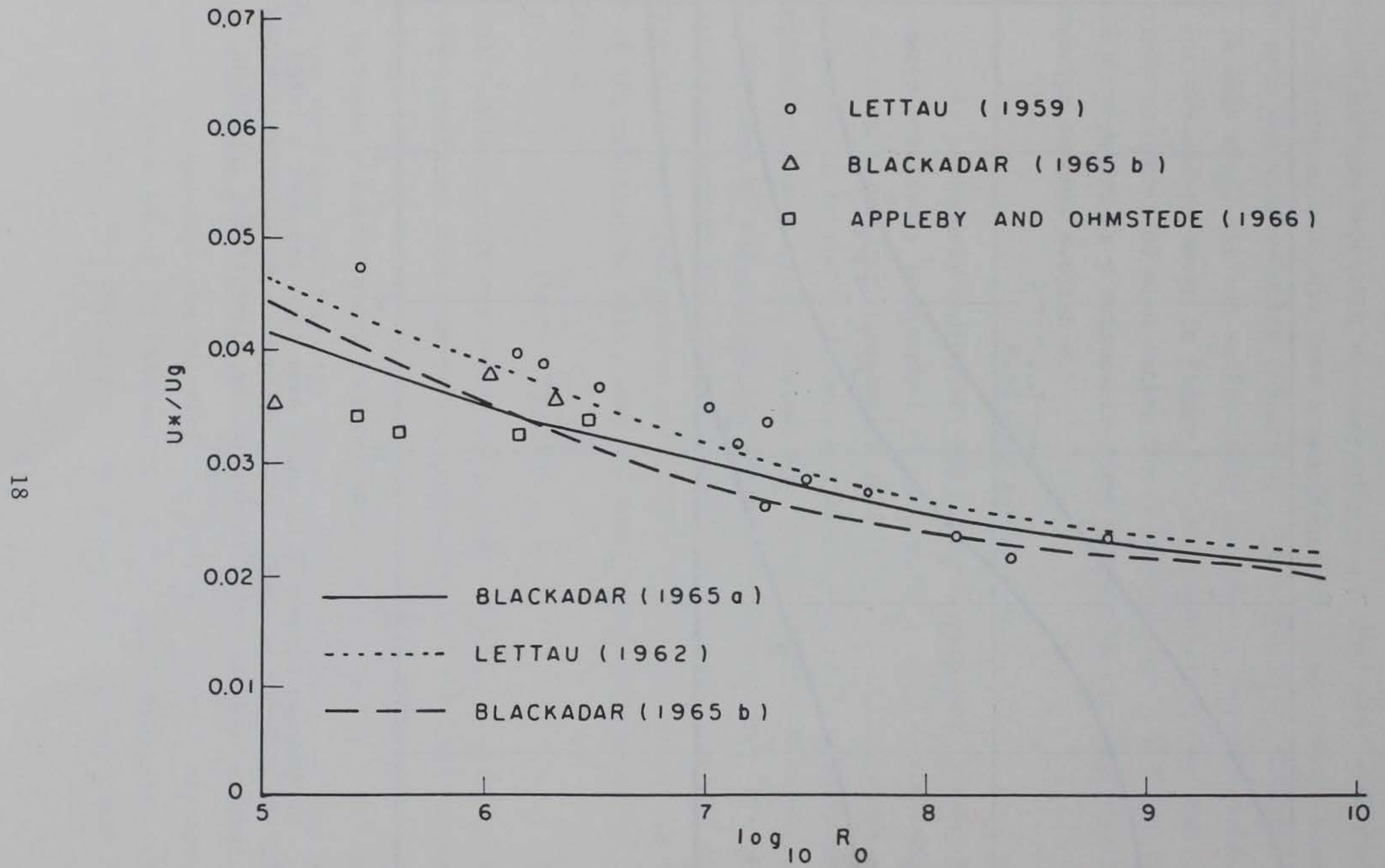

Figure 5. Published measurements and proposed theoretical forms for the variation of the surface geostrophic drag coefficient (after Cardone, 1969) 


$$
u(z)=\frac{u_{*}\left(R_{0}, u_{g}\right)}{K} \ln \left(\frac{z}{z_{0}}\right) \text {, }
$$

which to a good approximation is equal to

$$
u(z)=\frac{\left(b_{1}-b_{2} u_{g} \log R_{0}\right)}{K} \ln \left(\frac{z}{z_{0}}\right) \text {, }
$$

where $b_{1}=0.054$ and $b_{2}=0.003$ over the range of roughness heights common to the Great Lakes region. The low slope of the relationship between the ratio of friction velocity and geostrophic velocity and surface Rossby number suggests that, for a wide range of wind speeds at a fixed level, $\mathbf{Z}_{\boldsymbol{m}}$, the velocity over land is represented to a slightly less accurate degree by a linear function of the geostrophic velocity

$$
u\left(z_{m}\right)=k^{\prime} u_{g},
$$

where $K^{\prime}$ is a constant for a specified anemometer level, roughness height and latitude.

\section{PART III. COMPARISON OF LAND WINDS AND LAKE WINDS}

23. The two previous sections provide a means of estimating anemometer-level winds over land and lake surfaces. For the case of neutral density stratification, Figure 6 gives the relationships for land winds and lake winds as a function of geostrophic winds. For comparison, the data from Hasse and Wagner are also plotted on this figure. The shaded area in Figure 6 for the land wind indicates the uncertainty in assessing a roughness length for the Great Lakes region. If King and Lettau's (1961) value of $5-20 \mathrm{~cm}$ is taken, then this range of values is reasonable for an anemometer $20 \mathrm{ft}$ above the ground.

24. Since winds over both surfaces are dependent only on geostrophic wind speed, the ratio $R$ defined in Equation 1 can be represented by the ratio of the wind speeds as shown in Figure 6 . In order to test the validity of this relationship, the ratio is calculated empirically from ships observations (anemometer leve1 65 to $70 \mathrm{ft*}$ ) and observations at airport stations. The ships observations are 1-minute average wind speeds read from an anemometer and then corrected for ships speed. The airport data also represent a single 1-minute average wind for each hour.

* Personal communication W. E. Kennedy, Port Meteorological Officer, NOAA, Cleveland, Ohio. 


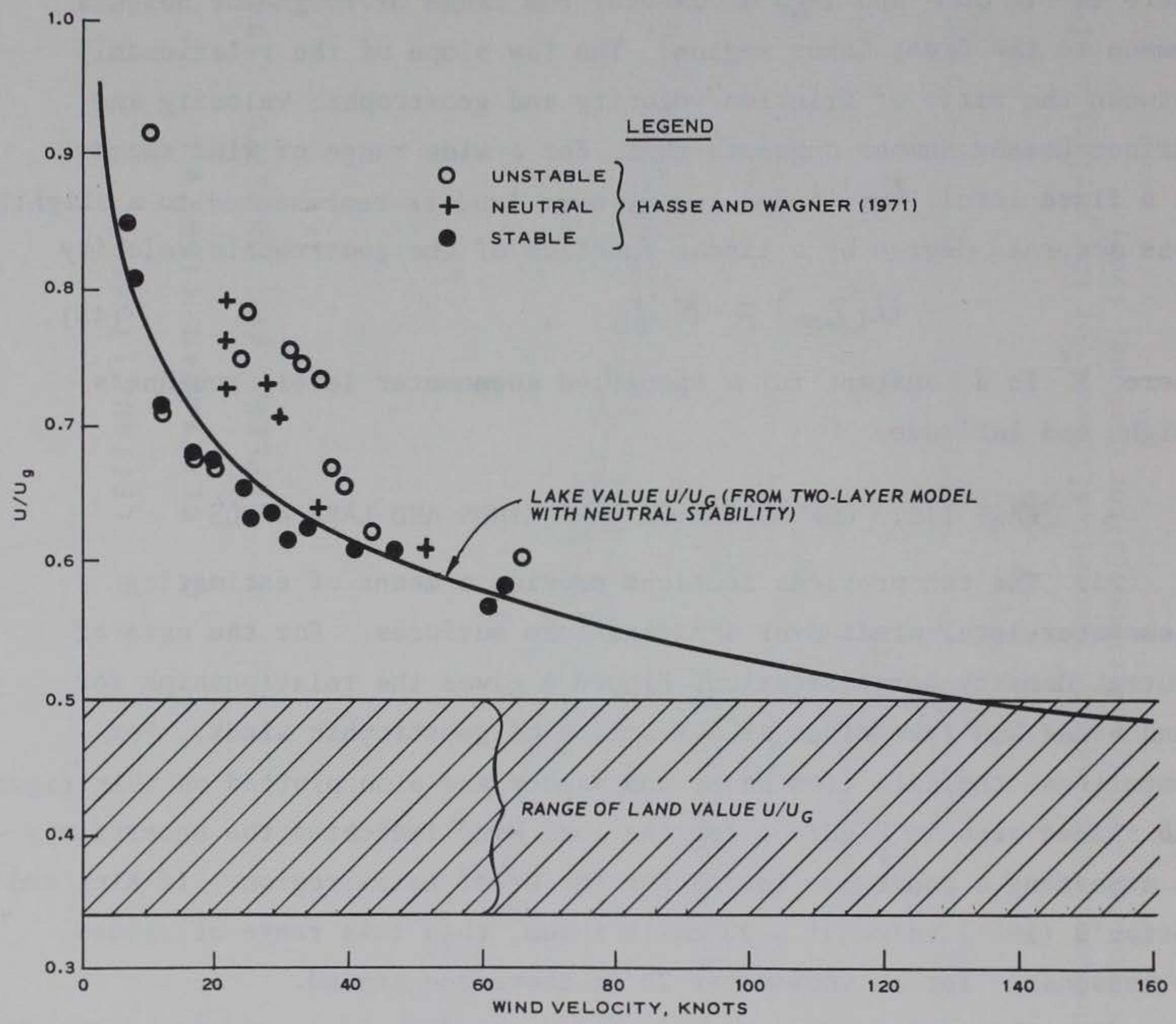

Figure 6. Dependence of the ratio of surface level wind speed to geostrophic wind speed as a function of surface wind speed (measured at $19.5 \mathrm{~m})$. Solid line represents results from two-layer model for a marine surface, symbols represent data from Hasse and Wagner (1971), and shaded region represents range of values estimated for over-land flow in Great Lakes region 
25. There are four airport stations considered in the study of Lake Erie and two for Lake Ontario (Figure 7). For Lake Erie, the ships observations were first partitioned into three segments as shown in Figure 7. The data sets were then merged so that all ships observations within each segment were paired with airport observations from the two stations which bounded the segment. In the merged data set, each ship's observation represents a sample of the winds over the lake set between land winds observed at the same time. There were over 63,000 ships observations on the original tapes provided by the National Climate Center in Asheville, North Carolina. Of these 51,249 had wind speed, wind direction, and air-sea temperature difference complete, giving this many paired data points in the merged set for the two lakes. The ratio of land wind speeds to ships wind speeds was defined by first averaging the land observations and then forming the ratio as defined in Equation 1. To test the dependence on velocity as predicted by Figure 6 , these samples were stratified into 3 knot categories. Figure 8 gives the results of the comparison between the observed ratio for each of the three lake segments as a function of velocity.* Results from studies by Richards et al. (1966) and Johnson are included for comparison.

26. Figure 8 demonstrates a strong agreement between theory and observation in estimates of winds over Lake Erie, over the range of observed velocities. This provides a well calibrated estimate of mean over lake winds up to about 40 knots. The sparse data available beyond this velocity indicate that the same relationship as shown in Figure 6 holds for high velocities as well. Consequently, the extension of the theoretical line to situations in which conditions were too rough for ships to be out.on the lake can be taken as a good unbiased estimate.

27. Since the results in Figure 6 were derived for neutral density stratification, the dependence of the ratio, $R$, on stability still needs to be considered in order to obtain a general formulation of winds over a lake. As discussed previously, the assumption of neutral density

\footnotetext{
* There is a nonlinearity in calculations such as this which tends to result in an overestimation of $R$ at low velocities and an underestimation of $\mathrm{R}$ at high velocities. The amount of bias is dependent on the standard deviation of sample points around the mean category value of $R$ and in this case was relatively small.
} 


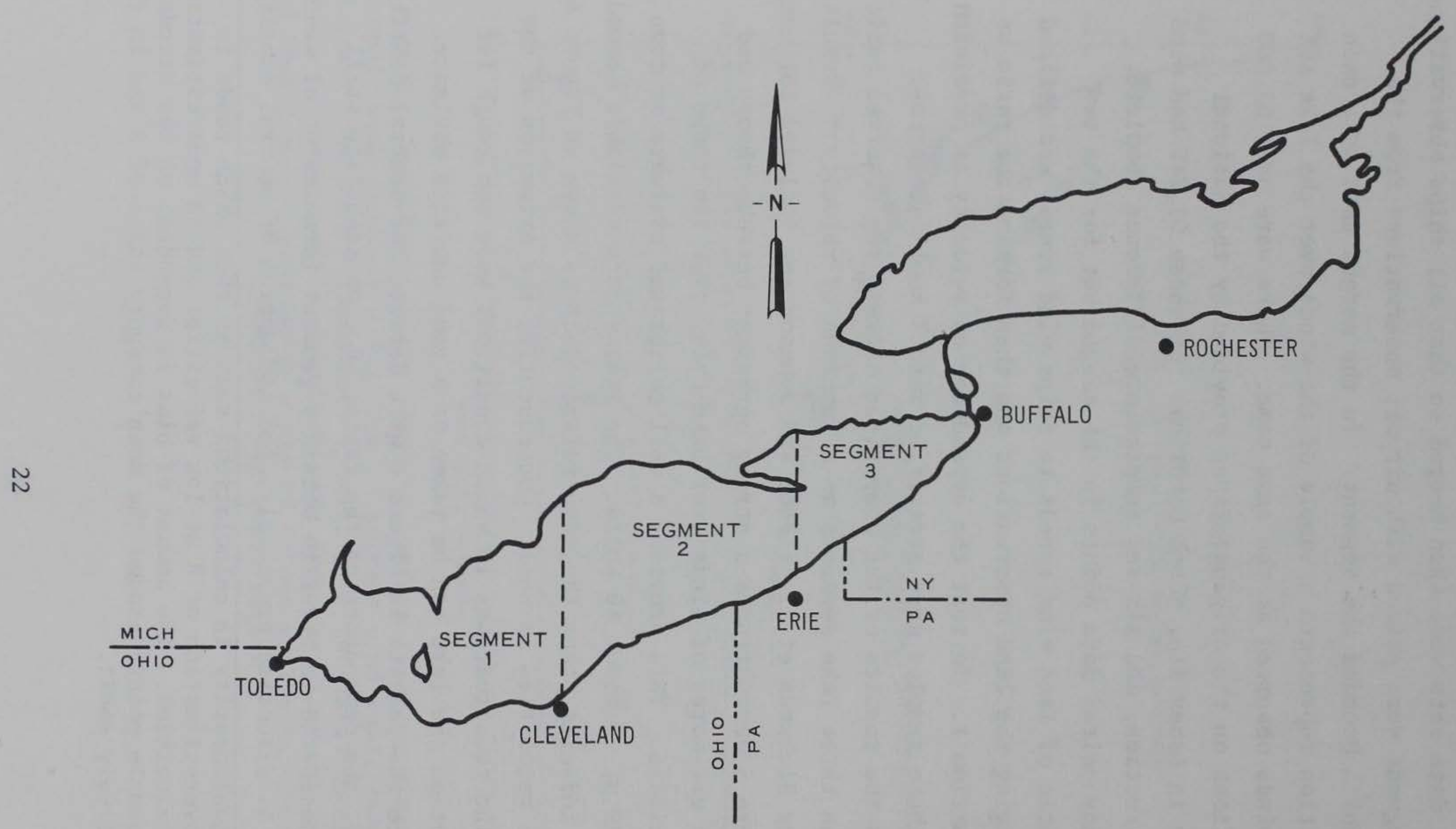

Figure 7. Location map for land stations used in comparisons to ships observations. Dashed lines across Lake Erie indicate segments into which this lake was divided in order to reduce errors due to spatial gradients 


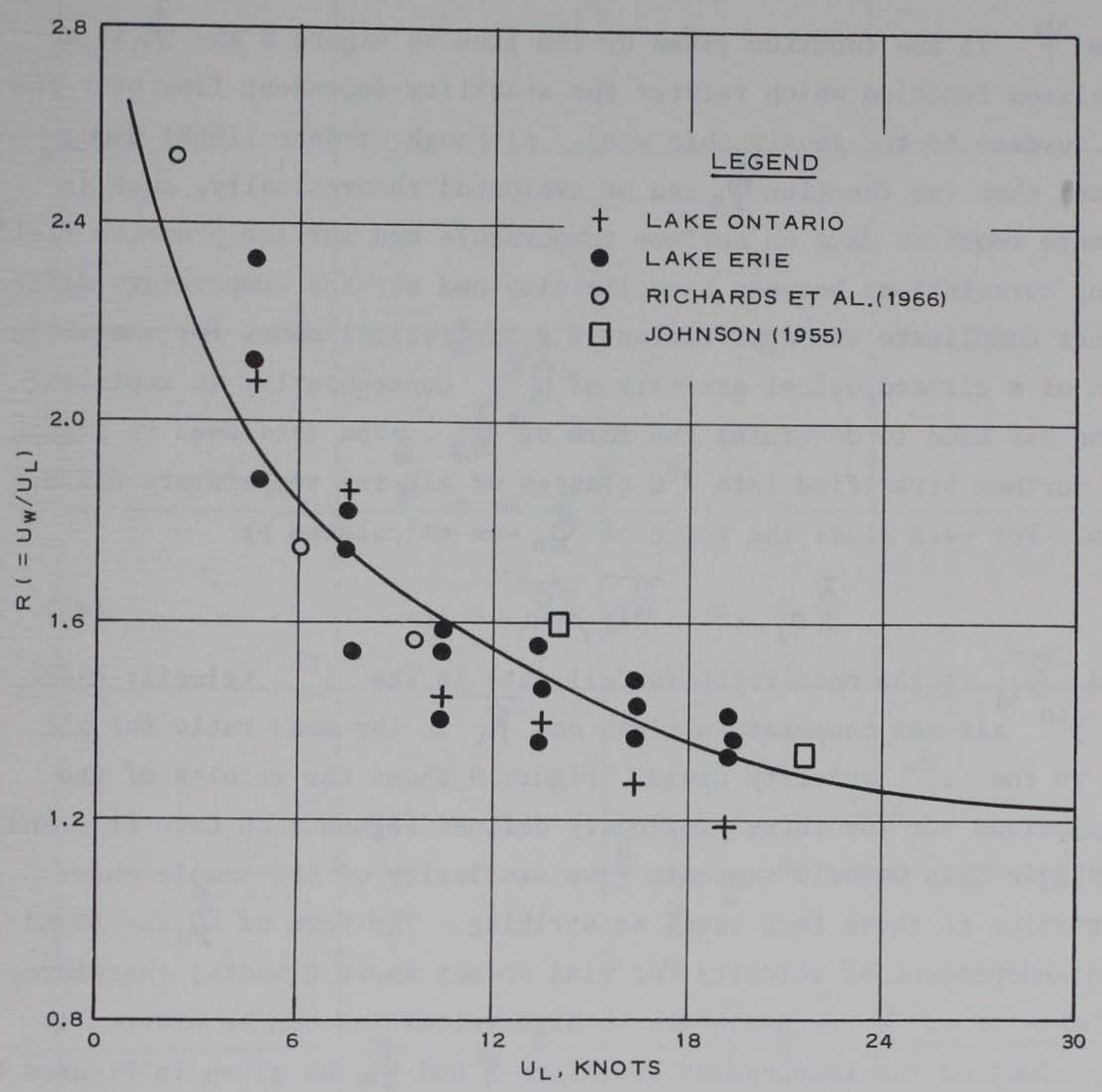

Figure 8. Proposed relationship between the ratio of over-1ake wind speed to over-land wind speed (R) and over-land wind speed $\left(U_{L}\right)$. Solid line represents combined theoretical treatments over over-1and and overlake atmospheric motion for neutral stability. Symbols represent data taken under neutral conditions 
stratification over land appears reasonable; thus, the dependence of $R$ on the stability is due primarily to variations in stability over the lake and can be expressed as

$$
R=\psi \Phi_{n},
$$

where $\psi$ is the function given by the line in Figure 8 and $\Phi_{n}$ is a normalized function which relates the stability-dependent flow over the lake surface to the geostrophic wind. Although Cardone (1969) demonstrates that the function $\Phi_{n}$ can be evaluated theoretically, such an estimate requires data on surface temperature and surface pressure fields. Strong correlations between baroclinicity and air-sea temperature differences further complicate the application of a theoretical model for the evaluation of a climatological estimate of $R$. Consequently, an empirical method was used to determine the form of $\Phi_{n}$. The data used in Figure 8 were further stratified into $3^{\circ} \mathrm{C}$ classes of air-sea temperature differences. For each class the value of $\Phi_{n}$ was calculated by

$$
\Phi_{n_{j}}=\overline{R_{i j}} / \overline{R_{i}},
$$

where $\overline{R_{i j}}$ is the mean ratio for all data in the $i^{\text {th }}$ velocity class and $j^{\text {th }}$ air-sea temperature class and $\overline{R_{i}}$ is the mean ratio for all data in the $i^{\text {th }}$ velocity class. Figure 9 shows the results of the calculations for the three previously defined segments on Lake Erie and the single Lake Ontario segment. The similarity of the sample characteristics in these four cases is striking. The form of $\Phi_{n}$ was found to be independent of velocity for wind speeds above 6 knots; therefore, the behavior of $R$ for moderate to high velocities can be written as the product of two independent functions $\psi$ and $\Phi_{b}$ as given in Figures 8 and 9 , respectively.

28. There is considerable evidence from previous investigations which tend to support the form of relationship between the land lake wind ratio and stability shown in Figure 9. Lettau (1959), using data from cornfields in $0^{\prime} \mathrm{Neil1}$, Nebraska, showed that the ratio of the friction velocity to geostrophic wind varied in a manner similar to that in Figure 9. Figure 10 shows results from Lettau's study along with calculations by Cardone (1969) using the two-layer model by Blackadar 


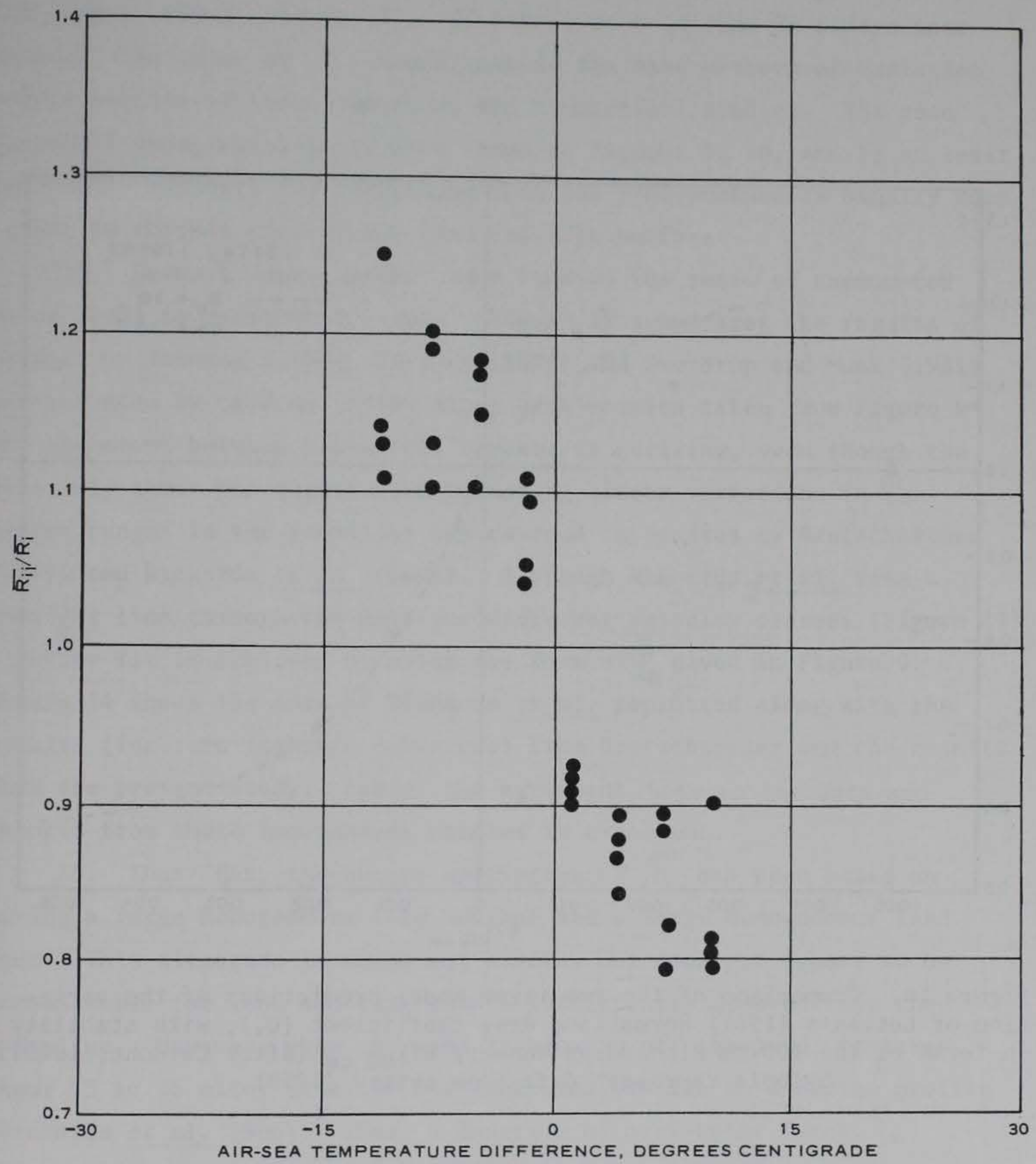

Figure 9. Normalized function $\Phi_{n}=\bar{R}_{i j} / \bar{R}_{i}$ as related to air-sea temperature difference. Symbols indicated data from ships observations and 1 and stations shown in Figure 7 


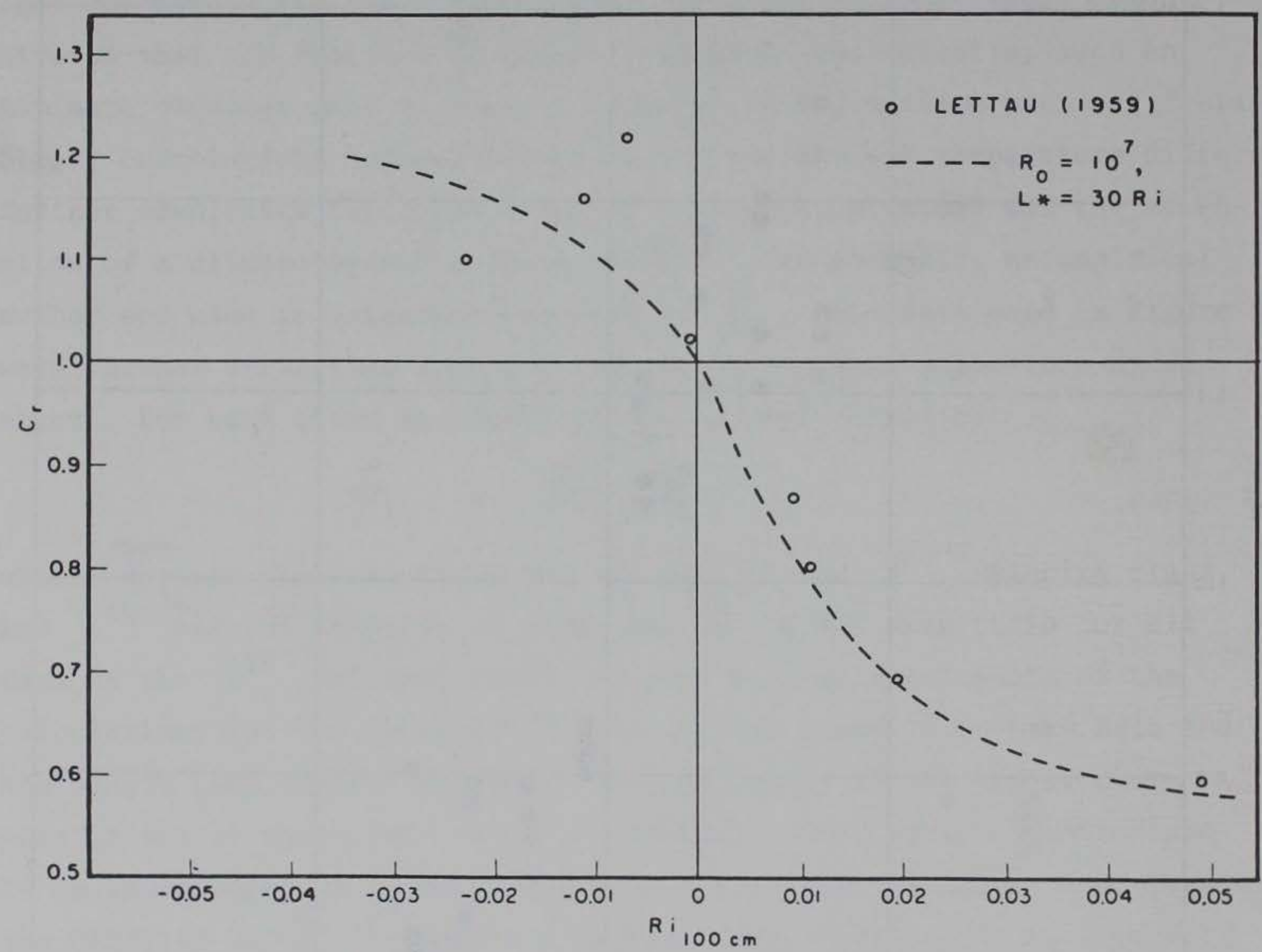

Figure 10. Comparison of the two-layer model predictions of the variation of Lettau's (1961) normalized drag coefficient ( $U_{*}$ ), with stability in terms of the $100-\mathrm{cm}$ Richardson Number, Ri $100 \mathrm{~cm}$ (after Cardone, 1969). Symbols represent data from Lettau (1959) 
and Ching (1965). As discussed by Cardone, additional evidence that this form is appropriate comes from a study by Clarke (Priestly, 1967) which investigated the dependence on stability of the ratio of $u_{*}$ to the wind at $500 \mathrm{~m}$ (Figure 11). If stability over land is always near neutral, the value of $R$ should contain the same pattern of variation as the results of these empirical and theoretical studies. The good agreement among the sets of data shown in Figures 9, 10, and 11 at least indirectly supports the contention that the land surface is usually much closer to thermal equilibrium than the lake surface.

29. Several investigators have studied the ratio of anemometer level winds to geostrophic winds. Figure 12 summarizes the results of studies by Johnson (1955), Bivjoet (1957) and Sverdrup and Munk (1951) as presented by Cardone (1969) along with results taken from Figure 9*. The agreement between these sets of data is striking, even though the data only cover the region with primarily linear variations in $\Phi_{n}$. Larger ranges in the stability are covered in studies by Bretschneider (1971) and Richards et a1. (1966). Although Richards et al. fits a straight line through the data for different velocity classes (Figure 13), a better fit is achieved by using the form of $\Phi_{n}$ given in Figure 9. Figure 14 shows the data of Richards et al. replotted along with the results (for zero isobaric curvature) from Bretschneider and the results from the present study. Again, the agreement between the data and results from these independent studies is excellent.

30. Thus far, the entire derivation of $R$ has been based on having a large homogeneous lake surface and a large homogeneous land area. This situation is never met exactly but does not appear to be unreasonable for land and lake points sufficiently removed from the shoreline. However, when the wind is blowing off the land, it takes about 15 to 25 miles to alter the land wind profile to a marine profile (Richards et al. 1966). Thus, a function of over-water fetch, $F_{k}$, must be included to further generalize the representation of $R$ :

$$
R=\psi \Phi_{n} F_{*},
$$

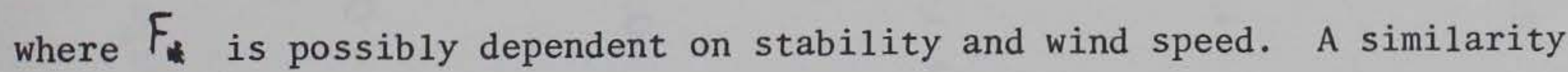

* These values were converted by dividing $u / u g$ by the ratio of land winds to geostrophic winds. 


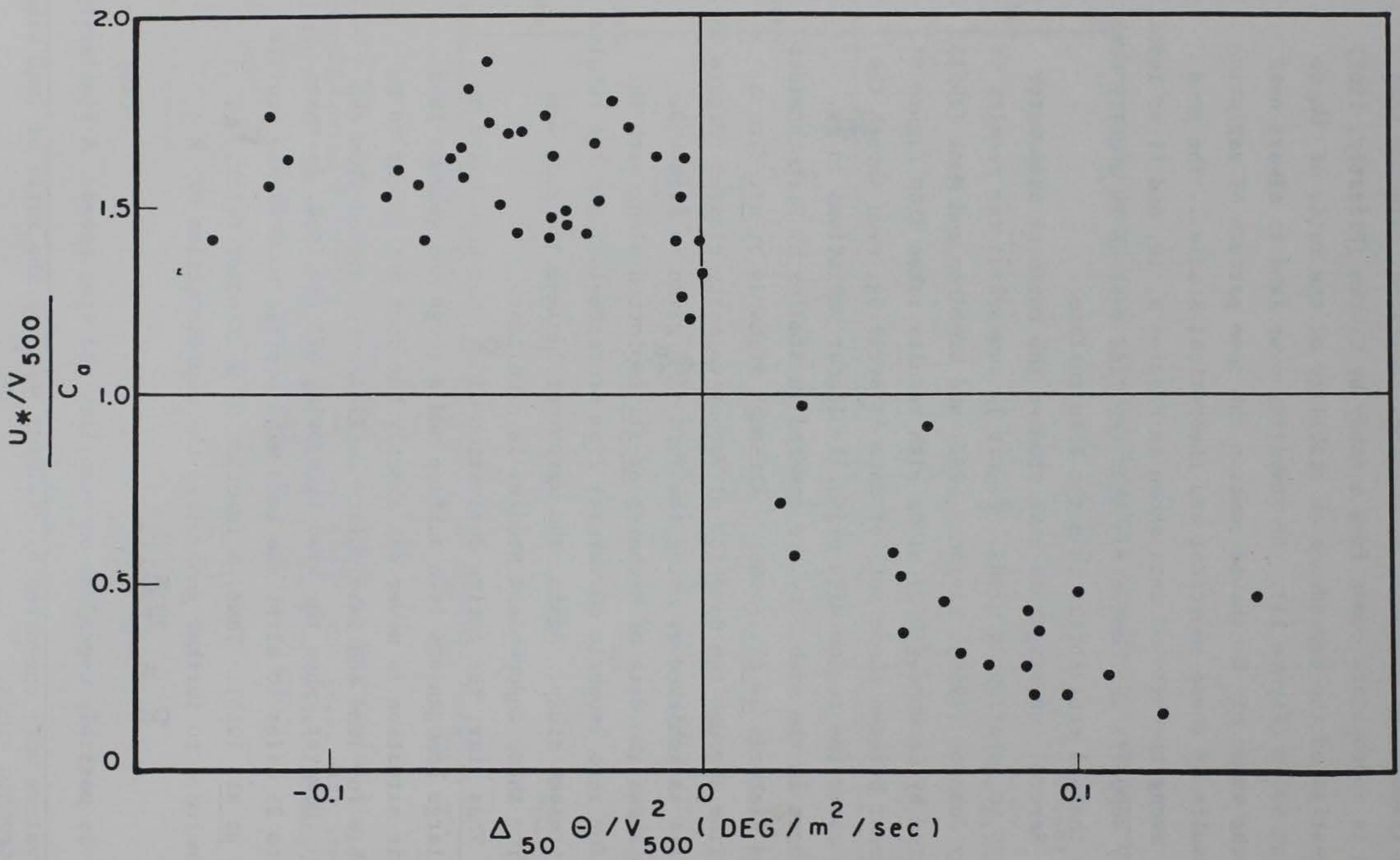

Figure 11. Clarke's measurements of the 500-m drag coefficient normalized by Lettau's empirical value for neutral conditions versus bulk stability (after Cardone, 1969) 


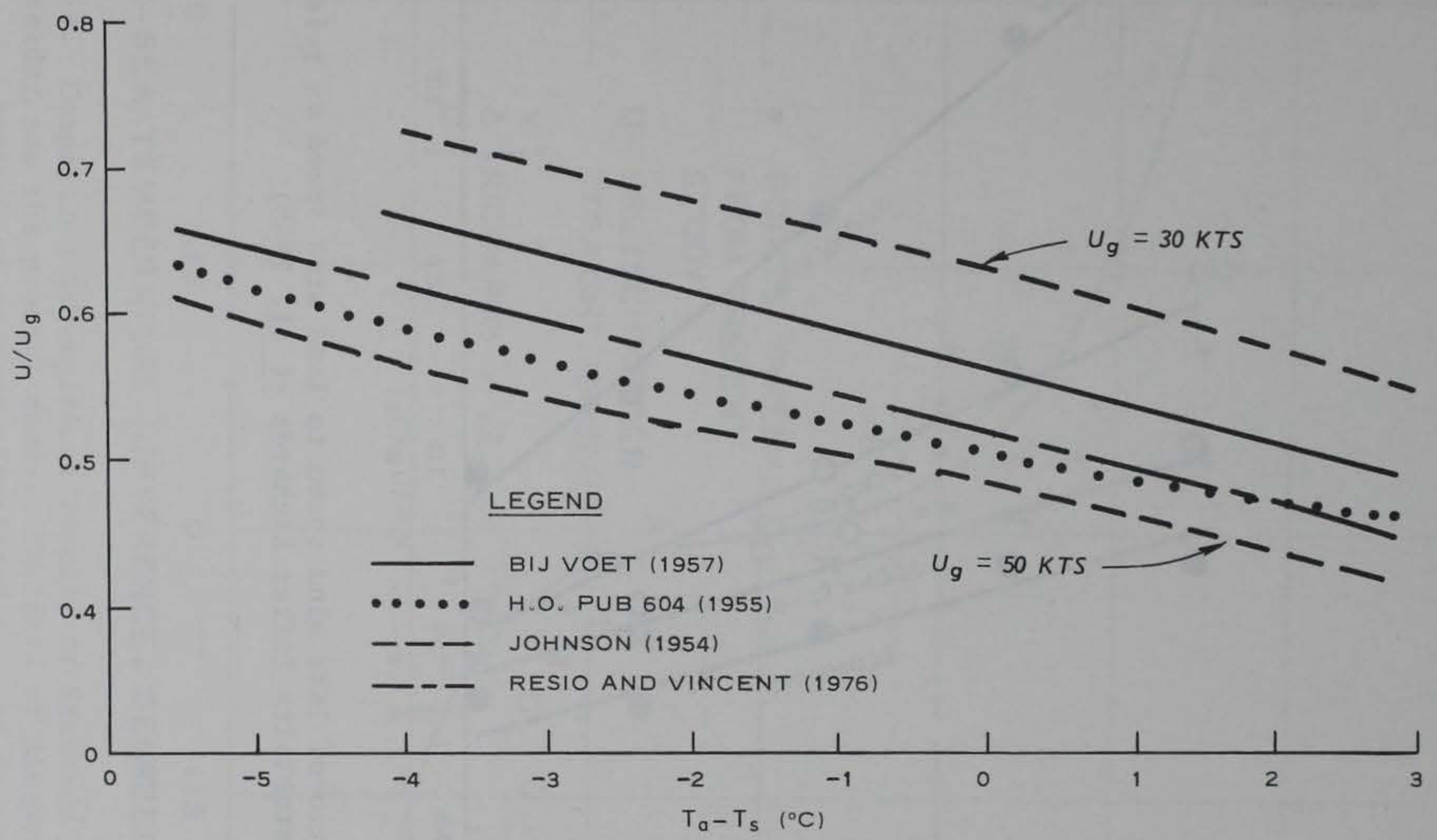

Figure 12. Comparison of empirical studies of the ratio of surface wind speeds to geostrophic wind speeds over narrow range in which the variation appears to be 1 inear 


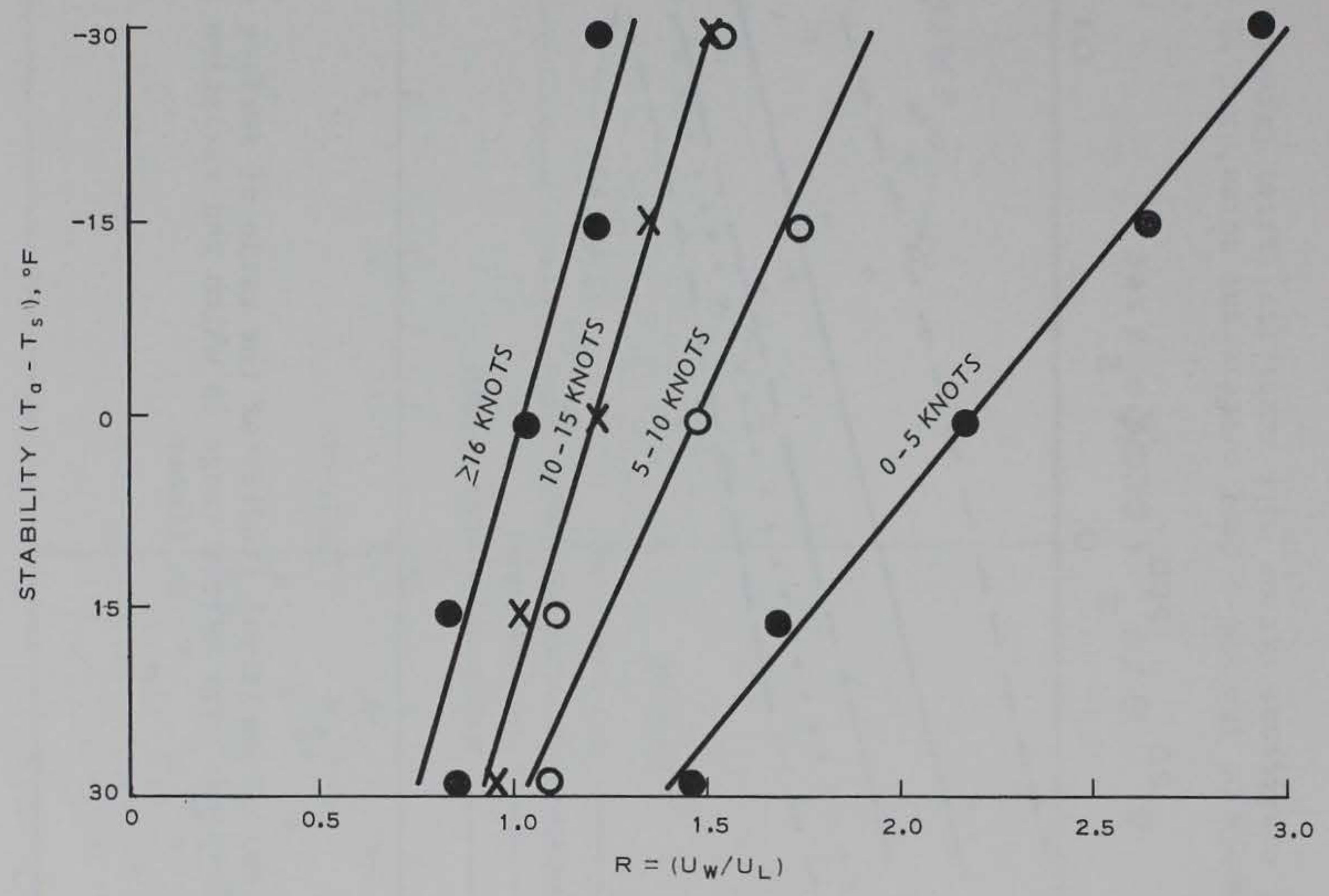

Figure 13. Ratio of lake wind speed to land wind speed as related to stability (after Richards et a1. 1966) 


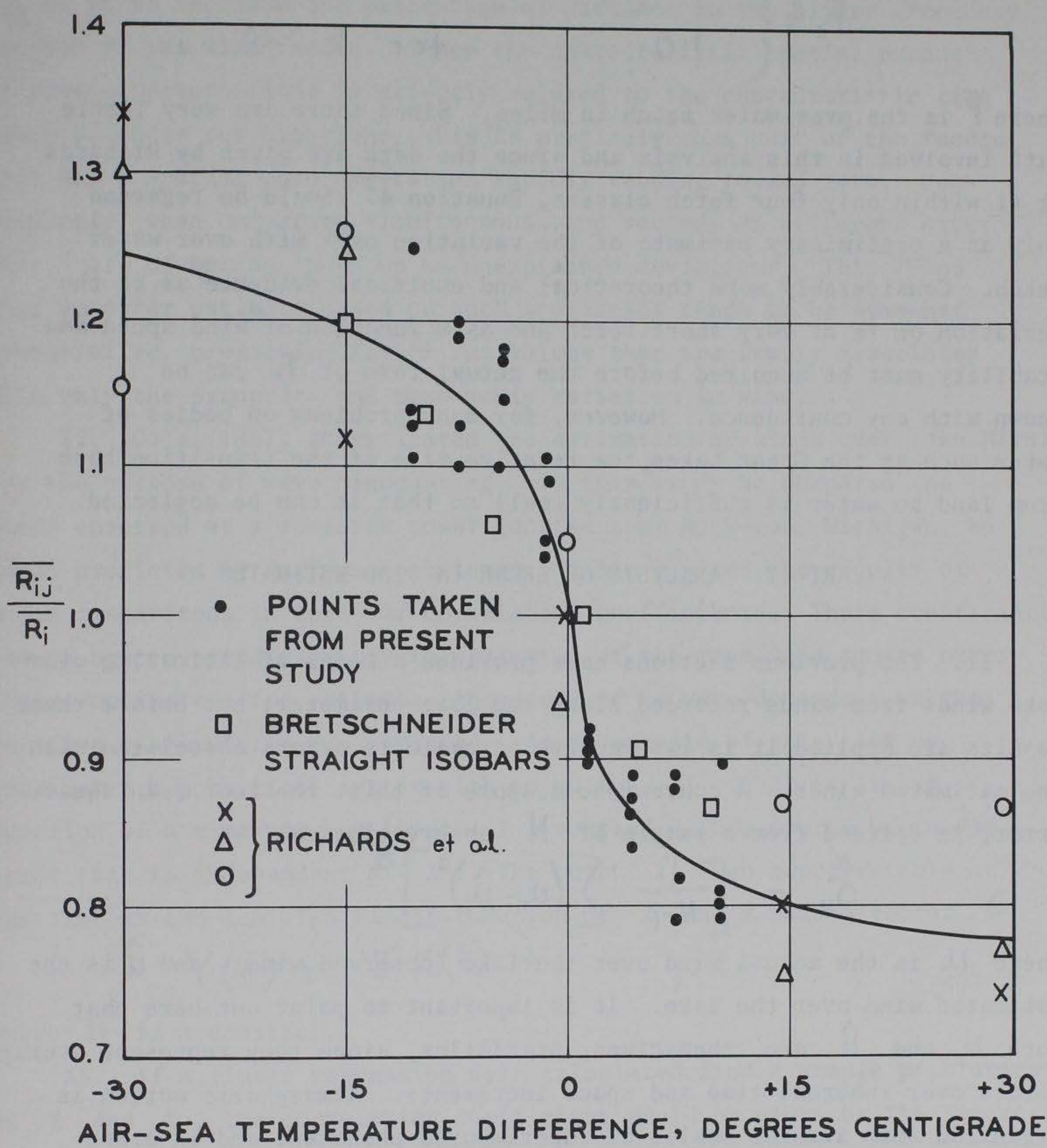

Figure 14. Comparison of empirical results of Richards et al. (1966), Bretschneider, and the present study. The data of Richards et al. and Bretschneider were normalized to 1 at neutral 
form for $F_{\sharp}$ would require many more parameters than there exist data from Richards et al. (1966), to test. A simple form for $F_{*}$ is given by

$$
F_{*}=\left\{\begin{array}{cc}
0.411 F^{0.297} & \text { for } F \leq 20 \\
1.0 & \text { for } F>20
\end{array},\right.
$$

where $F$ is the over-water fetch in miles. Since there are very little data involved in this analysis and since the data are given by Richards et al. within only four fetch classes, Equation 47 should be regarded only as a preliminary estimate of the variation of $R$ with over water fetch. Considerably more theoretical and empirical evidence as to the variation of $F_{*}$ at very short fetch and as a function of wind speed and stability must be acquired before the actual form of $F_{*}$ can be known with any confidence. However, for many problems on bodies of water such as the Great Lakes, the relative size of the transition zone from land to water is sufficiently small so that it can be neglected.

\section{PART IV. ANALYSIS OF ERROR IN WIND ESTIMATES}

31. The previous sections have provided a means of estimating over lake winds from winds recorded along the lake perimeter; but before these results are applied, it is instructive to evaluate errors associated with the estimated winds. A convenient measure of this, the root mean square error, is defined from a sample of $N$ observations as

$$
\hat{\sigma}_{u}=\left[\frac{1}{N-1}\left[(u-\hat{u})^{2}\right]^{1 / 2},\right.
$$

where $U$ is the actual wind over the lake (observed wind) and $\hat{U}$ is the estimated wind over the lake. It is important to point out here that both $U$ and $\hat{U}$ are, themselves, statistics, since they represent average values over inherent time and space increments. Atmospheric motion is organized into several scales of superimposed phenomena and in order for a particular analysis to be meaningful, the scales of motion which are relevant to the study must be isolated. For the Great Lakes, these scales are in the range of 1 to 3 hours and 30 to 100 miles. Unfortunately, wind data averaged over such time and space intervals do not exist for 
the Great Lakes region and analyses must use data which are based on 1-minute samples at single locations. The effect of the shorter averaging period is to increase the percentage of variance in the higher frequency portion of the wind record. Since the characteristic spatial extent of random perturbations is directly related to the characteristic time scale of those perturbations, this is precisely that part of the record that has a spatial autocorrelation rapidly tending toward zero. Consequently, when comparing simultaneous wind records at different sites this scale of motion shows up as unexplained deviations. This means that an error estimate based on such statistics tends to be somewhat conservative, predicting larger rms values than are really associated with only the synoptic- and meso-scale variation in wind.

32. Cole (1967) investigated the estimation of winds over Lake Michigan for the purpose of wave hindcasting. In this study he compared the winds observed at a research tower located near Muskegon, Michigan, to winds predicted by various techniques. Table 1 gives the results of these comparisons in terms of correlation coefficients. These coefficients cannot be converted directly to estimates of the root mean square error since, unlike the rms estimate, they tend to be very dependent on the relative range of the two variates. As an example of this, let us consider a hypothetical system with an output, $\mathrm{Y}$, that is linear function of a time-varying input, $X$, coupled with a source of random error that is independent of $X$. The output is then representable at any time as the sum of a linear function of $X$ and a random vector $\epsilon$

$$
Y(t)=B^{\prime} X(t)+\epsilon
$$

where $B^{\prime}$ is a constant.

33. If a linear regression were calculated from a sample population of $X$ and $Y$, the correlation coefficient would be given by the square root of the explained variance to the, unexplained variance

$$
\rho=\left(\frac{\sigma_{Y}^{2}-\sigma_{\epsilon}^{2}}{\sigma_{r}^{2}}\right)^{1 / 2}
$$

34. It can be seen from Equation 50 that the correlation would improve as the range of input values (and consequent1y output values) 
increased. Conversely, as the range of input values decreased relative to the error term, the correlation would tend toward zero.

35. Since Cole's analyses were performed with few data pairs (1ess than 50) during a month which typically has low wind speeds, the low values of the correlation coefficients are not surprising. Other factors such as the lack of treatment of possible gradients in the velocity field and the nonlinearity of the relationship between winds over 1 and and over water might also contribute to the exceedingly low correlation.

36. In the present study, the data are stratified by velocity and stability class. The rms value as calculated from Equation 48 is shown as a function of wind speed in Figure 15. There did not appear to be a well defined dependence of the rms values on stability. These results indicate that the technique described in this paper provides a reliable estimate of over-water winds at moderate to high velocities. It should be noted, however, that the ships were almost always located beyond 10 miles from shore; hence, these results do not necessarily imply the same accuracy in the transition zone close to shore.

37. The relationship between winds over land and over water, as given in Equation 46 along with Figures 8 and 9, requires information on air-sea temperature difference. In many instances, this is not available in the case of historical data or even for contemporary data. A reasonable estimate of over-water winds can still be obtained if a climatological basis for air-sea temperature difference is established. This should not create significant bias but will increase the rms error of the estimate.

38. Given that in a body of water the size of the Great Lakes the thermodynamic coupling between air and water is such that the temperature of the water surface, $T_{S}$, can be approximated by a time-averaged function of the air temperature, $T_{a}$, $T_{S}(t) \approx \frac{1}{\Delta t} \int_{t-\Delta t}^{t} T_{a}(t) d t$, ,
where $\Delta t$ is a (non-constant) characteristic averaging time (of the order of months); then for a random sequence of air temperatures, the air-sea temperature difference can be represented as a random sequence 


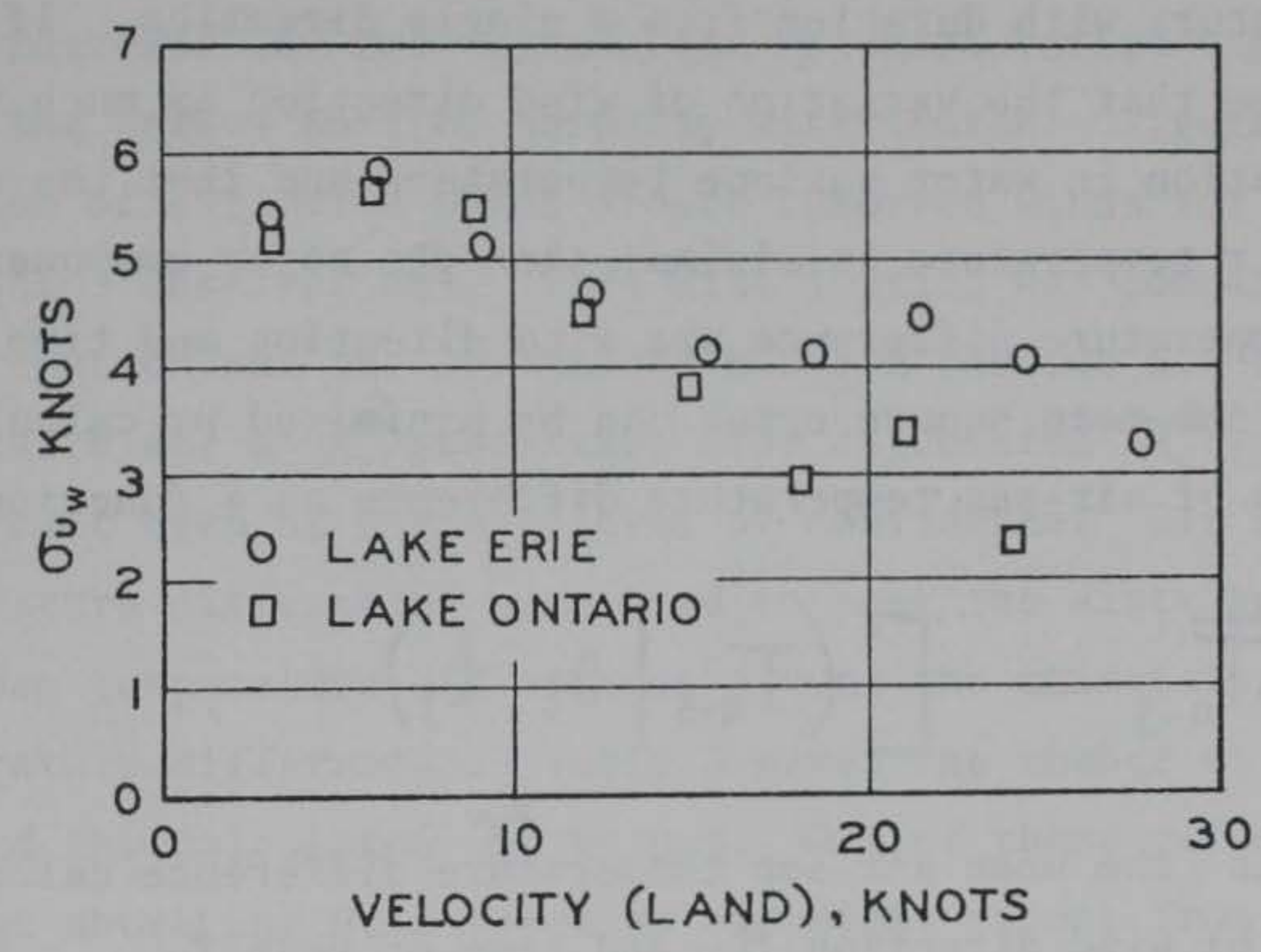

Figure 15. Root mean square errors for data from Lakes Erie and Ontario as a function of over-land wind speed 
with frequencies above $\frac{1}{\Delta t}$ only. This means that climatic-scale variations should not strongly alter air-sea temperature differences and that the advection of cold or warm air by the wind is most likely the major contributor to air-sea temperature differences for the Great Lakes.

39. It is hypothesized here that three factors control the deviation between the short term advection (air temperature) and longer term response (sea-surface temperature). These are time of year, direction of wind, and duration of wind. The direction and time of year dictate the air-mass source and temperature; whereas, the duration relates to the amount of adjustment by the water surface temperature and variations in air temperature with duration from a single direction. If it is further assumed that the variation of wind direction is much more rapid than the variation in water surface temperature and that the effect of duration on air temperature is minimal, then the major components of air-sea temperature difference are wind direction and time of year. Consequently, the mean square error can be minimized by calculating the expected value of air-sea temperature difference as a function of these two factors

$$
\bar{T}_{a-s}=\left[\left(T_{a-s} \mid \theta_{i}, t_{j}\right),\right.
$$

where $\bar{T}_{a-s}$ is the mean air-sea temperature difference calculated for each category of wind direction $\theta_{i}$ and time of year $t_{j}$. For the Great Lakes the time scale of seasonal change and the sampling density of air and sea temperatures are such that one month and $10^{\circ}$ were chosen as reasonable class widths for time and direction, respectively. Table 2 gives the mean air-sea temperature differences defined for Lakes Erie and Ontario along with the standard deviations of the distributions within these categories.

40. The rms error due to the use of climatological air-sea temperature values can be approximated from the sample standard deviations of airsea temperature difference as

$$
\hat{\sigma}_{u}=\hat{\sigma}_{T_{a-s}} \frac{\frac{\partial u}{\partial T_{a-s}}}{\text {, }}
$$


where the bar over the partial derivative denotes an averaging over the distribution of air-sea temperature differences. Equation 53 combined with the forms of $\psi$ and $\Phi_{n}$ shown in Figures 8 and 9 indicates that the rms error is highly dependent on air-sea temperature difference and wind velocity. Approximating Equation 53 for a given air-sea temperature difference and wind velocity, one obtains

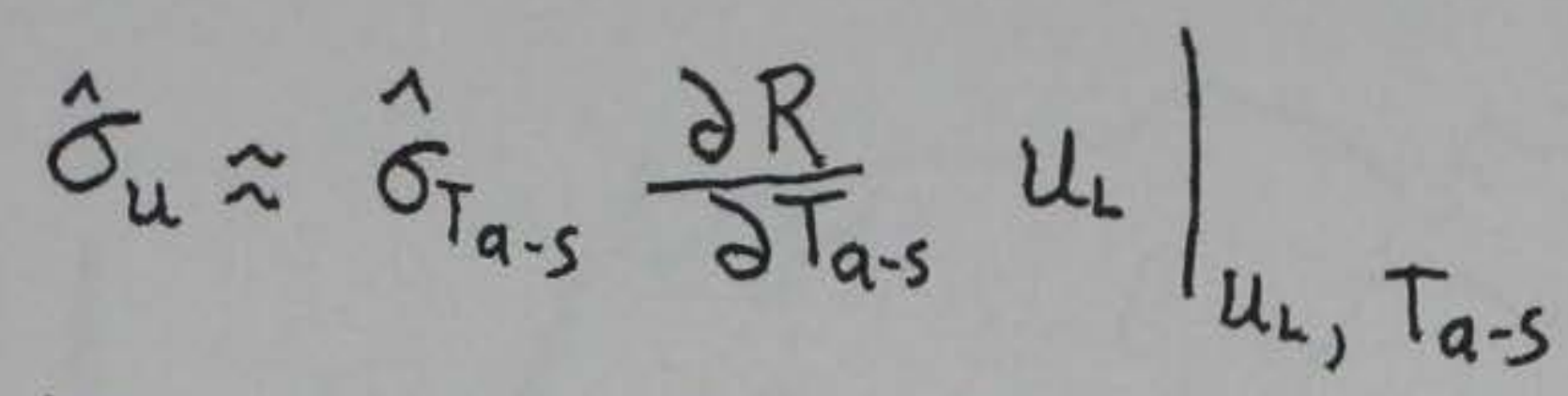

For most conditions on the Great Lakes this rms error calculated in this manner is under 4 knots.

41. In order for the rms value alone to characterize the error distribution, the errors must be normally distributed. Figure 16 shows the distribution of estimated winds around observed winds for a random sample of 53 ships observations. This distribution was compared to a normal distribution, and the deviations between the two distributions were used to calculate a $\chi^{2}$ statistic. The calculated $\chi^{2}$ value, 9.53, is not significant even at the 0.5 level of confidence. Six sets of air-sea temperature differences were used to test the distribution of observed air-sea temperature differences around the climatological mean air-sea temperature differences. Table 3 gives the number of samples in each set and the calculated $\boldsymbol{X}^{2}$ values. Out of these values two are significant above the 0.33 level as one might expect from random deviations. Consequently, the errors associated with the wind estimates using the technique described in this report are probably adequately described by the normal distribution, at least at moderate to high wind speeds.

\section{PART V. COMPARISONS OF RESULTS TO OTHER STUDIES}

42. It remains to be seen why previous investigations have found so little evidence of a strong relationship between winds observed over land and those observed over the lake. Figure 17 shows the location of the research tower at Muskegon, Michigan, and several airports around the lake. Jacobs (1965) calculated a correlation coefficient of 0.23 between winds 


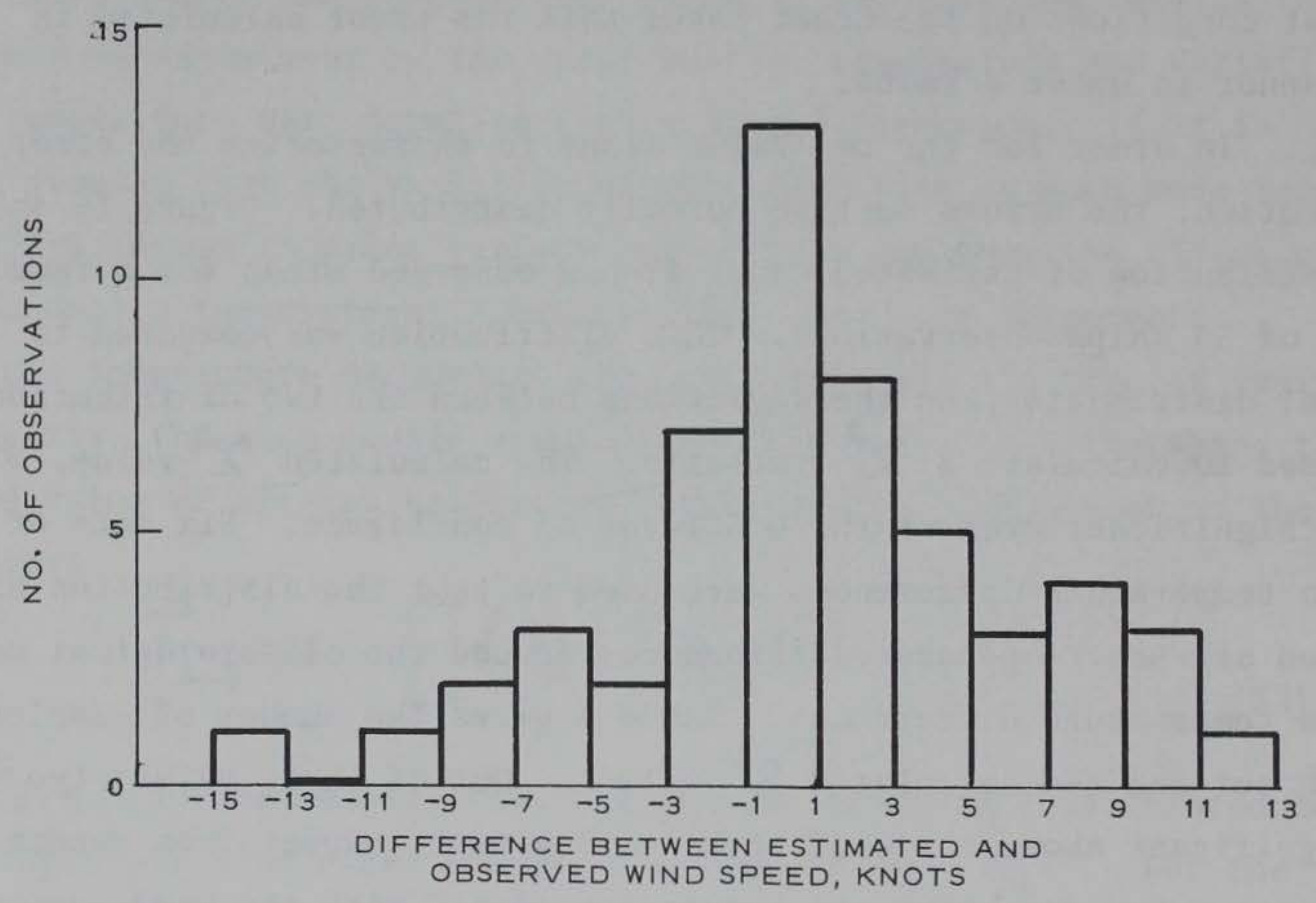

Figure 16. Distribution of deviations around wind speeds estimated by Equation 46 using climatological values of air-sea temperature difference 


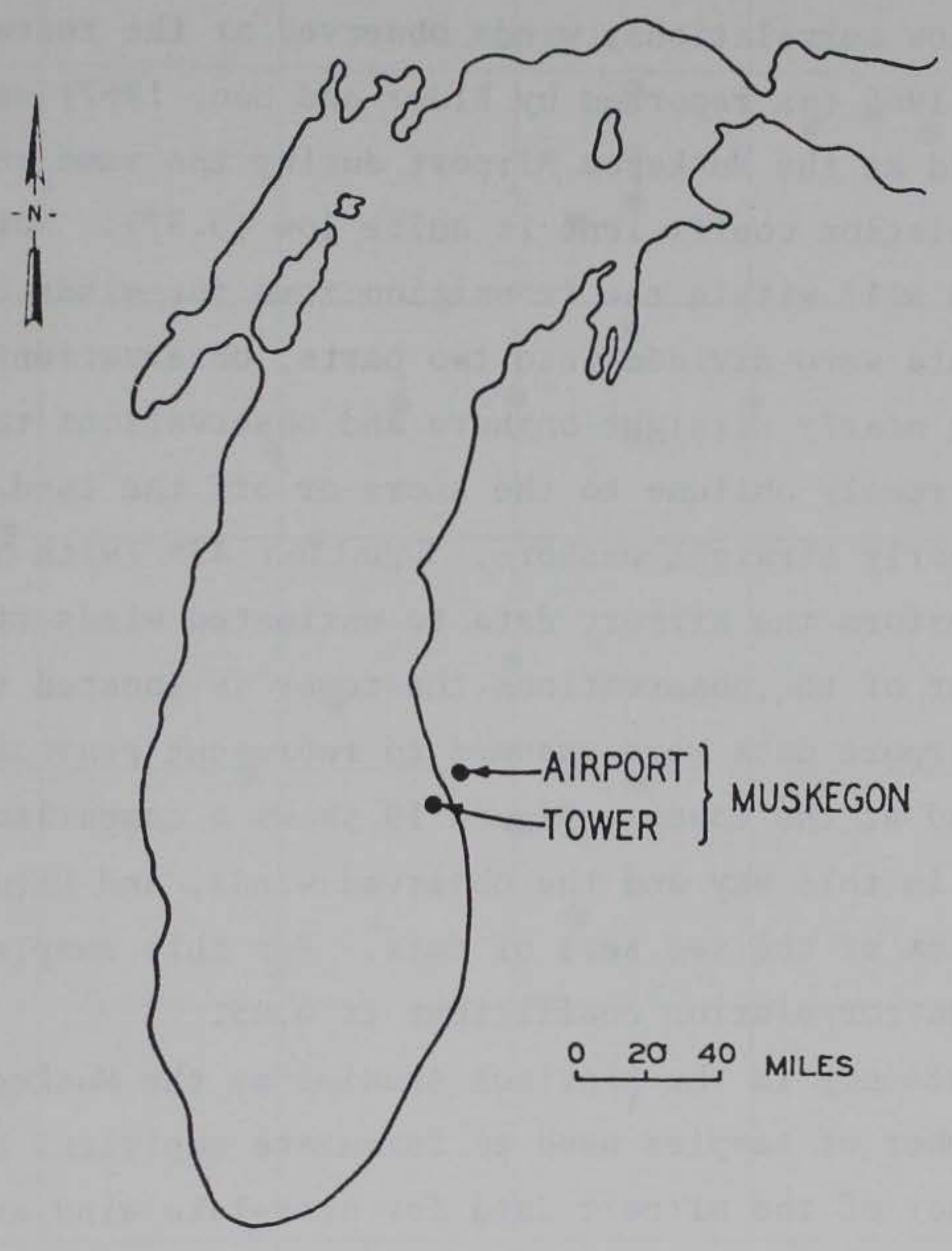

\section{LAKE MICHIGAN}

Figure 17. Location of Muskegon research tower in Lake Michigan and Muskegon Airport 
observed at the research tower and Muskegon Airport. Cole (1967) calculated a correlation coefficient of 0.35 between winds observed at the 16-m levels of the research tower and upwind airport stations and 0.24 between the $10-\mathrm{m} 1$ evel and upwind airport stations. Such low correlations certainly suggest that the use of winds over land to predict winds over the lake is not very accurate. In order to examine the possible causes of such low correlations, winds observed at the research tower in late October 1965 (as reported by Elder and Soo, 1967) were compared to winds observed at the Muskegon Airport during the same period (Figure 18). Again, the correlation coefficient is quite low $(0.32)$. Noting that the tower is located well within the transition zone for winds coming off the 1and, the data were divided into two parts, observations taken with the wind blowing nearly straight onshore and observations taken with the wind blowing extremely oblique to the shore or off the land. For the winds blowing nearly straight onshore, Equation $47^{*}$ (with $F_{*}$ set equal to 1 ) was used to transform the airport data to estimated winds at the tower. For the remainder of the observations the tower is located so close to land that the airport data were assumed to represent reasonable estimates of the wind at the tower. Figure 19 shows a comparison between the winds estimated in this way and the observed winds, and Figure 20 gives the time histories of the two sets of data. For this sample of 27 paired observations, the correlation coefficient is 0.95 .

43. A deficiency in the previous studies at the Muskegon tower is the small number of samples used to formulate empirical conclusions as to the adequacy of the airport data for over-lake wind estimates. Jacobs (1965) based his pessimism on a sample of only seven comparisons. Cole (1967) used 44 data pairs at the 16-m level and 36 data pairs at the $10-\mathrm{m}$ level to arrive at the conclusion that over-1and winds were not very representative of over-lake winds. The study by Jacobs used a linear correlation coefficient to measure the very nonlinear relationship between untransformed over-land winds and over-lake winds. As shown in

* The exact curve for $\Psi$ on Lake Michigan is very similar to Lake Erie and Lake Ontario but is displaced somewhat toward higher values. 


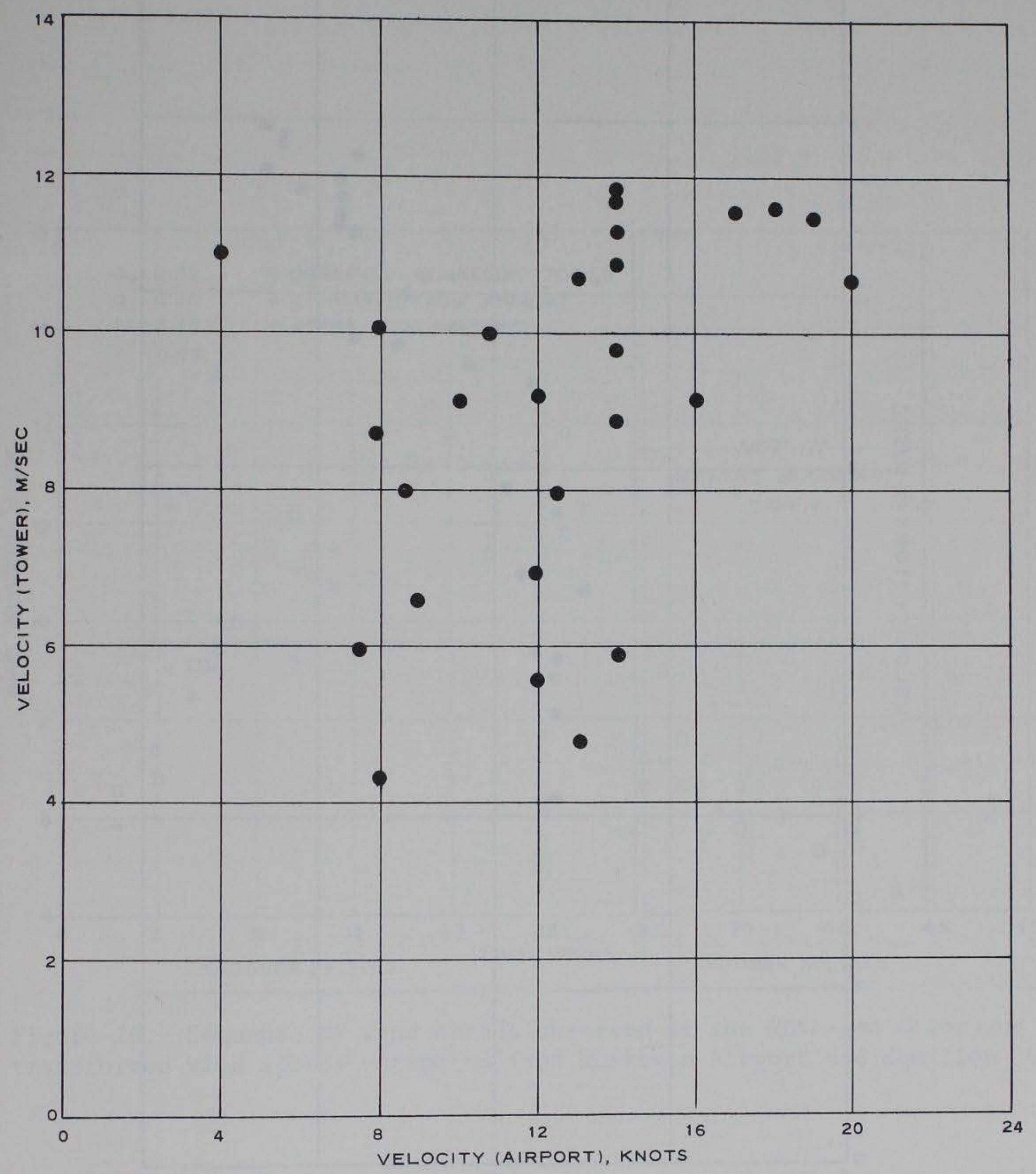

Figure 18. Comparison of wind speeds observed at the Muskegon tower (E1der and Soo, 1967) to untransformed wind speeds observed at the Muskegon Airport 


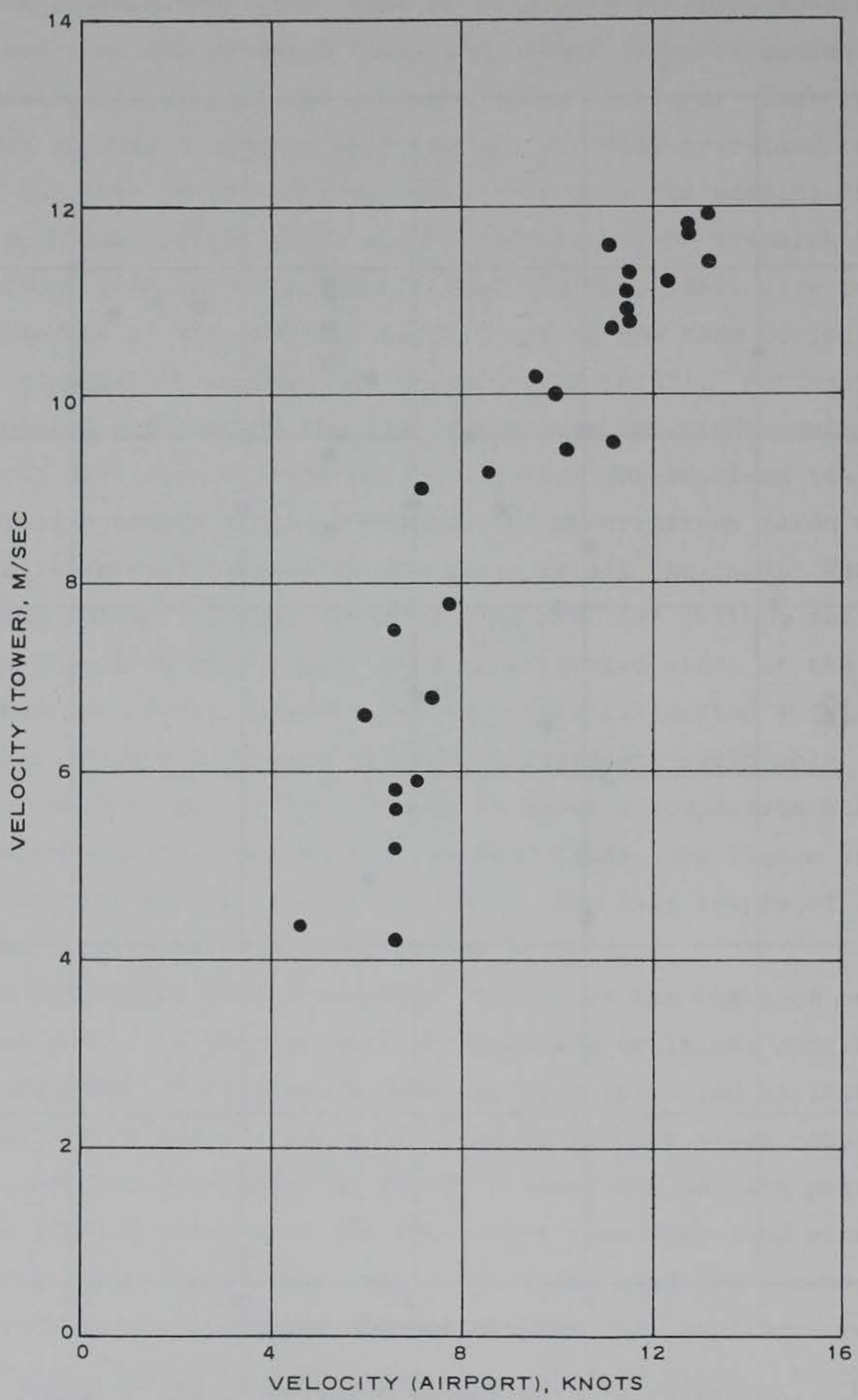

Figure 19. Comparison of wind speeds observed at the Muskegon tower (E1der and Soo) to transformed (using Equation 46) wind speeds observed at the Muskegon Airport 


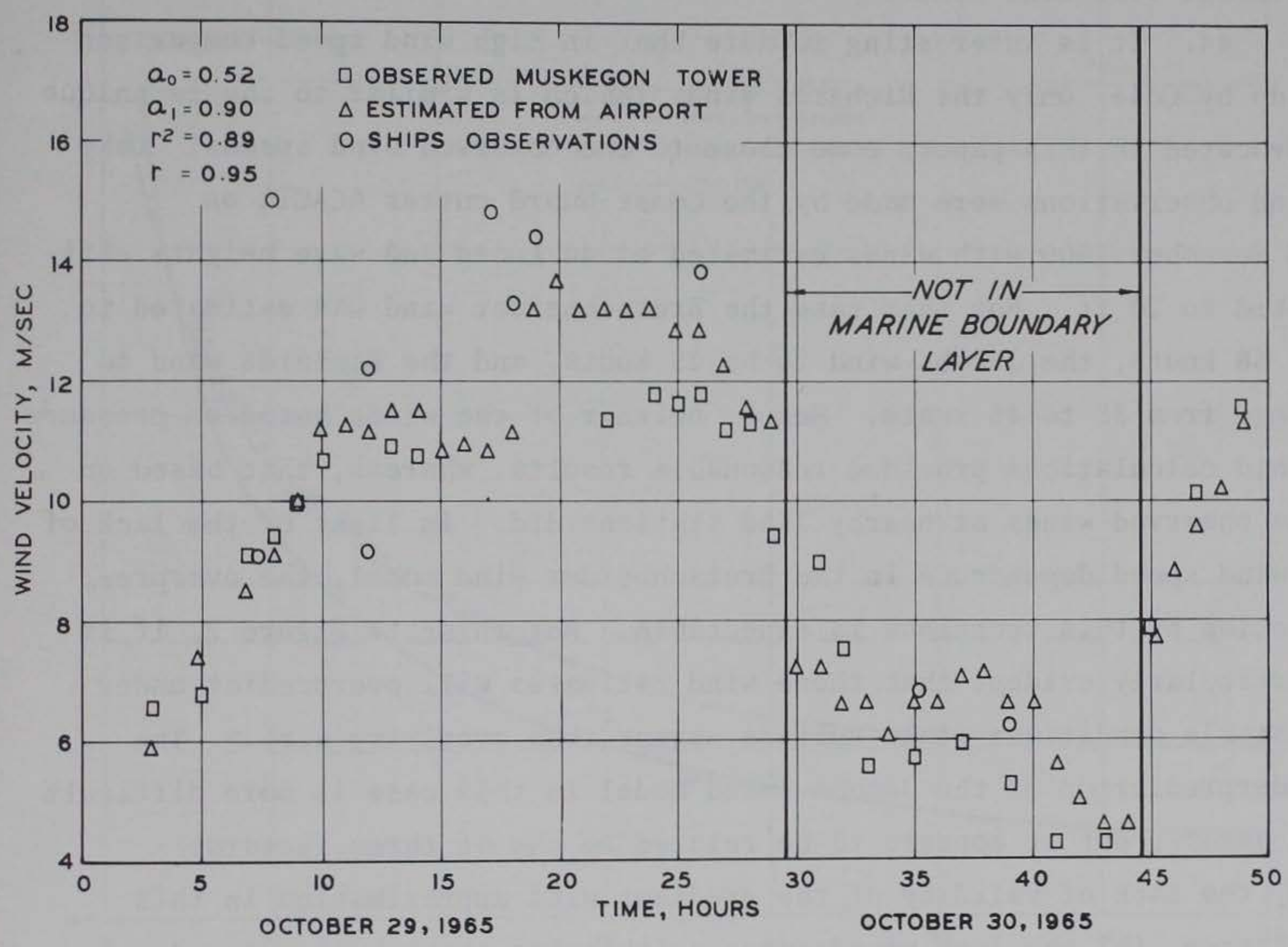

Figure 20. Sequence of wind speeds observed at the Muskegon tower and transformed wind speeds estimated from Muskegon Airport and Equation 46 
Figure 8, this nonlinearity is most pronounced at low velocities. Since the study by Jacobs was based on low winds observed during August, a low correlation is not unexpected. Likewise, the Cole study appears to examine cases in which the observed tower winds were less than 25 knots. As discussed in Part III, the use of a small range of input values tends to bias the correlation toward low values. Consequently, neither study offers strong statistical evidence against the use of over-1and winds to estimate over-1ake winds.

44. It is interesting to note that in high wind speed-comparison made by Cole, only the Richards winds (which is similar to the technique advocated in this paper) come close to the observed wind speeds. Lake wind observations were made by the Coast Guard cutter ACACIA on 28 November 1966 with winds estimated at 44 knots and wave heights estimated to $20 \mathrm{ft}$. For this case the Bretschneider wind was estimated to be 68 knots, the Jacobs wind to be 25 knots, and the Richards wind to range from 38 to 46 knots. Hence, neither of the winds based on pressure field calculations provided reasonable results. whereas, that based on the observed winds at nearby land stations did. In light of the lack of a wind speed dependence in the Bretschneider wind model, the overprediction by this technique is expectable. Returning to Figure 2, it is particularly evident that these wind estimates will overpredict under unstable conditions (lake surface warmer than overlying air).* The underprediction of the Jacobs wind model in this case is more difficult to assess, but it appears to be related to one of three factors:

(a) the lack of validity of the gradient wind approximation in this instance, (b) the lack of adequate calibration at high wind speeds, or (c) the influence of land on the winds upon which the empirical coefficients of the Jacobs technique were based.

45. As a final comparison of different studies, Figure 21 presents the results of all the methods based on Great Lakes data: Richards et al. (1966), Jacobs (1965), and the present study. These are contrasted to

Associated overestimates in significant wave heights based on wind speeds obtained by this technique have been documented by Cole (1967), Brebner and Kennedy (1962), and Resio and Vincent (1976). 


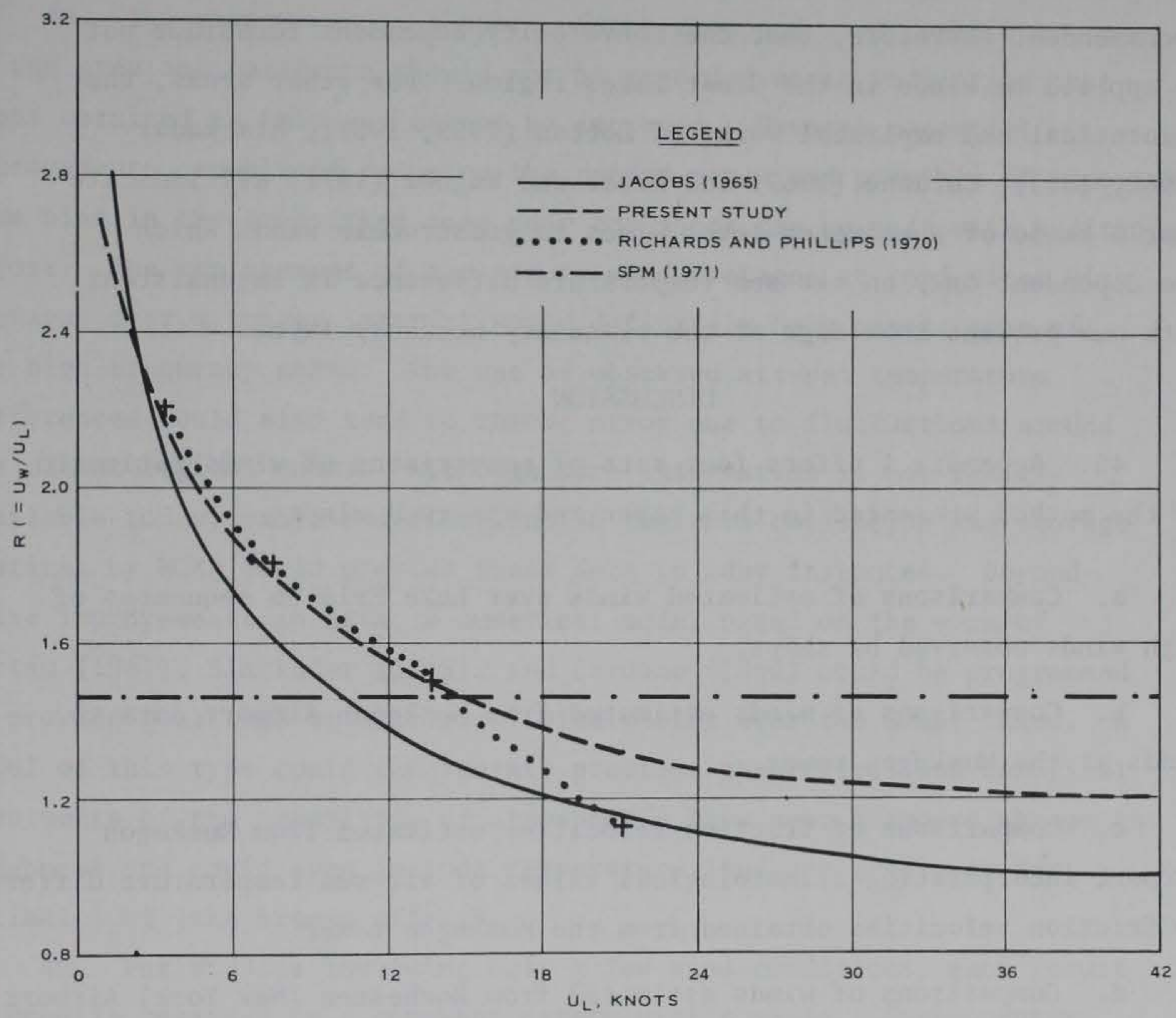

Figure 21. Comparison of studies of ratios of over-lake wind speeds to over-1and wind speeds. The results of the SPM (1971) method and Jacobs (1965) were normalized by dividing by 0.45 , the expected ratio of land wind speed to geostrophic wind speed for neutral stability 
the technique advocated by Cole (1967) and the SPM which are based primarily on empirical studies by Pierson et al. (1955) and Bretschneider (1971). Clearly, the agreement between the first three methods indicates a general support of a velocity-dependent behavior of $R$. The variations among these three studies are expectable due to sampling variabilities and possibly to small biases in the data sets and data analyses. It is recommended, therefore, that the nonvelocity dependent technique not be applied to winds in the Great Lakes region. For other areas, the theoretical and empirical works of Lettau (1959, 1961), Blackadar (1962, 1965), Cardone (1969) and Hasse and Wagner (1971) all indicate that a ratio of anemometer-level winds to geostrophic winds which are dependent only on air-sea temperature difference is inconsistent with our present knowledge of the planetary boundary layer.

\section{DISCUSSION}

46. Appendix A offers four sets of comparisons of winds estimated by the method presented in this paper and observed winds:

a. Comparisons of estimated winds over Lake Erie to sequences of high winds observed by ships.

b. Comparisons of winds estimated from Muskegon Airport data to winds at the Muskegon tower.

c. Comparisons of friction velocities estimated from Muskegon Airport incorporating climatological values of air-sea temperature difference to friction velocities obtained from the Muskegon tower.

d. Comparisons of winds estimated from Rochester (New York) Airport and winds observed at an offshore buoy in Lake Ontario.

47. The generally good agreement in these comparisons, particularly for high wind conditions, confirms the capability of the wind technique presented in this paper to function adequately over a wide range of moderate to high wind conditions. Since the theoretical basis involves the geostrophic wind, low wind conditions are probably not well estimated by the derived relationships. However, the dominant processes at the 
scale of the Great Lakes are affected primarily by higher winds; hence, the technique suffices for many design and planning purposes. The simplicity and low cost of this technique make it ideal even for small investigations; and when several stations around a body of water are transformed, an interpolation scheme can be employed to obtain a relatively reliable wind field over the entire area.

48. The statements in support of the proposed wind technique in the previous paragraph should not be regarded as an indication that winds obtained in this way cannot be improved. Several potential improvements capable of reducing the random error and possibly of removing some bias in the transition zone near the shore can be made with additional effort. The replacement of one-minute wind averages at land sites with averages over a longer interval would definitely help remove some of the high frequency noise. The use of observed air-sea temperature differences would also tend to remove error due to fluctuations around the climatological means. Although such information is not readily available today, small modifications in the data collection and storage routines by NOAA could provide these data in many instances. Beyond these improvements in data, a numerical model based on the work of Lettau (1961), Blackadar (1965), and Cardone (1969) could be programmed to provide real time or historical wind fields over the Great Lakes. A model of this type could incorporate previous theoretical and numerical treatments of the transition of atmospheric flow over a sudden change in roughness and could even include temperature land-sea gradients for estimates of lake breeze effects.

49. For studies involving only a few wind conditions, each result is usually regarded in a somewhat deterministic sense. Consequently, if estimated peak winds differ by 5 to 10 knots from observed peak winds (as they certainly will once in a while), there will be a tendency to reject the basic scheme of wind relationships presented in this paper. For such studies, it would certainly be advantageous to return to a detailed analysis to geostrophic (or gradient) flow conditions coupled with the appropriate numerical models to estimate surface winds. Such 
an effort requires considerably more time and expertise than the simplified model based on expected wind ratios and presupposes the availability of a good deal of meteorological and lake-surface data.

50. It is important to emphasize the need to calibrate the actual transformation ratios which are used on any body of water. Latitude and regional roughness variations may introduce significant deviations from the coefficients derived for Lake Erie and Lake Ontario, even though the general patterns of the curves should remain the same. For example, a preliminary investigation of the transformation ratios for Lake Michigan has revealed that, although they are remarkably similar to those for Lake Erie and Lake Ontario, they average about 18 percent higher than those reported in this paper. Besides the aforementioned factors of latitude and surface roughness, it is possible that such a calibration accounts empirically for any implicit dependence on lake size.

51. As a final point, it should be noted that the ratios presented in this paper pertain to a specific transformation from a level of $20 \mathrm{ft}$ on 1 and to $19.5 \mathrm{~m}$ over water. They are calculated in this manner because the winds are used in a wave hindcast program on the Great Lakes in which the wind is input at $19.5 \mathrm{~m}$ (Resio and Vincent, 1976a, 1976b) and the vast majority of airport data is now recorded at a standard height of $20 \mathrm{ft}$. Any land data at other than $20 \mathrm{ft}$ must first be converted to $20 \mathrm{ft}$ before the specific ratios derived in this paper can be applied. If the over-lake velocity is desired at some level other than $19.5 \mathrm{~m}$, then the wind must be transformed to this other level by the appropriate means.

\section{SUMMARY}

52. A theoretical treatment of winds over land and over a marine surface has been presented. The theoretical results provide a basis for comparison of many empirical data sets and help to establish a rational means of studying the differences between wind over 1 and and over a marine surface. This in turn affords a means of examining systematic variations in the ratio of winds over a lake to winds over land. The 
good agreement between theory and observation indicates that wind estimates over the lake can be made for a wide range of synoptic conditions with an rms error of under 5 knots. The theoretical curve for the lake-wind/ land-wind ratio provides a stable estimate of lake winds well beyond wind speeds for which there is good empirical data. Consequently, the technique presented here offers relatively good accuracy even in extreme wind conditions where there are little or no direct measurements of winds over the lake. 


\section{REFERENCES}

1. Appleby, J. F. and W. Ohmsteade, 1966, "Numerical Solutions of the Distribution of Wind and Turbulence in the Planetary Boundary Layer," Meteoro1. Rec. Note No. 8, Meteorology Department, U. S. Army Electronics Research and Development Activity, Fort Huachuca, Arizona.

2. Bijoet, H. C., 1957, "A New Overlay for the Determination of the Surface Wind over the Sea from Surface Weather Charts," Mededelingen en Verhandelingen, Koninklijk Netherlands Meteorologisch Institut.

3. Blackadar, A. K., 1962, "The Vertical Distribution of Wind and Turbulent Exchange in a Neutral Atmosphere, J. Geophys. Res., V. 67, pp 3095-3102.

4. Blackadar, A. K., 1965, "A Simplified Two-Layer Model of the Baroclinic Neutral Atmospheric Boundary Layer," Final Report: Flux of Heat and Momentum in the Planetary Boundary Layer of the Atmosphere, Penn. State Univ., 141 p.

5. Blackadar, A. K. and J. K. S. Ching, 1965, "Wind Distribution in a Steady-State Planetary Boundary Layer of the Atmosphere with Upward Turbulent Heat Flux," Final Report: Flux of Heat and Momentum in The Planetary Boundary Layer of the Atmosphere, Penn. State Univ. $141 \mathrm{p}$.

6. Bretschneider, C. L., 1973, "Deep-Water Forecasting Waves as a Function of Wind Speed, Fetch, and Duration," Shore Protection Manual, Vo1 1, pp 3-36 - 3-37, U. S. Army Coastal Engineering Research Center, Fort Belvoir, Va.

7. Cardone, V. J., 1969, "Specification of the Wind Distribution in the Marine Boundary Layer for Wave Forecasting," Technical Report 69-1, Geophysical Sciences Laboratory, New York University, New York, N.Y.

8. Cole, A. L., 1967, "An Evaluation of Wind Analysis and Wave Hindcasting Methods as Applied to the Great Lakes," Proceedings, Tenth Conference Great Lakes Research, pp 186-196.

9. Deardorff, J. W., 1972, "Parameterization of the P1anetary Boundary Layer for Use in General Circulation Models," Mon. Wea. Rev., V 100, pp 93-106.

10. E1der, F. C. and H. K. Soo, 1967, "An Investigation of Atmospheric Turbulent Transfer Processes Over Water," Special Report No. 29, Great Lakes Res. Div., Univ. of Mich., 46 p.

11. Ellison, T. H., 1957, "Turbulent Transfer of Heat and Momentum Form an Infinite Rough Plane, J. Fluid Mech., V 2, pp 456-466. 
12. Hasse L. and V. Wagner, 1971, "On the Relationship Between Geostrophic and Surface Wind at Sea," Mon. Wea. Rev., V 99, pp 255-260.

13. Jacobs, S. J., 1965, "Wave Hindcasts vs Recorded Waves," Univ. of Michigan Department of Meteorology and Oceanography, Report 06768-F, Ann Arbor, Michigan.

14. Johnson, P. W., 1955, "The Ratio of the Sea-Surface Wind to the Gradient Wind," Proceedings, First Conference on Ships and Waves, Chapter 9, pp 104-110.

15. Kazanski, A. B. and A. S. Monin, 1956, "Turbulentmost'v Prizemnykh Inversiiakh," Akad. Nauk. SSSR, Izvestiia, Ser Geofiz., V 1, pp 79-86.

16. King, E. C. and Lettau, H. H., 1961 "Regional and Meridional Distributions of Continental Vegetation Cover and Aerodynamic Roughness Parameters," Studies of the Three-Dimensional Structure of the Planetary Boundary Layer, Annual Report, Section 5, pp 45-61, Aug. 1961, U. S. Army Electronic Proving Ground, Fort Huachuca, Ariz.; prepared by Department of Meteorology, University of Wisconsin, under Contract No. DA-36-039-SC-80282.

17. Kitaigorodskii, S. A., 1970, "The Physics of Air-Sea Interaction," translated by A. Baruch, Israel Program for Scientific Translations, Ltd. (available from National Technical and Information Services, U. S. Department of Commerce, Springfield, VA) .

18. Kitaigorodskii, S. A. and Y. A. Volkov, 1965, "On the Roughness Parameter of the Sea Surface and the Calculation of Momentum Flux in the Lower Layer of the Atmosphere, Izv. Atm. and Ocean Phys. Ser. 1, pp 973-988.

19. Lettau, H. H., 1959, "Wind Profile, Surface Stress and Geostrophic Drag Coefficients in the Atmospheric Surface Layer, in Advances in Geophysics, V 6, pp 241-257, Academic Press.

20. Lettau, H. H., 1961, "Theoretical Wind Spirals in the Boundary Layer of a Barotrophic Atmosphere," Studies of the Three-Dimensional. Structure of the Planetary Boundary Layer, Annual Report, Section 9, pp 143-170, Aug 1961, U. S. Army Electronic Proving Ground, Fort Huachuca, Ariz.; prepared by Department of Meteorology, University of Wisconsin, under Contract No. DA-36-039-SC-80282.

21. McVehil, G. E., 1964, "Wind and Temperature Profiles Near the Ground in Stable Stratification, Quart. J. Roy. Meteoro1. Soc. V 90, pp 136-146.

22. Mendenha11, B. R., 1967, "A Statistical Study of Frictional Wind Veering in the Planetary Boundary Layer, "Atmospheric Science Paper No. 116, Dept. of Atm. Sci., Colorado State University, Fort Collins, CO.

23. Moss, M. S. and S. L. Rosenthal, 1975, "On the Estimation of Planetary Boundary Layer Variables in Mature Hurricanes," Mon Wea. Rev. V 103, pp 980-988. 
24. Panofsky, H. A., 1961, "An Alternative Derivation of the Diabatic Wind Profile, Quart. J. Roy. Meteorol. Soc., V 87, pp 109-110.

25. Panofsky, H. A., 1963, "Determinations of Stress from Wind and Temperature Measurements, Quart. J. Roy. Meteorol. Soc., V 89, pp 85-94.

26. Paulson, C. A., 1967, "Profiles of Wind Speed, Temperature, and Humidity Over the Sea," Sci. Rept. NSF GP-2418, Department of Atmospheric Sciences, Univ. of Washington.

27. Prandt1, L., 1952, Essentials of Fluid Dynamics, Blackie \& Son Limited, London and Glasgow, $452 \mathrm{p}$.

28. Priestly, C. H. B., 1967, "Handover in Scale of the Fluxes of Momentum, Heat, etc. in the Atmospheric Boundary Layer," Phys. of Fluids, V 10, pp 538-546.

29. Resio, D. T. and C. L. Vincent, 1976a, "Design Wave Information for the Great Lakes: Lake Erie," Tech. Report H-76-1 (Report 1) Hydraulics Laboratory, U. S. Army Engineer Waterways Experiment Station.

30. Resio, D. T. and C. L. Vincent, 1976b, "Design Wave Information for the Great Lakes: Lake Ontario," Tech. Report H-76-1 (Report 2), Hydraulics Laboratory, U. S. Army Engineer Waterways Experiment Station.

31. Richards, T. L., Dragert, H., and McIntyre, D. R., 1966, "Influence of Atmospheric Stability and Over-Water Fetch on Winds over the Lower Great Lakes," Monthly Weather Review, V 94, No. 1, pp 448-453.

32. Richards, T. L. and Phillips, D. W., 1970, "Synthesized Winds and Wave Heights of the Great Lakes," Climatological Studies No. 17, Meteorological Branch, Canadian Department of Transport, Toronto, Canada.

33. Sellers, W. D., 1962, "A Simplified Derivation of the Diabatic Wind Profile," J. Atmos. Sci. V 19, pp 180-181.

34. Sverdrup, H. V. and W. H. Munk, 1951, "Techniques for Forecasting Wind, Waves, and Swe11," Publication No. 604, Hydrographic Office, U. S. Department of the Navy, Washington, D. C.

35. U. S. Army Coastal Engineering Research Center, 1973, "Shore Protection Manual," Vol 1, Fort Belvoir, VA.

36. Wilson, 1960, "Note on Surface Wind Stress over Water at Low and High Wind Speeds," J. Geophys. Res., V 65, pp 3377-3381.

37. Wu, J., 1969, "Froude Number Scaling of Wind-Stress Coefficients, J. Atmos. Sci., V 26, pp 408-413. 
Table 1

WIND SPEED COMPARISONS BY COLE (1967)

Type of Comparison

Bretschneider winds vs 10-m winds

Jacobs $7.5-\mathrm{m}$ winds vs $7.5-\mathrm{m}$ winds

Jacobs $19.5-\mathrm{m}$ winds vs $16-\mathrm{m}$ winds

Richards winds vs $16-\mathrm{m}$ winds

Richards winds vs $10-\mathrm{m}$ winds

\section{Number of}

Data Pairs

36

43

49

44

36
Correlation

Coefficient

0.63

0.55

0.37

0.36

0.24 


\section{Month}

Jan. Feb. Mar. April May June July Aug. Sept. Oct. Nov. Dec.

\begin{tabular}{|c|c|c|c|c|c|c|c|c|c|c|c|c|}
\hline E & -3.0 & -3.1 & -0.9 & 1.6 & 1.1 & 0.4 & -1.1 & -2.1 & -3.1 & -4.3 & -3.2 & -2.9 \\
\hline & -13.3 & -3.8 & -4.9 & 1.6 & 0.7 & 0.7 & -0.4 & -2.4 & -3.1 & -3.3 & -3.4 & -5.5 \\
\hline & -3.9 & 3.5 & -3.1 & 2.7 & 2.0 & 0.3 & -0.7 & -1.9 & -3.0 & -3.0 & -2.5 & -4.4 \\
\hline & -3.3 & 1.5 & -1.4 & 2.3 & 2.4 & 1.0 & -0.4 & -1.5 & -2.7 & -1.8 & -2.0 & -5.9 \\
\hline & -3.9 & -.7 & 2.6 & 1.9 & 1.2 & 0.8 & -0.5 & -1.2 & -1.9 & -1.7 & -3.5 & -2.5 \\
\hline & -11.8 & -2.7 & 2.8 & 2.0 & .1 & 1.6 & -0.0 & -1.1 & -2.0 & -1.5 & -3.5 & -2.6 \\
\hline & -8.6 & -3.9 & 0.3 & 1.7 & .1 & 1. & 0.4 & -0.7 & -1.5 & -1.1 & -2.8 & -3.4 \\
\hline & -8.8 & -1.4 & -0.1 & 2.5 & 2.4 & 1.4 & 0.1 & -1.2 & -1.5 & -1.5 & -1.8 & -2.8 \\
\hline & -2.0 & 1.4 & 2.7 & 2.4 & .5 & 1.4 & -0.2 & -0.7 & -0.9 & -0.9 & -2.4 & -1.9 \\
\hline $\mathrm{N}$ & -1.0 & -4.0 & -1.5 & 2.3 & 3.1 & 1.6 & 0.7 & -0.5 & -1.1 & -0.6 & -2.6 & -2.5 \\
\hline & -4.5 & -5.8 & 1.3 & 3.2 & 2.5 & 2.1 & 0.1 & -0.3 & -1.3 & -0.4 & -2.0 & -2.9 \\
\hline & -10.1 & -2.4 & -0.1 & 2.7 & 2.6 & 2.3 & 1.0 & -0.2 & -0.9 & -1.0 & -1.5 & -2.3 \\
\hline & -1.5 & -0.7 & 3.9 & 3.7 & 5.6 & 1.5 & 0.4 & -0.7 & -1.1 & -0.2 & -1.6 & -2.2 \\
\hline & -7.5 & -4.3 & -1.4 & 3.4 & 3.7 & 2.2 & 1.2 & -0.2 & -0.9 & -0.1 & -1.4 & -1.7 \\
\hline & -1.8 & -3.2 & 0.2 & 4.3 & 2.4 & 1.9 & 0.4 & 0.3 & -0 & 0.0 & -1.9 & -0.5 \\
\hline & 1.9 & 7.5 & 1.6 & 3.6 & 3.5 & 2.8 & 1.0 & 0.4 & -0.1 & -0.1 & -0.8 & -1.6 \\
\hline & 2.0 & 1.4 & $1 .($ & 4.1 & 4.6 & 2.6 & 0.3 & 0.3 & -0.1 & 0.0 & -1.1 & -0.5 \\
\hline & -.4 & 1.7 & 6. & 4. & & 3.2 & 0.9 & 0.5 & & -0.3 & -0.6 & -2.4 \\
\hline & -2.9 & 2.0 & 3.4 & 4.8 & 4.5 & 3.2 & 1.0 & 0.1 & -0.0 & 0.1 & -0.9 & 0.5 \\
\hline & -3.8 & 3.6 & 2.6 & 5.1 & 4.5 & 3.1 & 1.2 & 0.4 & 0.3 & -0.2 & -1.5 & -0.9 \\
\hline & -3.8 & 1.0 & 0. & 4. & & 3.3 & 1. & 0.9 & & & -1.2 & -0.4 \\
\hline & -1.0 & -3.5 & -0.7 & 4. & 3.5 & 3.0 & 1.3 & 1.1 & 0.4 & -0.7 & -1.3 & -1.3 \\
\hline & -2.2 & 0.3 & 2.1 & 3.1 & 3.8 & 3.1 & 1.4 & 1.0 & -0.1 & -0.5 & -1.5 & -0.6 \\
\hline & -0.6 & -1.3 & -0.7 & 3.0 & 1 & 2.6 & 1.3 & 0.9 & & & -2.4 & -2.2 \\
\hline & -1.9 & -2.2 & -2.7 & 2. & 3.7 & 2.9 & 1.5 & 0.7 & -0.7 & -1.9 & -3.0 & -2.2 \\
\hline & -9.2 & -5.6 & -2.9 & 2.3 & & 2.8 & 1.0 & 0.5 & & & -3.0 & -2.6 \\
\hline & -9.4 & -11.4 & 4.5 & 1.6 & 2.7 & 1.6 & 1.2 & -0.0 & & -2.3 & -3.9 & -3.8 \\
\hline S & -7.3 & 0.7 & -1.5 & 1.6 & 2.6 & 2.4 & 0.7 & -0.8 & -1.7 & -3.1 & -4.5 & -4.9 \\
\hline & -10.4 & -5.5 & -0.6 & 1.6 & 1.7 & 1.9 & 0.6 & & & & -4.5 & -4.9 \\
\hline & -8.5 & -2.5 & 3.5 & 1.9 & 1.1 & 1.3 & 0.4 & -1.3 & -2.2 & -3.9 & -4.6 & -5.5 \\
\hline & -7.9 & -5.4 & -0.4 & 1.4 & 1.7 & 0.7 & -0.4 & -1.9 & -2.7 & -4.1 & -5.0 & -5.6 \\
\hline & -7.0 & -8.9 & 2.3 & 1.8 & 1.6 & 0.6 & -0.7 & -2.2 & & -4.6 & -4.6 & -5.0 \\
\hline & -5.3 & 4.2 & -3.2 & 2.2 & 0.8 & 0.9 & -0.7 & -1.7 & & -4.8 & -5.3 & -5.5 \\
\hline & -5.9 & -5.4 & 0.9 & 2.0 & 1.3 & 0.7 & -1.1 & -2.5 & -4.4 & -5.3 & -4.8 & -6.5 \\
\hline & -8.8 & -6.1 & 2.1 & 1.4 & 1.6 & 0.5 & -1.3 & -2.4 & -3.9 & -4.9 & -4.1 & -4.9 \\
\hline & -8.6 & -9.4 & 2.0 & 2.2 & 1.8 & 0.0 & -0.5 & -2.2 & -3.5 & -4.7 & -3.9 & -5.6 \\
\hline
\end{tabular}

Columns represent averages of air-sea temperature differences by month. Rows represent averages of air-sea temperature difference by wind vector direction within $10^{\circ}$ classes (class 1 = due East, $10=$ due North, $19=$ due West, 28 = due South) 
TABLE 2A

Standard Deviations From Climatological

Mean Air-Sea Temperature Difference:

Lake Erie

Month

Jan. Feb. Mar. April May June July Aug. Sept. Oct. Nov. Dec.

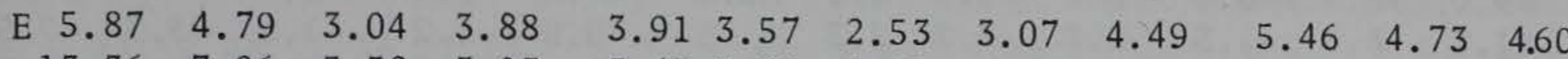

$\begin{array}{llll}13.36 & 7.06 & 5.58 & 3.03\end{array}$

$\begin{array}{llll}4.87 & 4.36 & 3.53 & 3.97\end{array}$

$\begin{array}{llll}3.45 & 3.09 & 2.59\end{array}$

$4.06 \quad 4.54$

4.71

$5.07 \quad 6.74$

$6.00 \quad 1.66$

$1.98 \quad 3.67$

$3.88 \quad 2.64$

2.58

$3.06 \quad 4.27$

4.87

$4.17 \quad 6.12$

4.53

2.96

4.05

4.12

$4.28 \quad 3.05$

2.69

2.81

4.03

3.64

$3.93 \quad 7.36$

$11.80 \quad 4.26$

2. 80

3.85

3.702 .95

1.85

2.70

3.78

3.05

4.71

4.13

$8.60 \quad 5.57$

3.06

3. 20

$3.85 \quad 3.51$

2.68

2.35

3.07

3.03

4.48

4.06

$\begin{array}{llll}8.80 & 3.83 & 0.22 & 3.77\end{array}$

4.502 .95

2. 39

2.23

2. 74

3.18

4.25

4.42

$4.05 \quad 1.98$

3.47

3.61

$4.06 \quad 2.93$

2.05

2.08

3.07

3.62

3.70

4. 23

N

$6.50 \quad 5.80$

4.132 .74

2.17

2.41

2. 88

2.78

3.79

4.01

$10.10 \quad 3.05$

$3.93 \quad 4.08$

$4.34 \quad 3.47$

2.00

2.27

3. 16

2.97

4.2

3.85

$8.10 \quad 0.70$

$3.90 \quad 4.99$

$4.20 \quad 3.41$

2.92

2.12

2.45

3.27

3.68

3.92

$\begin{array}{ll}7.58 & 6.09\end{array}$

$5.38 \quad 2.90$

2.50

2.47

2.67

3.68

3.55

3.15

$4.3 \quad 4.00$

$1.40 \quad 5.18$

5.193 .82

2.41

2.21

3.25

3.15

$3.49 \quad 5.16$

$4.30 \quad 2.93$

2.36

1.99

2. 89

$3.09 \quad 4.20$

$2.17 \quad 7.50$

1.824 .96

4.864 .40

2. 7

2.8

2.96

2.55

$4.01 \quad 3.89$

$2.06 \quad 3.30$

1.34

6.11

5.814 .02

2. 11

2.75

2. 51

2.80

3.48

3.43

2.5

1.81

$6.53 \quad 5.96$

$4.76 \quad 4.49$

2.40

2.69

2.38

2.61

3.85

3.25

W 2.98

2.77

$\begin{array}{ll}4.83 & 6.01\end{array}$

5.964 .28

2.39

2.51

2. 67

2.91

3.94

3.66

3.95

3.115 .96

5.794 .29

2.70

2.05

2.71

2.90

3.76

3.61

5.72

2.26

$0.81 \quad 5.62$

$5.57 \quad 4.57$

2.69

2.64

2.68

3.03

4.38

4.02

2.993 .50

$\begin{array}{lll}1.07 & 6.38\end{array}$

4.604 .12

2.55

2.73

2.71

2.76

4.15

3.88

$\begin{array}{lll}5.68 & 4.07\end{array}$

3.46

3.94

$5.54 \quad 4.46$

2.95

$\begin{array}{ll}2.48 & 2.99\end{array}$

3.03

4.43

4.00

$\begin{array}{ll}1.68 & 5.71\end{array}$

$0.70 \quad 4.85$

5.264 .33

2.49

2.45

3.11

3.12

3.87

4.06

$3.86 \quad 5.57$

$\begin{array}{ll}0.701 & 4.69\end{array}$

5.234 .05

2.63

2.38

2.91

3.34

4.29

4.89

$9.67 \quad 10.02$

$\begin{array}{ll}4.17 & 4.58\end{array}$

5.324 .06

2.55

2.32

3.09

3.45

$4.98 \quad 4.67$

$9.63 \quad 12.65$

$\begin{array}{ll}4.50 & 4.38\end{array}$

$\begin{array}{lll}4.39 & 3.47\end{array}$

2.82

2.51

2. 79

3.76

5.05

4.67

$\mathrm{S}$

10.87

0.70

$3.26 \quad 4.33$

$4.30 \quad 3.73$

2.44

2.89

3.44

3.68

5.41

5.38

3.974 .19

2.79

2.93

3.44

4.32

6.02

6.13

8.756 .03

$\begin{array}{ll}3.70 & 3.66 \\ 3.24\end{array}$

$3.33 \quad 3.50$

3.04

3.03

3.89

4.33

6.07

6.44

$8.10 \quad 8.15$

4.39

3.90

$4.00 \quad 2.58$

2.82

3.56

3.88

4.96

5.89

6.71

$6.28 \quad 8.90$

2.30

3.722 .94

3.14

3.78

4.45

5.28

6.23

6.72

$3.75 \quad 3.47$

2.74

3.63

4.70

5.73

$5.93 \quad 6.14$

$\begin{array}{ll}7.51 & 5.57\end{array}$

0.90

3.643 .04

$3.59 \quad 5.26$

6.25

6.626 .53

$\begin{array}{llll}9.68 & 6.12 & 2.10 & 3.68\end{array}$

3.693 .16

2.81

$3.42 \quad 4.91$

6.43

$\begin{array}{ll}6.06 & 7.60\end{array}$

$8.60 \quad 9.44$

$2.55 \quad 4.19$

$\begin{array}{lll}4.01 & 2.45 \quad 2.68\end{array}$

$3.59 \quad 4.77$

6.02

$5.31 \quad 5.65$

Columns represent averages of standard deviation of air-sea tempera- 
Month

Jan. Feb. Mar. April May June July Aug. Sept. Oct. Nov. Dec.

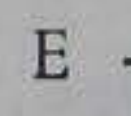

1.0 $-0.1-1.8$ $-3.1$ $-4.1$ $\begin{array}{lll}-11.1 & -10.7 & -1.5\end{array}$

0.8

$3.2 \quad 2.3$

1.5 $\begin{array}{ll}-0.7 & -2.1\end{array}$

$\begin{array}{lll}-12.2 & -5.6 & -0.3\end{array}$

1.1

$2.6 \quad 3.5$

1.3

$-0.9$

$\begin{array}{lll}-10.5 & -15.1 & -1.7\end{array}$

1.7

$\begin{array}{ll}2.6 & 2.9\end{array}$

1.7

0.5

$\begin{array}{lll}-8.3 & -4.9 & -0.6\end{array}$

1.1

$\begin{array}{ll}2.7 & 2.8\end{array}$

1.8

$-0.2$

$\begin{array}{rrr}-10.1 & -1.2 & -0.3\end{array}$

2.2

$\begin{array}{ll}2.5 & 2.7\end{array}$

1.5

0.6

$-1.2$

$-1.7$

$-3.2$

$-8.4$

$\begin{array}{lll}-5.6 & -2.8 & -0.7\end{array}$

1.7

$2.8 \quad 3.3$

2.9

$\begin{array}{ll}0.1 & -0.3\end{array}$

$\begin{array}{lll}-1.5 & -3.3 & -7.5\end{array}$

$\begin{array}{lll}-1.6 & -3.1 & -0.4\end{array}$

1.9

$2.8 \quad 3.1$

3.3

$0.9 \quad 0.5$

$\begin{array}{lll}-1.2 & -2.1 & -6.9\end{array}$

$\mathrm{N}-4$

$\begin{array}{lll}-0.8 & -2.9 & -1.0\end{array}$

2.8

$\begin{array}{ll}3.6 & 3.2\end{array}$

2.9

$\begin{array}{ll}1.0 & 0.5\end{array}$

$\begin{array}{llll}-1.1 & -2.0 & -5.4\end{array}$

$\begin{array}{lll}-6.3 & -1.8 & 1.1\end{array}$

2.5

$3.6 \quad 3.4$

2.6

0.8

0.7

$\begin{array}{ll}1.0 & -0.5\end{array}$

$\begin{array}{lll}-0.7 & -1.3 & -6.6\end{array}$

$\begin{array}{lll}-3.7 & -1.1 & 1.3\end{array}$

2.4

$4.2 \quad 3.5$

3.0

1.6

0.3

3.54 .8

2.6

1.4

1.2

3.54 .2

2.7

1.1

0.2

2.5

0.9

0.0

$\begin{array}{lll}0.9 & -1.5 & -6.3\end{array}$

$\begin{array}{lll}-1.3 & -3.0 & 1.4\end{array}$

3.5

4.5 4.1

2.2

0.9

0.8

$\begin{array}{llll}1.2 & -1.2 & -5.3\end{array}$

$\begin{array}{ll}-4.0 & -0.8\end{array}$

0.9

2.5

$4.7 \quad 4.4$

2.5

1.8

0.3

$\begin{array}{llll}0.9 & -2.0 & -4.0\end{array}$

$-1.8-1.3$

0.1

2.8

$\begin{array}{ll}4.4 & 4.2\end{array}$

3.1

2.1

1.0

$\begin{array}{llll}-1.1 & -1.6 & -2.8\end{array}$

$\begin{array}{llll}-0.1 & -2.2 & -5.8\end{array}$

W $-2.5 \quad-2.6$

0.3

2.4

5.24 .9

3.8

2.1

1.2

$\begin{array}{llll}0.1 & -1.8 & -3.4\end{array}$

$\begin{array}{ll}-1.9 & -2.2\end{array}$

1.8

$\begin{array}{ll}4.1 & 4.7\end{array}$

3.4

2.0

1.0

$\begin{array}{llll}0.4 & -1.7 & -1.7\end{array}$

$\begin{array}{lll}-2.7 & -2.3 & 1.6\end{array}$

$4.5 \quad 4.9$

3.3

1.8

2.0

$4.3 \quad 4.2$

3.0

1.8

1.2

$\begin{array}{ll}4.5 & 3.9\end{array}$

2.6

1.8

1.5

3.84 .5

2.8

1.1

1.4

$\begin{array}{lll}0.0 & -1.3 & -7.2\end{array}$

$\begin{array}{lll}-3.2 & -3.7 & -0.3\end{array}$

2.4

$3.7 \quad 4.2$

2.4

1.4

0.1

$0.4 \quad 0.0 \quad-5.3$

$\begin{array}{lll}-3.3 & -3.4 & -0.3\end{array}$

2.2

3.54 .0

2.5

1.0

0.2

$\begin{array}{llll}0.1 & -0.4 & -4.3\end{array}$

$\begin{array}{lll}-3.6 & -4.4 & -0.6\end{array}$

2.5

$2.9 \quad 3.9$

2.2

$\begin{array}{ll}1.7 & -0.0\end{array}$

$\begin{array}{llll}0.5 & -0.3 & -2.7\end{array}$

$\mathrm{S}-4$

$\begin{array}{lll}-4.5 & -4.6 & -1.8\end{array}$

2.0

$\begin{array}{ll}2.9 & 3.8\end{array}$

1.9

$\begin{array}{ll}1.4 & -0.5\end{array}$

1.1

$0.3-4.0$

$\begin{array}{lll}-7.3 & -6.7 & -2.3\end{array}$

2.3

3.53 .2

2.2

$3.6 \quad 4.0$

2.2

$\begin{array}{ll}1.3 & -0.5\end{array}$

0.6

$\begin{array}{lll}-7.1 & -5.9 & -2.4\end{array}$

1.8

2.93 .3

2.0

$\begin{array}{ll}0.4 & -0.7\end{array}$

$\begin{array}{lll}-8.2 & -6.6 & -2.7\end{array}$

2.2

2.5

3.3

1.8

$\begin{array}{ll}0.6 & -0.4\end{array}$

$\begin{array}{ll}0.8 & -1.2\end{array}$

$\begin{array}{lll}2.5 & 3.2 & 2.1\end{array}$

$\begin{array}{lll}-8.7 & -6.2 & -1.9\end{array}$

1.3

$3.4 \quad 3.3$

1.9

$\begin{array}{ll}1.2 & -0.9\end{array}$

$-0.2-1.6$

$\begin{array}{llll}1.1 & -1.2 & -2.9\end{array}$

$\begin{array}{llll}0.8 & -1.1 & -2.0\end{array}$

$\begin{array}{llll}-0.1 & -1.1 & -1.6\end{array}$

$\begin{array}{lll}-12.5 & -5.5 & -1.4\end{array}$

1.8

$3.0 \quad 3.0$

2.0

$\begin{array}{ll}1.2 & -1.4\end{array}$

$\begin{array}{lll}0.0 & -1.4 & -3.0\end{array}$

$\begin{array}{lll}-0.7 & -2.1 & -3.2\end{array}$

$\begin{array}{lll}-8.3 & -6.7 & -3.2\end{array}$

0.4

3.7

2.8

1.3

$\begin{array}{ll}0.1 & -0.8\end{array}$

$\begin{array}{lll}-0.4 & -2.9 & -2.8\end{array}$

$\begin{array}{lll}-0.9 & -2.2 & -2.8\end{array}$

$\begin{array}{lll}-1.4 & -2.9 & -5.9\end{array}$

$\begin{array}{lll}-1.3 & -2.9 & -5.3\end{array}$

$\begin{array}{llll}-2.1 & -3.1 & -7.4\end{array}$

$\begin{array}{llll}-2.9 & -4.3 & -6.9\end{array}$

$\begin{array}{lll}-2.5 & -4.0 & -7.5\end{array}$

$\begin{array}{lll}-3.5 & -4.6 & -7.5\end{array}$

$\begin{array}{lll}-4.3 & -5.1 & -7.9\end{array}$

$\begin{array}{lll}-2.6 & -4.9 & -9.1\end{array}$

Columns represent averages of air-sea temperature differences by month. Rows represent averages of air-sea temperature difference by wind vector direction within $10^{\circ}$ classes (class $1=$ due East, $10=$ due North, $19=$ due West, 28 = due South)

(Continued) 
TABLE $2 B$

Standard Deviations From Climatological

Mean Air-Sea Temperature Difference:

Lake Ontario

Month

Jan. Feb. Mar. April May June July Aug. Sept. Oct. Nov. Dec.

E $9.23 \quad 9.48 \quad 1.36 \quad 2.6$

$\begin{array}{llll}10.95 & 12.08 & 2.61 & 3.87\end{array}$

$\begin{array}{llll}12.61 & 11.97 & 4.05 & 4.26\end{array}$

$\begin{array}{llll}13.82 & 6.87 & 1.32 & 4.32\end{array}$

$12.74 \quad 15.10 \quad 3.62 \quad 3.30$

$\begin{array}{llll}11.01 & 7.25 & 1.99 & 3.18\end{array}$

11.47

8.36

3.56

1.49

1.99

2.75

3.27

2. 57

2.90

N

$\begin{array}{lll}6.38 & 0.50 & 1.5\end{array}$

2. 59

4.09

2.57

3.71

9.60

5.60

8.55

2.70

3.10

1.60

3.43

4. 10

5.59

2.15

4.93

3.23

5.98

2.75

2.58

3.16

0.86

2.21

2.07

3.79

3.99

4.64

1.85

5.06

5.27

3.91

3.91

$3.96 \quad 2.36$

$\begin{array}{lll}5.43 & 4.67 & 2.68\end{array}$

$\begin{array}{lll}4.31 & 4.36 & 2.62\end{array}$

$\begin{array}{lll}5.66 & 5.00 & 2.78\end{array}$

6.39

5.47

2.04

5.64

4.67

1.50

5.66

5.42

2. 74

$5.83 \quad 2.96$

5.87

5.33

3.93

$9.29 \quad 7.73$

4.07

8.15

6.81

4.02

9.22

7.54

4.08

3.60

9.43

9.80

3.52

10.33

7.44

2.47

7.05

5.16
3.28

3.18

4. 19

3.66

4.50

4.66

3.78

3.67

3.82

3. 29

5.08

4.52

4.81

4.27

3.54

3.46

3.83

3.59

3.67

2. 85

3. 34

3.35

3.47

2.70

3.70

3.93 $\begin{array}{lll}4.25 & 4.47\end{array}$

$4.46 \quad 4.36$

$4.22 \quad 3.22$

$3.60 \quad 4.94$

$3.54 \quad 4.35$

3.794 .18

$3.78 \quad 3.71$

$3.58 \quad 4.38$

3.914 .12

$4.54 \quad 4.36$

$4.58 \quad 3.96$

4.994 .56

4.435 .72

4.405 .46

$5.44 \quad 5.35$

4.965 .45

5.875 .60

$5.69 \quad 5.32$

6.435 .95

5.775 .63

5.725 .80

5.705 .06

$5.59 \quad 4.89$

5.125 .43

4.745 .11

4.625 .02

3.965 .00

3.724 .81

$4.48 \quad 4.40$

$4.85 \quad 5.15$

$3.92 \quad 4.70$

3.755 .02

$3.34 \quad 4.32$

$4.24 \quad 4.28$

$4.44 \quad 4.44$

$4.82 \quad 4.25$

2.43

2.44

2. 91

2. 70

2.64

2.87

2.57

3.91

4.18

4.07

4.26

3.82

3.49

3.94

3. 78

3.27

3.3

4.50

4.77

4.53

4. 32

3.94

3.87

3.99

3. 82

3.52

3.52

3.43

4.04

3.83

4.04

3. 35

4. 15

3.44

3.80

3.43

Columns represent averages of

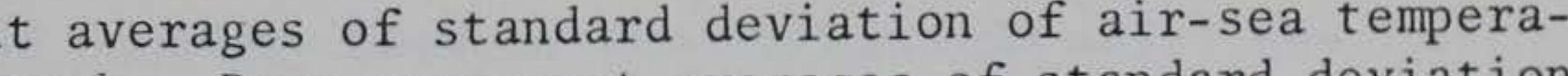
Rows represent averages of standard deviation of air-sea temperature differences by wind vector direction within $10^{\circ}$ classes $($ class $1=$ due East, $10=$ due North, $19=$ due West, $28=$ due South). 
Table 3

$x^{2}$ VALUES FOR TEST OF ERROR DISTRIBUTION

OF AIR-SEA TEMPERATURE DIFFERENCES

Degrees of

Freedom

7

7

7

7

7

7
Number of

Samples

31

91

86

98

151

131 $\underline{x^{2} \text { Value }}$

12.5

8.8

5.6

10.7

25.8

15.4
Significant above

0.33 leve 1

no

no

no

no

yes

yes 
Symbol

- $a$

$A_{h}$

$A_{s}$

$b_{1}, b_{2}$

$B$

B。

$B^{\prime}$

$C_{1}, C_{2}, C_{3}$

C

$c_{0}$

$C_{D}$

$C_{p}$
$F_{*}$

g

$H$

$H_{B L}$

K

$k^{\prime}$

Definition

Eddy diffusivity in Ekman spiral formulation

Ratio of eddy diffusities of momentum and heat

Constant relating roughness height to the characteristic roughness length over a fully roughened surface

Constants in regression equation for friction velocity over land

Constant in linear term of $10 \mathrm{~g}$-linear wind profile

Constant in Blackadar's similarity form for depth of constant stress layer

Arbitrary constant

Constants in Volkov and Kitaigorodskii's equation for roughness length

Phase velocity of surface wave

Phase velocity associated with wave frequency located at spectral peak

Coefficient of drag

Specific heat of air at constant pressure

Coriolis acceleration

Nondimensional term relating variations in $R$ to over water fetch

Acceleration due to gravity

Characteristic height of surface protuberances

Heat flux

Height of boundary between constant stress layer and

Ekman 1ayer

Von Karman's constant

Constant relating surface wind velocity to geostrophic wind velocity 
$k_{h}$

$\mathrm{K}_{\mathrm{m}}$

$l$

L

$L^{\prime}$

$m_{0}$

N

$P$
$\frac{R}{R_{i}}$
$\frac{R_{i j}}{R}$

$R_{0}$

$S$

t

$\Delta t$

$T_{a}$

$T_{s}$

$u$

$\bar{u}, \bar{v}$

$u_{g}$

$u_{L}$

$u_{w}$

$u_{*}$

Eddy conductivity

Eddy viscosity

Mixing length

Stability length

Modified stability length

Function relating variation in roughness length to

Number of observations in a sample

Pressure

Ratio of over-1ake wind speed to over-land wind speed

Average value of $R$ within $i^{\text {th }}$ velocity class

Average value of $R$ within $i^{\text {th }}$ velocity class and $j^{\text {th }}$ airsea temperature class

Surface Rossby number

Constant in KEYPS profile equation

Time

Characteristic averaging period

Air temperature

Water surface temperature

Nondimensional scaling temperature

Wind velocity in constant stress layer

Components of velocity in Ekman layer parallel to and perpendicular to geostrophic wind, respectively

Geostrophic wind speed

Wind velocity in constant stress layer over land

Wind velocity in constant stress layer over water

Friction velocity 
Horizontal coordinate parallel to geostrophic wind vector

Horizontal coordinate perpendicular to geostrophic wind vector

Z Vertical coordinate

$Z_{0} \quad$ Roughness length

$\delta$

Depth of viscous sublayer

$\epsilon \quad$ Error vector

$\theta \quad$ Potential temperature

$\lambda \quad$ Function in Blackadar's mixing length formulation

$P \quad$ Correlation coefficient

$\rho_{a} \quad$ Density of air

$\sigma_{Y}^{2}, \sigma_{\epsilon}^{2} \quad$ Variance associated with $Y$ and $\epsilon$ sample

$\hat{\sigma}_{u}$

Estimate of wind speed rms error

$\hat{\sigma}_{T_{a-s}}$

Estimate of air-sea temperature standard deviation around climatological mean

$\sigma_{n} \quad$ rms value of surface displacements

$\tilde{\sigma}_{n} \quad$ Nondimensional function of $\sigma_{n}$

$\tau_{x z}, \tau_{y z}$ Vertical stress in $x$ and $y$ direction, respectively

Nondimensional heat flux

$\phi_{u} \quad$ Nondimensional momentum flux

$\Phi \quad$ Function relating $h_{s}$ to $\widetilde{\sigma}_{n}$

$\Phi_{n} \quad$ Normalized function relating variations in $R$ to air-sea temperature difference

$x^{2} \quad$ Chi-square statistic

$\Psi_{a} \quad$ Integral function of stability in Equations 9 and 10

$\Psi \quad$ Function relating $R$ to $U_{L}$ 
1. This appendix presents additional comparisons between winds estimated by the technique described in the body of this paper and winds measured over a lake. It is hoped that these comparisons will aid any person using this technique in understanding the types of errors encountered in various applications.

\section{High Wind Comparisons}

2. Three comparisons of estimated over-1ake winds to winds observed by ships are presented in Figures A1, A2, and A3. These comparisons are taken from segment 1 of Lake Erie as shown in Figure 6 and are compared to winds estimated from airports located in Cleveland and Toledo. It can be seen in these figures that the one-minute ships observations contain a considerable amount of variation for the same observation period. Such variation is not seen in longer average observations taken in the IFYGL program on Lake Ontario; hence, much of this variation is probably due either to observer error or fluctuations in wind velocity at the turbulent or convective scale of atmospheric motion. Figure A4 shows a scattergram type of comparison for estimated winds and ships observations.

\section{Additiona1 Comparisons at the Muskegon Tower}

3. Figure A5 presents a scattergram type of comparison between winds estimated from Muskegon Airport data and winds observed at the Muskegon tower (E1der and Soo, 1967). The line on this chart has a slope of $1: 1.1$ in order to compensate for the difference in anemometer levels. The wind estimates are calibrated to a level of $19.5 \mathrm{~m}$; whereas, the tower observations are made at $10 \mathrm{~m}$. The 1.1 factor is used in this case purely for simplicity. A more realistic factor for the conversion to $10 \mathrm{~m}$ from $19.5 \mathrm{~m}$ would be dependent on roughness length and stability.

4. A single set of data is available at the Muskegon tower which indicates wind speeds in excess of 35 knots. These are the data collected at the tower just before its collapse on 23 September 1964 . Figure A6 shows a comparison of winds observed at the tower, ships observations between 
$42^{\circ} \mathrm{N}$ and $44.5^{\circ} \mathrm{N}$ latitude, and over-lake wind estimates based on winds observed at the Muskegon Airport. The general synoptic-scale variations in wind speed appear to be well represented in this storm by winds estimated from the Muskegon Airport.

\section{Comparisons of Estimated Friction Velocities ( $\left.\boldsymbol{U}_{\boldsymbol{*}}\right)$ With Friction} Velocities Observed at the Muskegon Tower

5. Figure A7 presents a scattergram type of comparison between friction velocities obtained by the solution of the system of Equations 9, 17, and 26 and those estimated at the Muskegon tower (E1der and Soo, 1967) from anemometers $8 \mathrm{~m}$ and $14.6 \mathrm{~m}$ above the mean water surface. Although the comparison is favorable on the whole, there appears to be a slight tendency of the predicted friction velocities to be higher than those observed at the tower.

\section{Comparisons of Data From PDCS Station 10 to Wind} Estimates Based on Rochester Airport Data

6. During part of 1972 , a large experiment to measure over-1ake meteorological conditions was performed. A comparison of wind estimates based on observed winds at Rochester Airport, located about 10 miles inland, to winds observed at a buoy positioned approximately $10 \mathrm{miles}$ offshore from Rochester is included here (Figure A8) to indicate the agreement and error distribution encountered at relatively low winds on Lake Ontario. Also included on this figure is a comparison of nine days of average transformed winds from Buffalo and Rochester Airports to winds observed at this PDCS buoy. Unfortunately, there were few reliable observations of high wind speeds during this program. As shown in Figure 15, the rms error in Figure A7 tends to decrease from low to moderate velocities, approaching a somewhat constant value at wind speeds (over lake in this example) above 20 knots. 


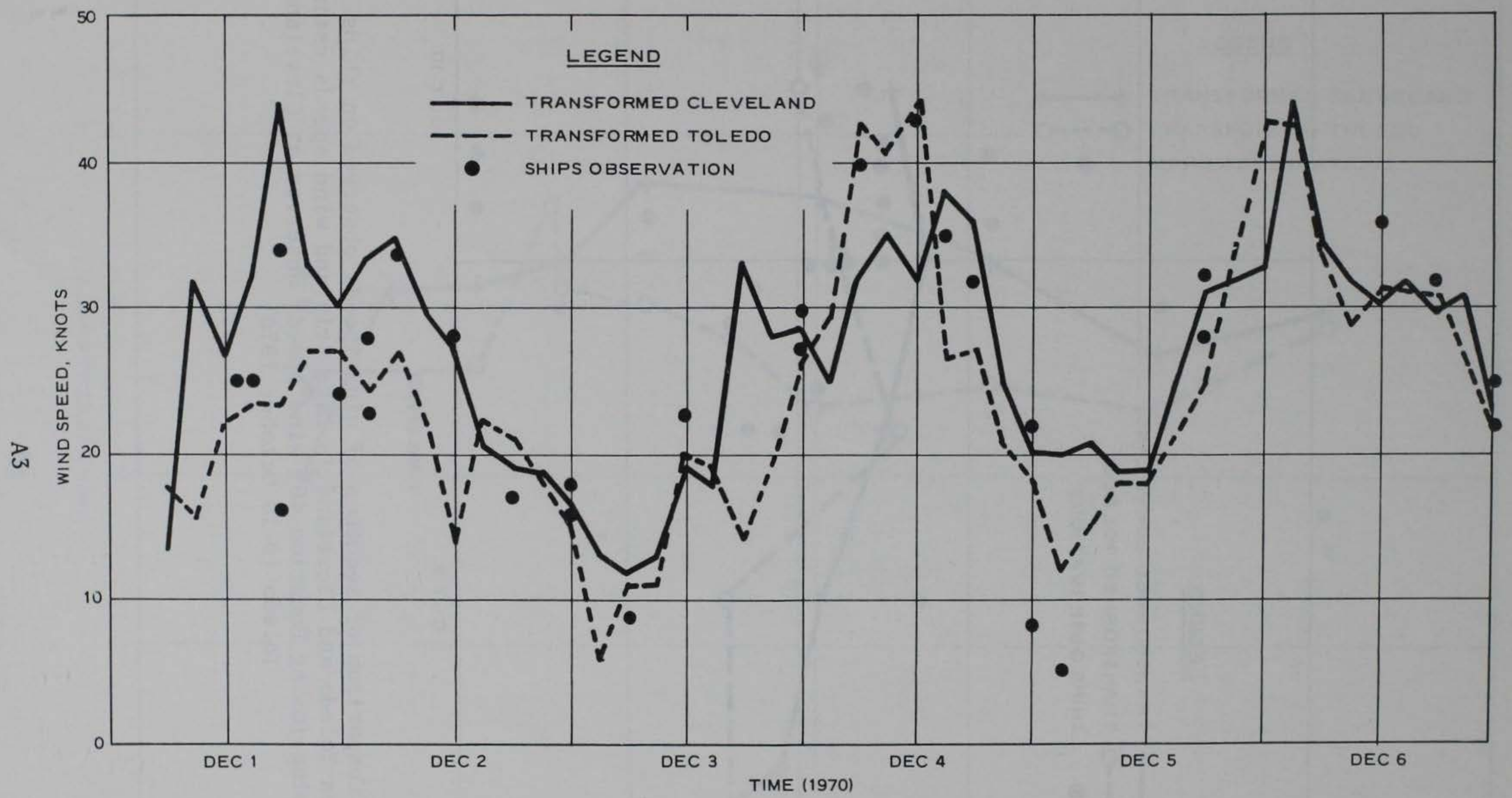

Figure Al. Comparison of sequence of wind speeds observed on ships located between Toledo and Cleveland in Lake Erie and wind speeds estimated by transforming (using Equation 46) wind speeds observed at Cleveland and Toledo (1-6 December 1970) 


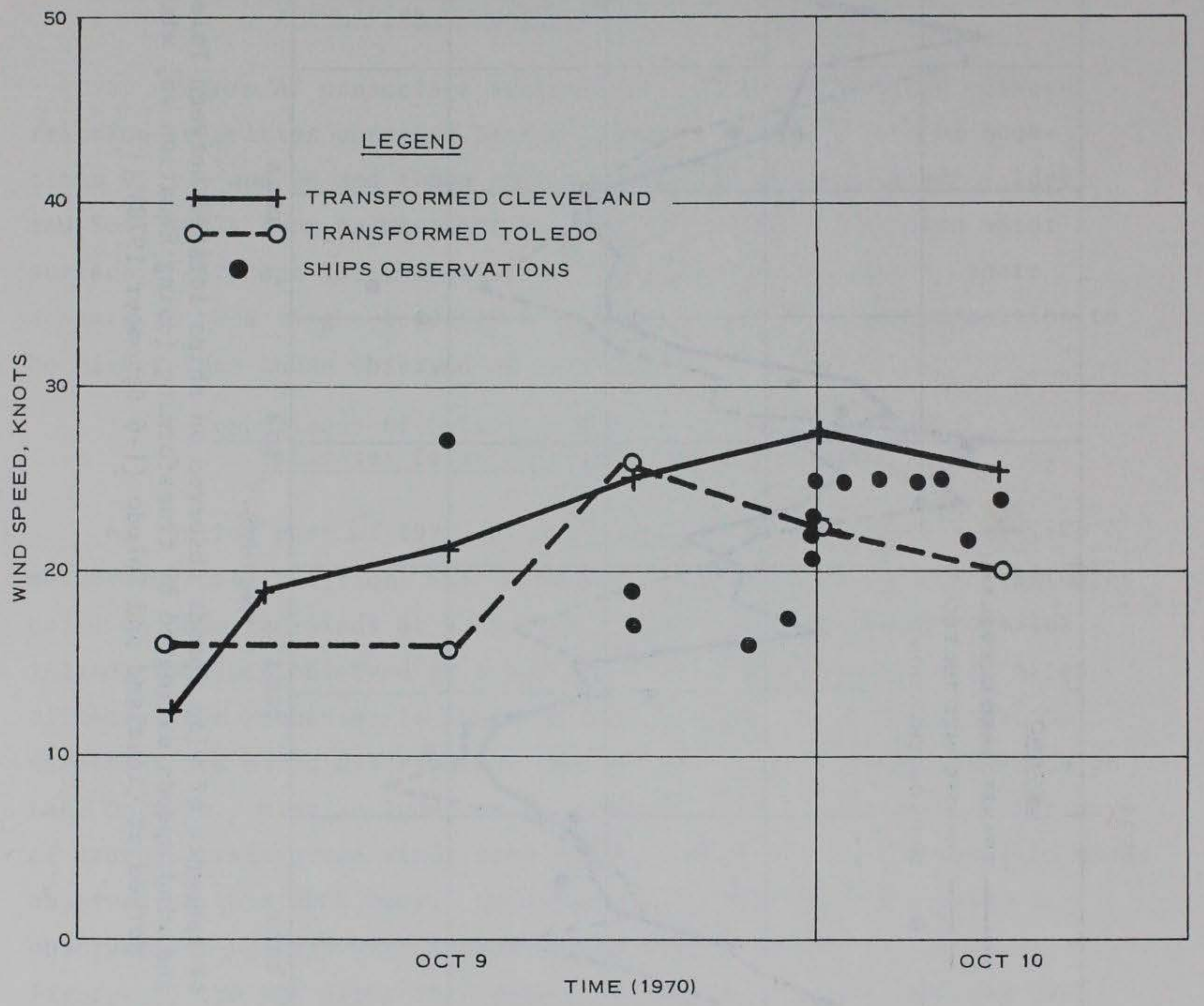

Figure A2. Comparison of sequence of wind speeds observed on ships 10cated between Toledo and Cleveland in Lake Erie and wind speeds estimated by transforming (using Equation 46) wind speeds observed at Cleveland and Toledo (9-10 October 1970) 


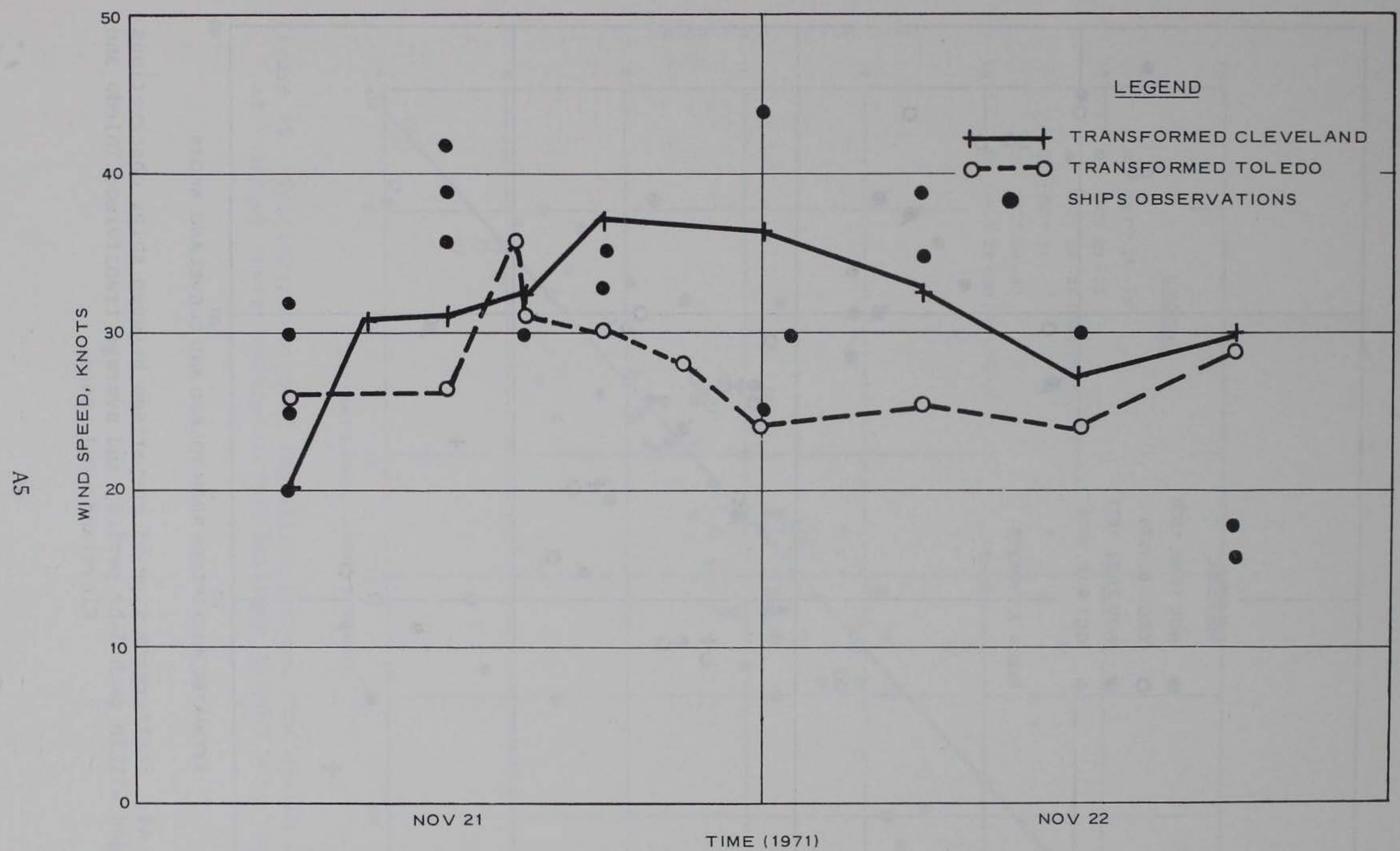

Figure A3. Comparison of sequence of wind speeds observed on ships located between Toledo and Cleve1 and in Lake Erie and wind speeds estimated by transforming (using Equation 46) wind speeds observed at Cleveland and Toledo (21-22 November 1971) 


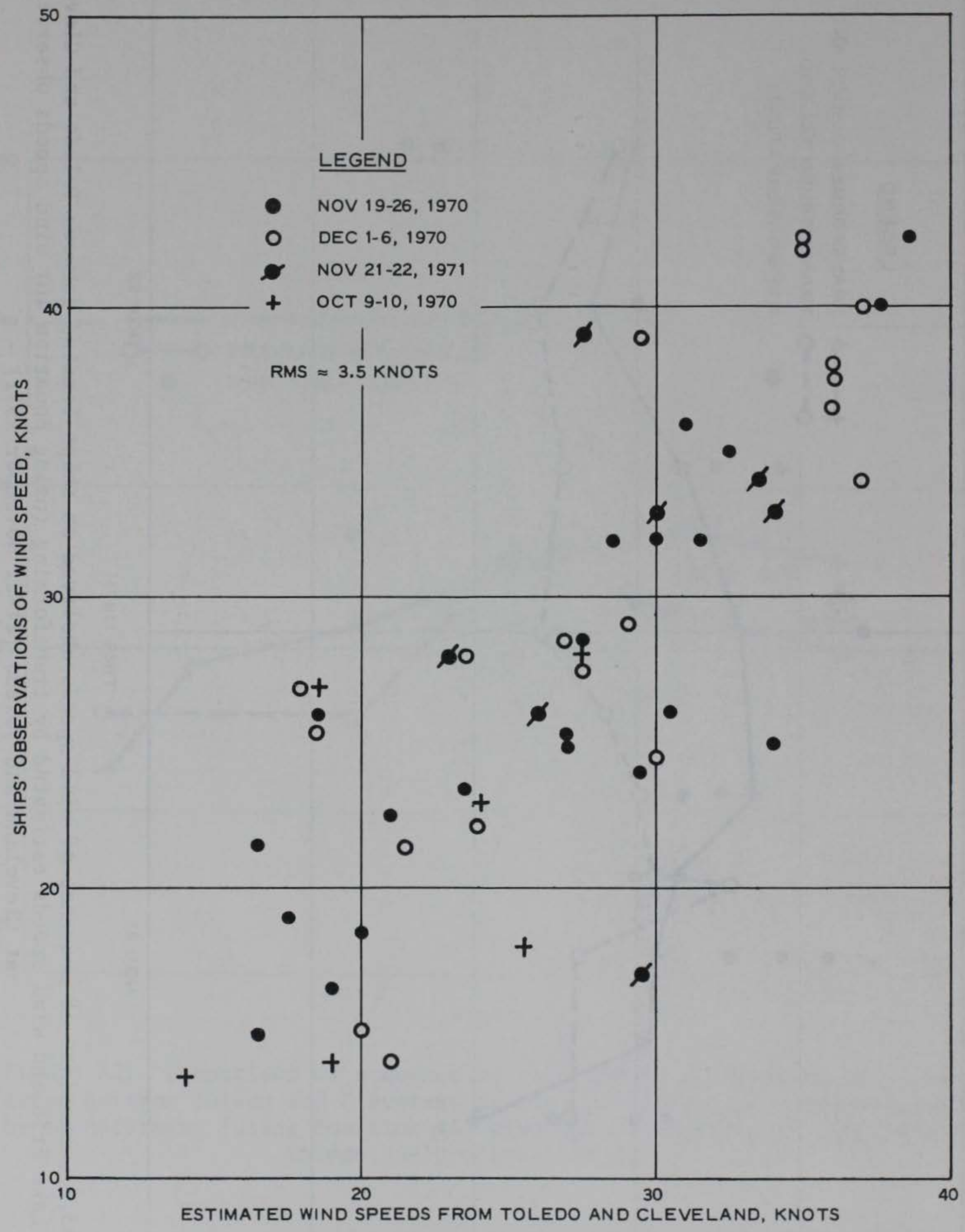

Figure A4. Scattergram type of comparison between ships observations (averaged within each 3-hr period) and average transformed Toledo and Cleveland wind speeds 


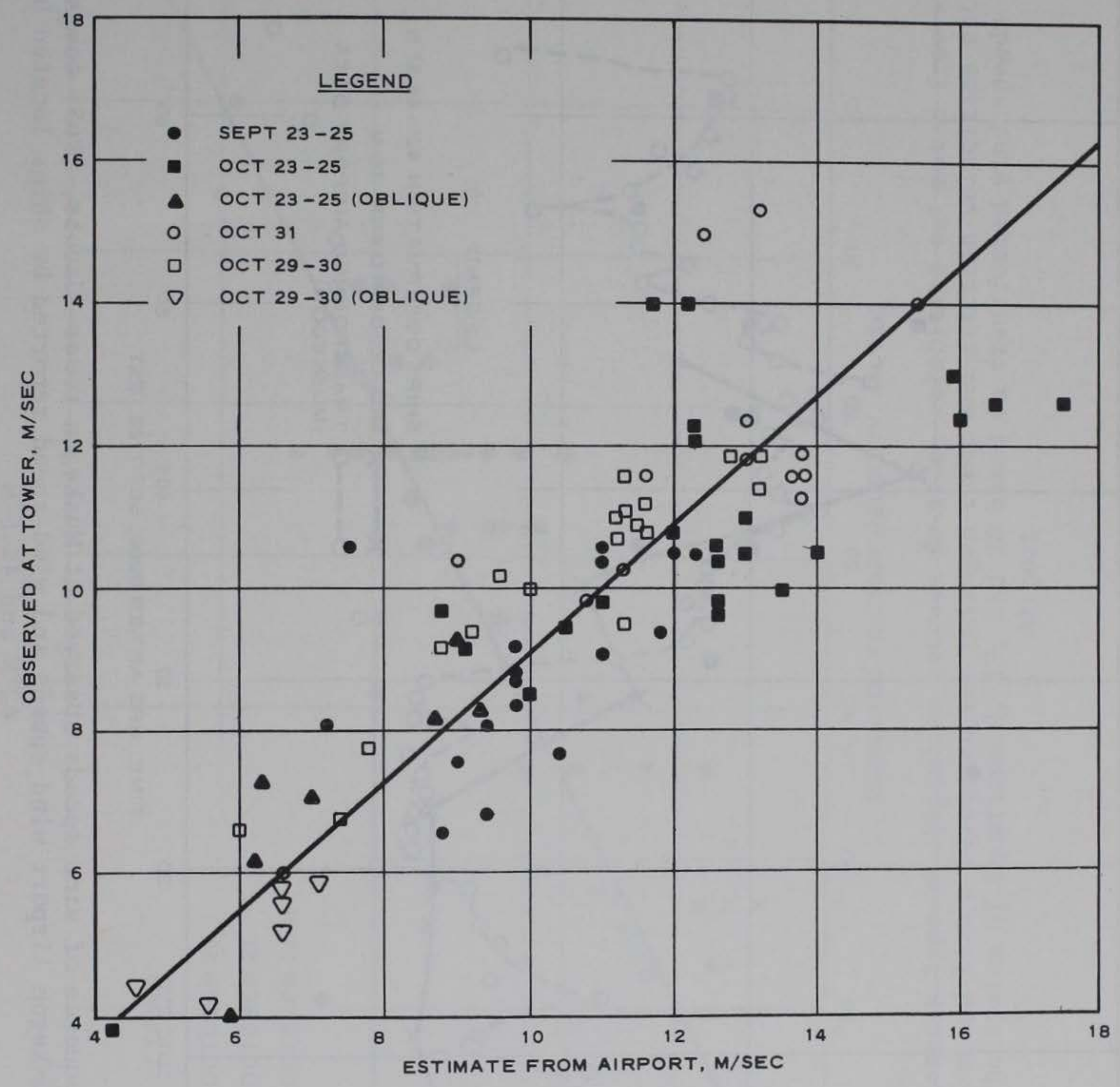

Figure A5. Scattergram type of comparison between wind speeds observed at Muskegon tower and transformed Muskegon Airport wind spęeds 


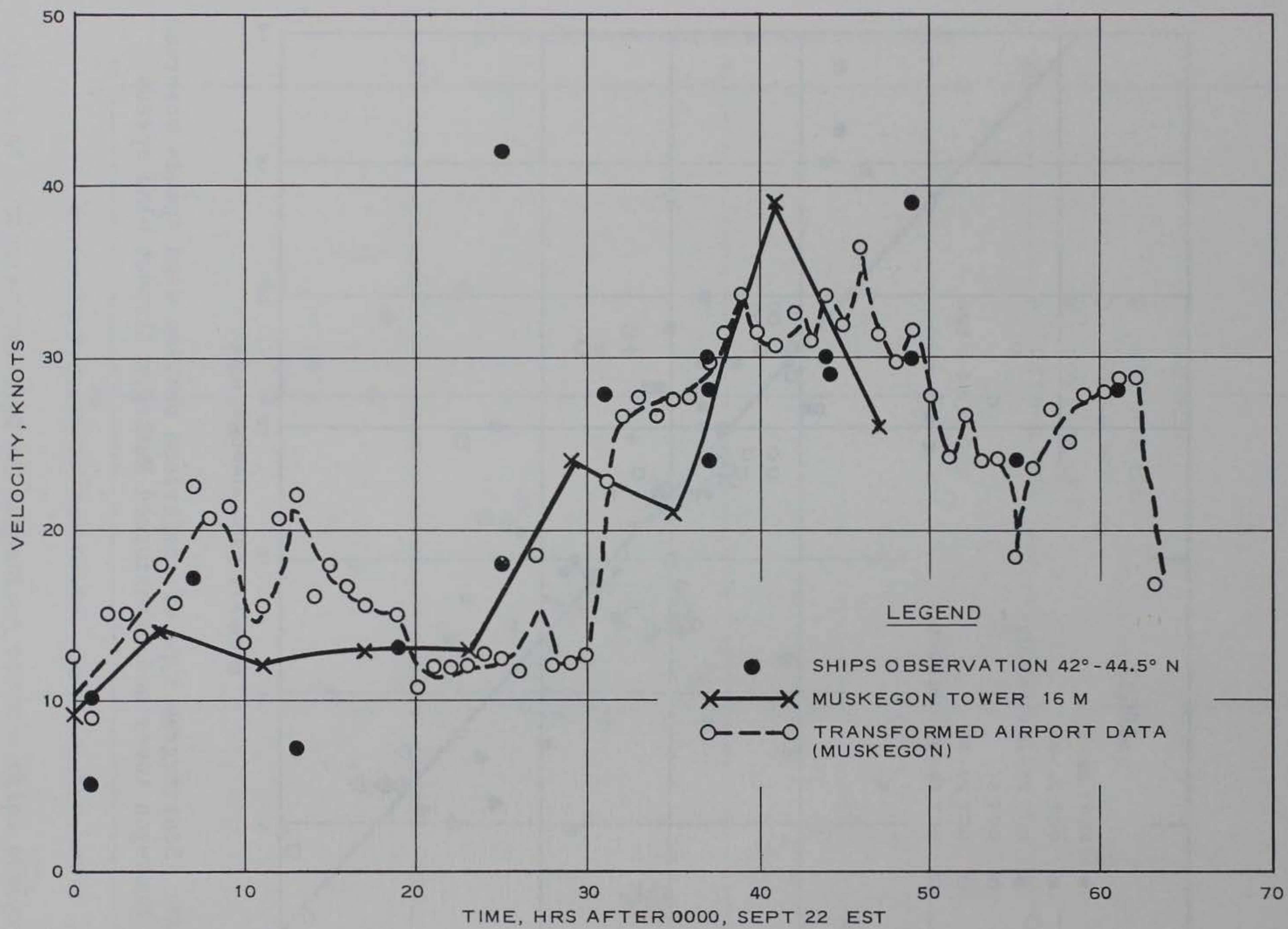

Figure A6. Sequence of wind speeds observed at Muskegon tower (Jacobs, 1965) compared to transformed Muskegon Airport wind speeds and wind speed reported by ships located between $42^{\circ} \mathrm{N}$ and $44.5^{\circ} \mathrm{N}$ 


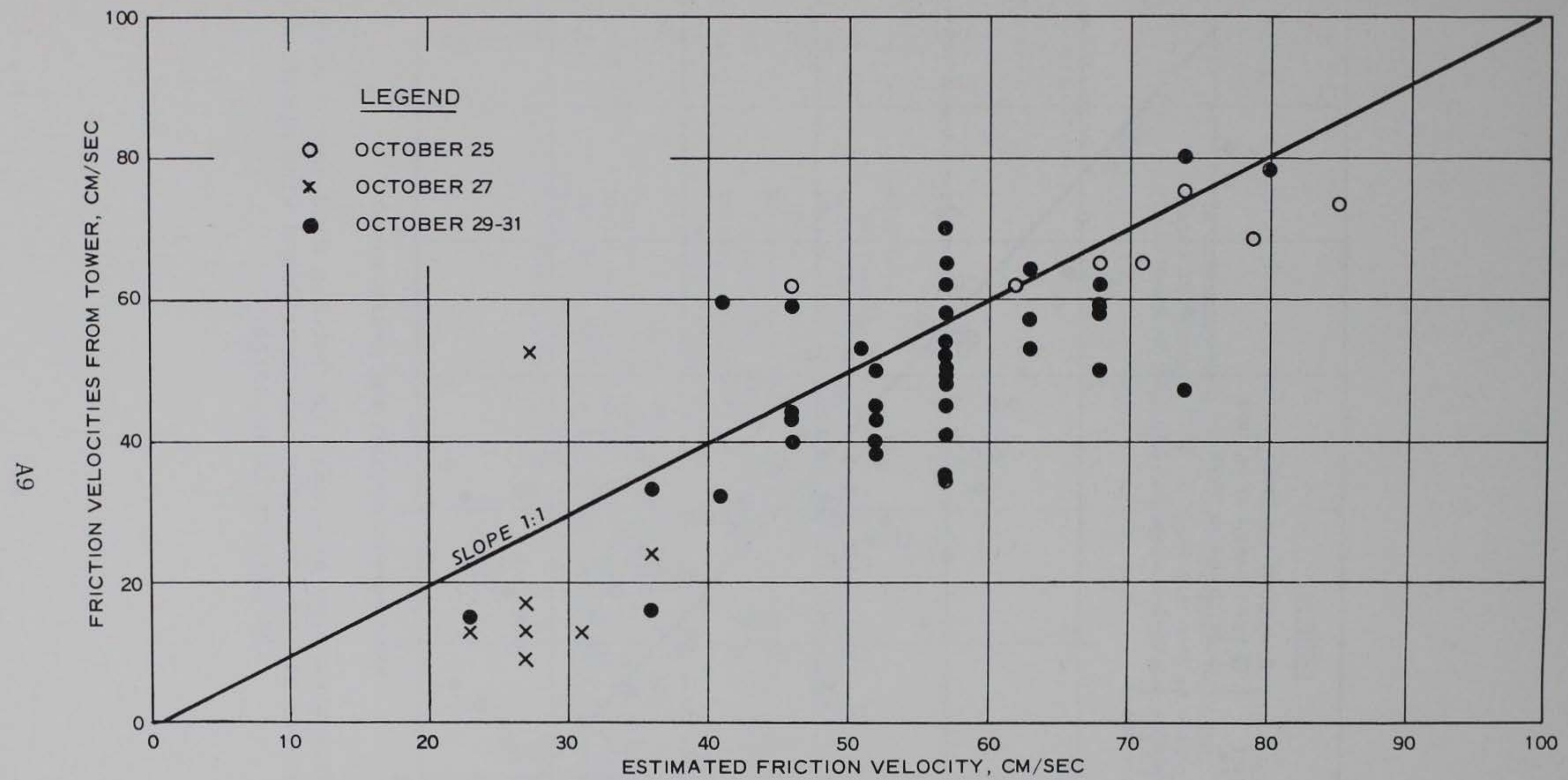

Figure A7. Scattergram type of comparison between friction velocities estimated from wind speeds observed at the $8-\mathrm{m}$ and $14.6-\mathrm{m}$ levels on the Muskegon tower and friction velocities estimated from the solution to the system of Equations 9, 17, and 26 based on transformed wind speeds from Muskegon Airport 


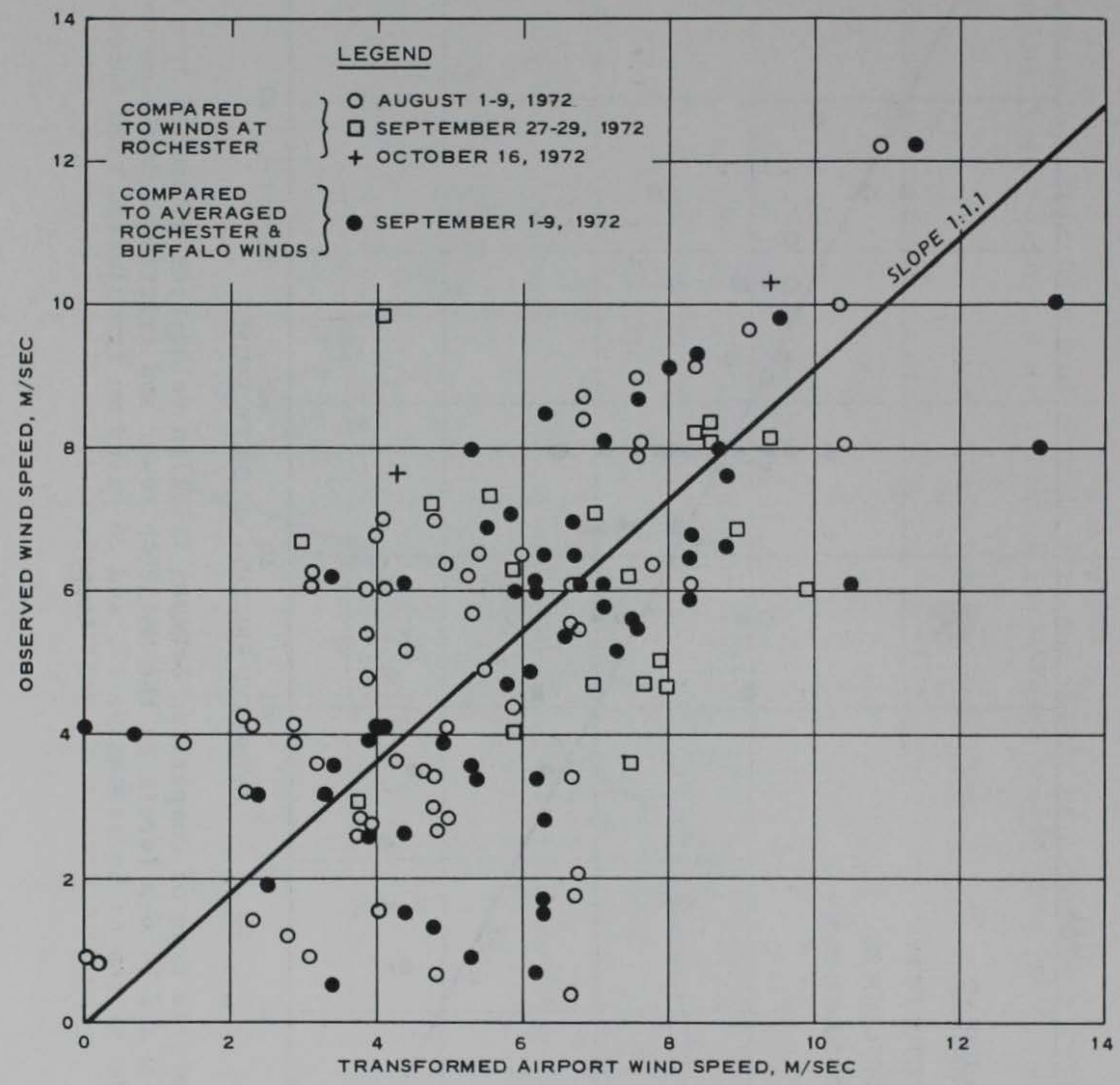

Figure A8. Scattergram type of comparison between wind speeds observed at PDCS buoy located off of Rochester and transformed wind speeds from the airport in Rochester 